INSTITUTO DE PESQUISAS ENERGÉTICAS E NUCLEARES

Autarquia associada à Universidade de São Paulo

\author{
UM ESTUDO DA FÍSICA DE SISTEMAS \\ MULTIPLICATIVOS SUBCRÍTICOS ACIONADOS POR \\ FONTES E A UTILIZAÇÃO DE CÓDIGOS \\ DETERMINÍSTICOS NO CÁLCULO DESTES SISTEMAS
}

ALBERI ANTUNES

Dissertação apresentada como parte dos requisitos para obtenção do Grau de "Mestre na Área de Concentração em Reatores Nucleares de Potência”.

Orientador:

Dr. José Rubens Maiorino 
INSTITUTO DE PESQUISAS ENERGÉTICAS E NUCLEARES

Autarquia associada à Universidade de São Paulo

\author{
UM ESTUDO DA FÍSICA DE SISTEMAS \\ MULTIPLICATIVOS SUBCRÍTICOS ACIONADOS POR \\ FONTES E A UTILIZAÇÃO DE CÓDIGOS \\ DETERMINÍSTICOS NO CÁLCULO DESTES SISTEMAS
}

ALBERI ANTUNES

Dissertação apresentada como parte dos requisitos para obtenção do Grau de "Mestre na Área de Concentração em Reatores Nucleares de Potência”.

Orientador:

Dr. José Rubens Maiorino 


\section{AGRADECIMENTO}

Ao Prof.Dr. José Rubens Maiorino pela paciência e orientação.

Ao Prof. Dr. Adimir dos Santos, do CEN, pelas importantes observações.

Ao Gilson e à Graciette pela importante ajuda nos momentos de dificuldades.

Aos meus colegas da pós-graduação do CEN pelo companheirismo.

Ao IPEN e a secretaria da pós-graduação pelo apoio institucional.

À toda a equipe do CEN pelo apoio.

À CNEN pelo suporte financeiro através da bolsa de estudos.

À Agência Internacional de Energia Atômica (IAEA) pelo suporte financeiro parcial através do contrato de pesquisa (RC 13388). 


\title{
UM ESTUDO DA FÍSICA DE SISTEMAS MULTIPLICATIVOS SUBCRÍTICOS ACIONADOS POR FONTES E A UTILIZAÇÃO DE CÓDIGOS DETERMINÍSTICOS NO CÁLCULO DESTES SISTEMAS
}

\author{
Alberi Antunes
}

\section{RESUMO}

Este trabalho apresenta um estudo da Física dos Sistemas dirigidos por Fontes Externas (ADS). É apresentada a definição de alguns parâmetros estáticos e cinéticos da Física do reator que são importantes na avaliação e definição destes sistemas. O objetivo é demonstrar que há diferenças nestes parâmetros quando o sistema está no nível crítico ou subcrítico. Além disso, o trabalho mostra as diferenças observadas nos parâmetros para diferentes modelos de cálculo. São mostradas nesta dissertação duas metodologias de cálculo: Gandini\&Salvatores e Dulla e são calculados alguns destes parâmetros utilizando as duas metodologias. O código determinístico de transporte ANISN é utilizado no cálculo destes parâmetros. Numa configuração subcrítica do Reator IPEN/MB-01 dirigido por uma fonte externa de nêutrons são calculados alguns parâmetros físicos. No final do trabalho são apresentadas as conclusões obtidas através destes cálculos. 


\title{
A STUDY OF PHYSICS OF SUB CRITICAL MULTIPLICATIVES SYSTEMS DRIVEN BY SOURCES AND THE UTILIZATION OF DETERMINISTICS CODES IN CALCULATION OF THIS SYSTEMS
}

\begin{abstract}
Alberi Antunes
ABSTRACT

This work presents the Physics of Source Driven Systems (ADS). It shows some statics and kinetics parameters of the reactor Physics and when it is sub critical, that are important in evaluation and definition of these systems. The objective is to demonstrate that there are differences in parameters when the reactor is critical. Moreover, the work shows the differences observed in the parameters for different calculation models. Two calculation methodologies are shown in this dissertation: Gandini\&Salvatores and Dulla, and some parameters are calculated. The ANISN deterministic transport code is used in calculation in order to compare these parameters. In a sub critical configuration of IPEN/MB-01 Reactor driven by an external source some parameters are calculated. The conclusions about calculation realized are presented in end of work.
\end{abstract}


Página

1 INTRODUÇÃO. .08

1.1 O Estado da Arte de Sistemas Subcríticos Acionados por Fontes (Accelerator Driven System - ADS) .08

1.2 Revisão dos Métodos de Cálculo de ADS, Benchmarks Numéricos e Experimentais. .16

1.2.1 Métodos de Cálculo de ADS .16

1.2.2 "Benchmarks" Numéricos .18

1.2.3 "Benchmarks" Experimentais 21

1.3 Objetivos e Divisão do Trabalho. 24

2 A EQUAÇÃO DE TRANSPORTE NA SOLUÇÃO DE CÁlCULOS DE PARÂMETROS DE FÍSICA DE REATORES...................................................................27

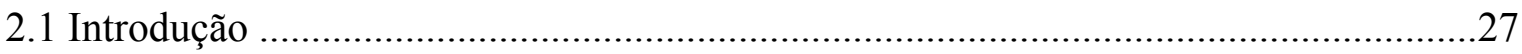

2.2 Métodos Numéricos de Solução da Equação de Transporte .......................................31

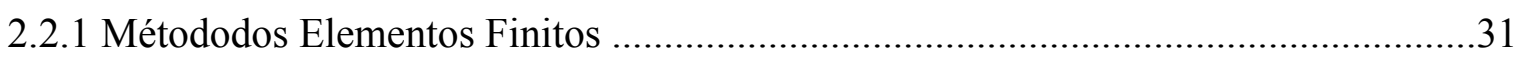

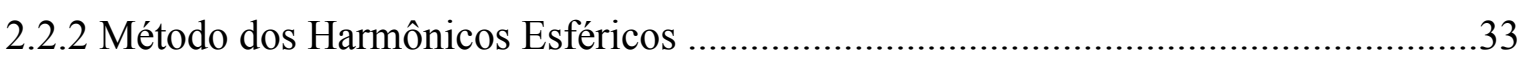

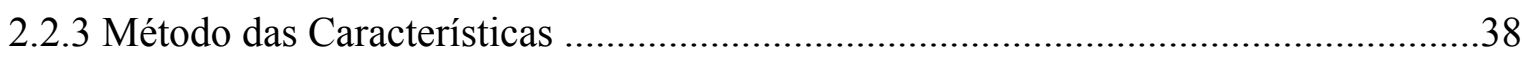

2.2.4 Método de Probabilidade de Colisão ..........................................................................

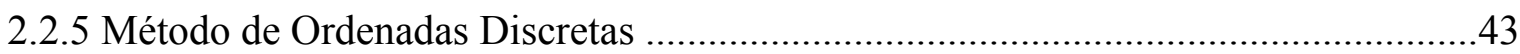

3 A FÍSICA DE SISTEMAS SUBCRÍTICOS ACIONADOS POR FONTES

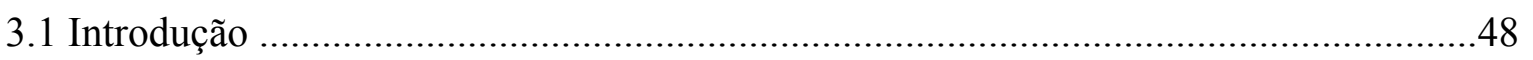

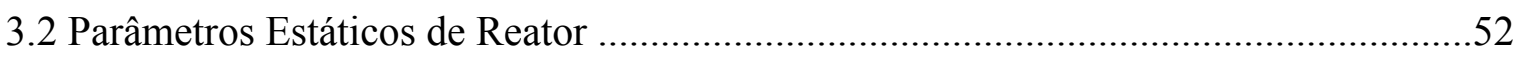

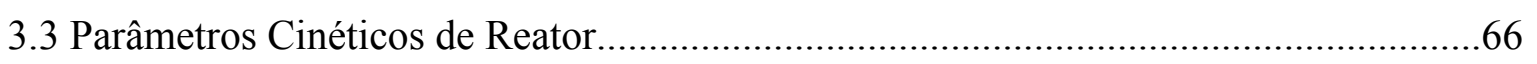

4 CÁlCULOS DE PARÂMETROS DA CONFIGURAÇÃO SUBCRÍTICA DO REATOR IPEN-MB-01 COM UMA FONTE EXTERNA DE NÊUTRONS UTILIZANDO O CÓDIGO TORT. ....................................................................77

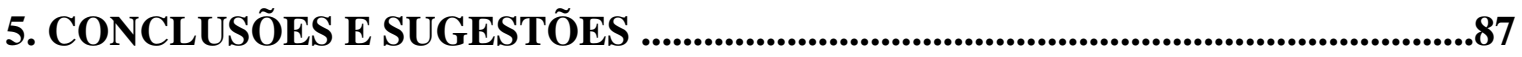

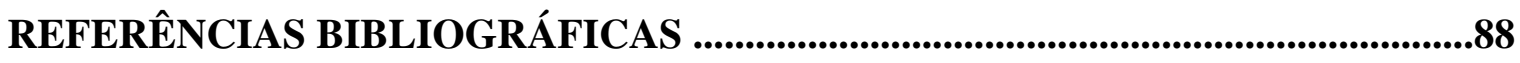

ANEXO A - CONSTANTES MULTIGRUPO UTILIZADAS NOS CÁLCULOS DE 
A.1 - Uma Região e um Grupo de Energia .......................................................................93

A.2 - Uma Região e três Grupos de Energia ..................................................................93

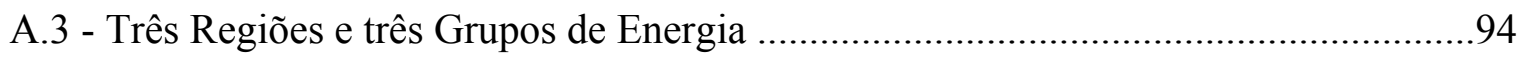

A.4 - Estrutura de Grupos de Energia : 16 grupos..........................................................95

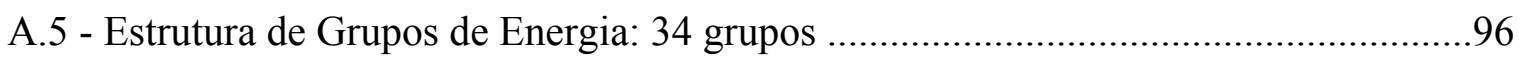

ANEXO B - CÓDIGOS NUCLEARES S $\mathrm{N}_{\mathrm{N}}$ ANISN e TORT ....................................97

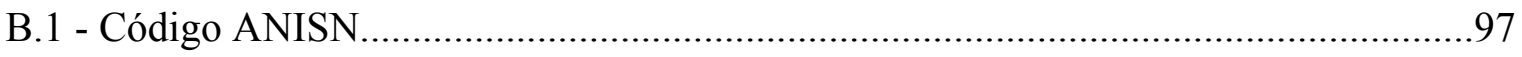

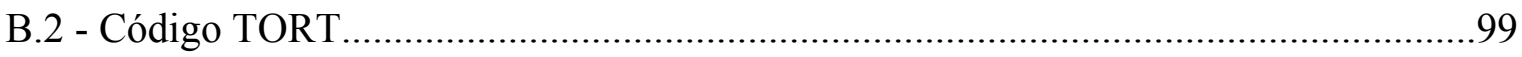

ANEXO C - GERAÇÃO DE SEÇÕES DE CHOQUE - CONSTANTES DE

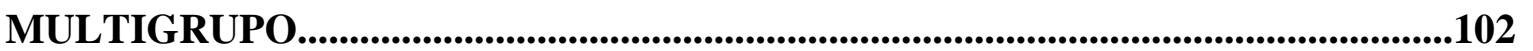




\section{INTRODUÇÃO}

\subsection{O Estado da Arte dos Sistemas Subcríticos Acionados por Fontes (Accelerator Driven System - ADS)}

A sustentabilidade ${ }^{1}$ é o maior desafio no desenvolvimento de tecnologias nucleares inovadoras como opção em longo prazo. O desafio da sustentabilidade tem três principais aspectos: recursos naturais, meio ambiente e economicidade. Em relação aos recursos naturais sabe-se que a produção de energia nuclear não pode ser sustentável se apenas $0,7 \%$ dos recursos físseis em Urânio natural forem utilizados. Isto significa que todas as reservas férteis (Urânio-238, que são os 99,3\% restantes do Urânio natural e Tório) serão exploradas. A utilização de regeneração e ciclos fechados para assegurar o suprimento de combustível em longo prazo para geração de eletricidade com energia nuclear tem sido o principal alvo do desenvolvimento de reatores rápidos e permanece como último objetivo a ser atingido. Em relação aos rejeitos nucleares, apesar do risco de contaminação ser mínimo, este aspecto continua sendo o "Calcanhar de Aquiles" da energia nuclear, pois ainda não há uma solução definitiva para estes. Portanto, a energia nuclear não é considerada sustentável. Os aspectos econômicos não serão considerados nesta abordagem.

Para tornar a energia nuclear uma fonte sustentável de energia, com relação aos recursos naturais e rejeitos nucleares deve ser considerada a utilização de ciclos fechados de Plutônio em reatores rápidos, bem como a transmutação/incineração de actinídeos menores (AM) e produtos de fissão de longa vida (PFLV) em vários tipos de reatores de fissão, tal como os ADS.

\footnotetext{
${ }^{1}$ Sustentabilidade: é um conceito sistêmico relacionado com a continuidade dos aspectos econômicos, sociais, culturais e ambientais da sociedade humana. Para um empreendimento humano ser sustentável, tem de ter em vista quatro requisitos básicos. Este empreendimento tem de ser: 1) ecologicamente correto; 2) economicamente viável; 3) socialmente justo e 4) culturalmente aceito.
} 
Neste contexto surgiu o conceito de ADS, que são sistemas dedicados à transmutação de resíduos de alta atividade para reduzir os requisitos nos repositórios geológicos [1-5]. Uma razão importante para o interesse na utilização destes sistemas é a possibilidade de geração de energia da fissão e ao mesmo tempo incinerar rejeitos radioativos. Algumas das vantagens deste sistema são: ausência de acidentes de reatividade, alta capacidade de transmutação, baixa produção de rejeitos e melhor utilização dos recursos naturais em longo prazo.

Os sistemas acionados por fonte consistem num sistema rápido subcrítico mantido em estado estacionário por uma fonte externa de nêutrons. Na FIG. 1, ilustra-se o conceito básico de um ADS, o qual em resumo consiste de: 1) Acelerador (Ciclotron ou Linac), o qual acelera o feixe de prótons ( $1 \mathrm{GeV}$; poucos $\mathrm{mA})$; 2) alvo, onde os nêutrons são produzidos por "spallation", ou por qualquer reação nuclear (por exemplo, D-T e DD); 3) refrigerante (loop ou piscina), sódio, chumbo, ou chumbo-bismuto fundido, ou gás (Hélio); 4) núcleo subcrítico ( $\mathrm{k} \sim 0,95$ - 0,98), consistindo de combustíveis em forma metálica, óxido, ou nitreto, com material nuclear (U, Th, Pu, Actinídeos Menores, Am, $\mathrm{Np}, \mathrm{Cu}$, etc.), onde a energia é gerada com um ganho positivo e a incineração dos actinídeos menores é possível, além de regeneração (U/Pu; Th/U).

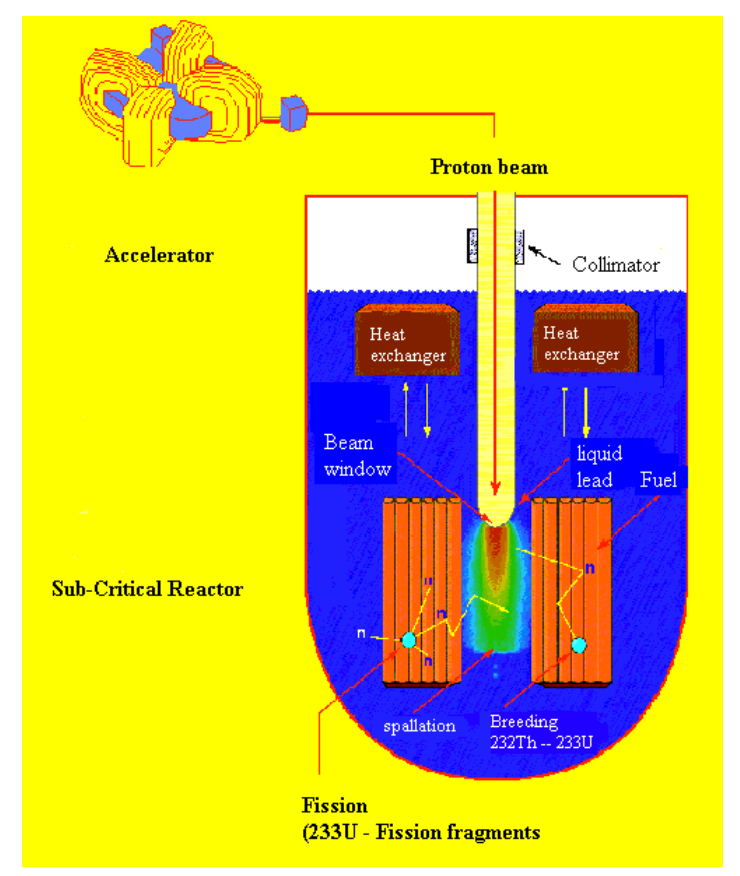

FIGURA 1 - Conceito Básico do ADS. 
A utilização de aceleradores para transmutação não é recente, pois desde os anos 40 é conhecido dos trabalhos com pesquisa em aceleradores, que o bombardeio de um alvo de Urânio por prótons de alta energia ou deutérios podem produzir uma grande produção de nêutrons [6]. Nesta época (1941) Glenn Seaborg produziu o primeiro Plutônio artificial utilizando um acelerador. Um conceito realístico de ADS, onde a segurança e a transmutação de rejeitos eram características principais, foi desenvolvido nos anos 80 pelo grupo de pesquisa liderado por H. Takahashi e G. Van Tuyle do Laboratório Nacional de Brookhaven. Entretanto, o uso dos primeiros conceitos de ADS em uma instalação de transmutação utilizando nêutrons térmicos foi publicado [7] em 1992, onde foi introduzido o nome "The Accelerator Transmutation of Waste" (ATW) e se previu a utilização de um acelerador $(1 \mathrm{GeV})$ no programa AAA (“Advanced Accelerator Application").

Em 1993 um grupo de cientistas do CERN liderados por Carlo Rubbia apresentou os conceitos básicos do "Energy Amplifier", que consistia em um sistema nuclear subcrítico baseado no ciclo $\mathrm{Th} / \mathrm{U}$ alimentado por um acelerador de prótons de alta energia. Este conceito tinha como proposta principal a produção de energia com transmutação de AM e PFLV.

Para verificar o princípio de amplificação de energia por uma cascata de alta energia foram realizados dois experimentos: FEAT ("Fast Energy Amplifier Test") [8] e TARC (“Transmutation by Adiabatic Resonance Crossing”). O experimento FEAT (1994) [8] foi realizado no CERN sob a liderança de Carlo Rubbia e com a participação de vários grupos de pesquisa da Europa. Este experimento baseou-se num núcleo subcrítico de 3,5 toneladas de Urânio natural metálico dirigido por uma fonte de nêutrons ativada por um feixe de prótons vindo de um acelerador. Alvos de Urânio natural e Chumbo foram usados nos experimentos. TARC (1997-1998) representou uma segunda série de experimentos realizados no CERN a fim de estudar a transmutação de produtos de fissão de longa vida (PFLV) em uma matriz de Chumbo com algumas amostras de material específico, particularmente Tc-99.

Em 1998 alguns países da Europa estabeleceram um grupo para discutir o uso de ADS para transmutação em Ciclo de Combustível de duplo extrato à fím de reduzir o tempo de armazenamento nos repositórios. Este encontro levou ao estabelecimento de um 
grupo de trabalho sob a liderança de Carlo Rubbia para identificar as questões técnicas principais envolvidas em ADS e, ao mesmo tempo preparar um mapa de rotas para um programa de demonstração para ser executado no prazo de doze anos. Estabeleceram-se os passos necessários para começar a construção de um ADS experimental (XADS) nas várias áreas (Física de reatores, materiais, alvos, etc.), com uma dupla vertente: um reator refrigerado à Chumbo Bismuto (conduzido pela Ansaldo) e o projeto MYHRRA [9].

O desenvolvimento do estudo da Física dos ADS teve seu maior avanço na Europa, onde a maior parte das atividades em Pesquisa e Desenvolvimento (P\&D) na área de Partição e Transmutação (P\&T) foi realizada na estrutura do EURATOM [no $5^{\circ}$ (19882002) e $6^{\circ}$ programa (2002-2006)].

No quinto programa havia treze projetos distribuídos entre redes em P\&D na transmutação e um na partição. As redes de partição incluíam os projetos PYROREP, PARTNEW e CALIXPART. As redes de transmutação eram FUETRA, BASTRA e TESTRA [10].

Os três projetos FUETRA (“Fuel for Transmutation”) eram FUTURE, CONFIRM e THORIUM CYCLE. O projeto FUTURE [11] ("Fuel for Transmutation of Transuranium Elements") incluiu atividades em P\&D e objetivou o desenvolvimento de combustível homogêneo de óxido de transurânicos para transmutação. O projeto CONFIRM [11] ("Collaboration on Oxide \& Nitride Fuel Irradiation \& Modelling") esteve focado no combustível de nitreto inerte (Urânio-“free”) (caracterização, fabricação, desempenho, etc.). O projeto THORIUM CYCLE investigou a factibilidade do ciclo do Tório para reatores à água leve e ADS.

A rede BASTRA ("Basic Studies for Transmutation”) incluiu três projetos: MUSE, HINDAS e n-TOF_ND_ADS. A série de experimentos de potência zero MUSE ("MUltiplication of Source Externe") foi realizada na instalação MASURCA na França. A instalação MASURCA é uma instalação de potencia zero extremamente flexível e permite vários arranjos combustível. O objetivo destes experimentos foi validar a metodologia de Física de reatores para análise de núcleos subcríticos. Por exemplo, os experimentos MUSE-4 acoplaram um acelerador de deutério, GENEPI, colocado fora da MASURCA, com um alvo de D-T ou D-D, colocado no centro do reator. O projeto HINDAS ("High 
and Intermediate Energy Nuclear Data for ADS") está voltado para dados nucleares de alcance intermediário e de alta energia $(20 \mathrm{MeV}-2 \mathrm{GeV})$ necessários para a simulação de um alvo de "spallation"2 em cálculos de Física de ADS.

Além do trabalho experimental, o projeto HINDAS também abrangeu a teoria em P\&D (simulações de modelos nucleares, avaliação de dados, geração de bibliotecas). O projeto n-TOF_ND_ADS esteve baseado no tempo de vôo dos nêutrons (n-TOF) no CERN, que tem a fonte de nêutron de maior intensidade para este tipo de instalação: feixe de prótons de intensidade $20 \mathrm{GeV} / \mathrm{c}$. O projeto n-TOF_ND_ADS incluiu as medidas e avaliações das seções de choque de captura e fissão para AM e PFLV, captura e (n, 2n) seções de choque para $\mathrm{Pb}, \mathrm{Bi}$, To e $\mathrm{Zr}$, além das seções de choque totais.

A rede TESTRA (“Technological Support for Transmutation”) abrangeu estudos de tecnologia necessária para transmutação e esteve subdividida em quatro projetos: ASCHLIM, MEGAPIE-TEST, TECLA e SPIRE. O projeto ASCHLIM tratou da parte de termo hidráulica de metal líquido pesado. O projeto MEGAPIE-TEST ("Megawatt Pilot Experiment") [12] abrangeu o trabalho experimental e analítico em P\&D para um alvo de spallation de Pb-Bi Eutético (LBE) de intensidade $1 \mathrm{MW}$ que foi irradiado na instalação SINQ na Suíça. O projeto TECLA ("Technologies, Materials and Thermal-hydraulics for Lead Alloys") estudou as propriedades físicas e químicas da liga de Chumbo como refrigerante e material de alvo de spallation. O projeto SPIRE ("Spallation and Irradiation Effects") investigou os efeitos da irradiação de nêutrons e prótons nas estruturas de aço. Maiores descrições destes projetos podem ser encontradas na Referência [13].

Além das três redes de transmutação em P\&D também está sendo gerada uma estrutura para estudos preliminares de um ADS experimental (projeto PDS-ADS) [14]. O projeto está avaliando - para todos os sistemas de ADS (acelerador, alvo de spallation, e reator subcrítico) - as escolhas tecnológicas mais importantes e identificando as pesquisas nas áreas de P\&D necessárias. Aceleradores Ciclotron e lineares estão sendo avaliados.

\footnotetext{
${ }^{2}$ Spallation: Em geral é o processo no qual um núcleo emite um número grande de nucleons como resultado de um choque por uma partícula de alta energia.
} 
No FP5 ("Framework Programme"), a coordenação entre o trabalho em P\&D realizado nas quatro redes P\&T, por um lado, e as atividades do projeto PDS-ADS, por outro lado, foi assegurada por uma rede de trabalho de colaboração internacional chamada de ADOPT (“Advanced Options for Partitioning and Transmutation”) [15].

As atividades em P\&T igualmente continuaram na estrutura do FP6. Propostas e avaliações destas atividades ainda não estão finalizadas. Após a primeira chamada para propostas do FP6, as atividades de partição em P\&D estão agrupadas em um projeto integrado chamado IP EURPOART. Para a segunda chamada por propostas do FP6 um esboço das propostas do IP EUROTRANS ("European Research Programme for the Transmutation of High Level Nuclear Waste in an Accelerator Driven System”) está atualmente sendo discutida pela comunidade Européia. De acordo com as propostas deste esboço, os objetivos do IP EUROTRANS devem ser demonstrar experimentalmente a operação de ADS e entregar um projeto conceitual para um ADS Europeu de demonstração.

Fora da União Européia, também estão sendo realizadas atividades em P\&T na China, Índia, Japão, República da Coréia, Rússia e alguns outros países da Comunidade dos Estados Independentes na estrutura de trabalho do ISTC ${ }^{3}$, além dos Estados Unidos. A razão e desempenho das atividades variam de país para país. Entretanto, independente se produção de energia ou transmutação de rejeitos de longa vida é considerada a direção principal, e independente das estratégias serem de curto, médio ou longo tempo, há diversas atividades realizadas por muitos grupos, para as quais a colaboração internacional é solicitada.

2 ISTC ("International Science and Tecnology Centre"): Foi estabelecido por um acordo internacional em Novembro de 1992 como um programa de não proliferação de armas. O ISTC coordena os esforços de vários governos, organizações internacionais e setores da indústria privada, enquanto provê aos cientistas de armas da Rússia e da Comunidade de Estados Independentes oportunidades novas na sociedade internacional. Através da estrutura política, legal e financeira, o ISTC contribui à Pesquisa Fundamental, Programas Internacionais e Inovação e Comercialização, unindo as demandas de mercados internacionais com o talento científico. 
Na China, um programa em duas fases está em questão, o qual objetivou na primeira fase (1998-2002) sistemas de otimização, Física de reatores, Física de aceleradores e P\&D em materiais nucleares. A segunda fase do programa (2000-2007) foi dedicada ao estudo e verificação de conceitos de ADS. Com relação a sistemas híbridos Fusão/Fissão, em curto prazo a ênfase está posta nos experimentos realizados em duas grandes instalações testes, HL-1M e HT-7. A China também está prevendo ADS para geração de energia, regeneração, transmutação, etc.

$\mathrm{Na}$ Índia, as atividades existentes estão relacionadas a (a) um plano experimental de um núcleo subcrítico dirigido por nêutrons de $14-\mathrm{MeV}$ da reação $\mathrm{T}(\mathrm{n}, \mathrm{d})^{4} \mathrm{He}$ para estudos de Física de reator; (b) desenvolvimento de um acelerador linear de prótons de alta intensidade $(10 \mathrm{MeV})$ como interface de aceleradores para ADS; (c) estabelecimento de um "loop" experimental de Chumbo Bismuto Eutético e (d) estudo dos aceleradores.

No Japão, um conceito de núcleo subcrítico de 800 MWth refrigerado a Chumbo Bismuto Eutético foi proposto. Atividades em P\&D estão planejados na JAERI nos campos de projeto de núcleo subcrítico, tecnologia de alvo de spallation, desenvolvimento de aceleradores e combustível de actinídeos menores. Com o objetivo de estudar e avaliar os aspectos relativos à Física e Engenharia de ADS, a JAERI tem proposto a construção da Instalação Experimental de Transmutação (TEF) na estrutura de trabalho do Projeto de Aceleradores de Prótons de Alta Intensidade [16].

Na República da Coréia, a KAERI tem trabalhado no conceito HYPER ("HYbrid Power Extraction Reactor") desde 1997. O projeto da KAERI em P\&D de ADS consiste em três estágios: o conceito básico no primeiro estágio (1997-2000), a tecnologia básica no segundo estágio (2001-2003) e o projeto conceitual no terceiro estágio (20042006). Atualmente a KAERI está focada em LBE e no estudo de combustíveis. Para estudos de combustíveis está sendo discutida a possível colaboração com a ANL-West, e também investigando testes de irradiação de produtos de fissão usando o reator de pesquisa HANARO.

Na Rússia há estudos avançados de ciclos de combustíveis que têm como alvo a minimização de rejeitos e simplificação do ciclo de material combustível. Também estão 
inclusos: (a) a entrega de um alvo MK-1 para a Universidade de Nevada, Las Vegas; (b) análise de uma proposta para estabelecer um projeto internacional de um ADS de demonstração em Obninsk (Projeto "Nuclear Waste Burner" (NWB): a construção do NWB pode ser completada em sete ou oito anos, e resultados preliminares mostram uma taxa de queima $\sim 10-20 \mathrm{~kg}$ de AM por ano e pode ser obtido no núcleo subcrítico tendo 200 a $400 \mathrm{~kg}$ de inventário de AM); e (c) atividades na estrutura de trabalho do Conjunto Subcrítico Dubna (SAD).

Um dos projetos ISTC relacionados à $P \& D$ é a Pesquisa Teórica e Experimental em Transmutação de PFLV e AM em um conjunto subcrítico dirigido por um gerador de nêutrons que está sendo realizado na instalação YALINA, em Minsk, na Bielo - Rússia. A instalação YALINA consiste de um gerador de nêutrons de $14 \mathrm{MeV}$ e um conjunto subcrítico de potência zero. Os experimentos realizados na YALINA têm os seguintes tópicos: (a) medidas de taxa de transmutação de produtos de fissão e MA; (b) investigação de cinética de sistemas subcríticos dirigidos por fontes externas de nêutrons; (c) validação de várias técnicas experimentais; e (d) investigação de características dinâmicas de sistemas subcríticos dirigidos por fontes externas de nêutrons operando no modo pulso.

Nos Estados Unidos dentro do Programa AAA o programa Iniciativa de Ciclo de Combustível Avançado (AFCI) é voltado para o desenvolvimento de ciclos combustíveis e o gerenciamento de rejeitos, incluindo transmutação. O programa enfatiza atividades nas áreas de reatores e aceleradores baseados na transmutação, combustíveis avançados e redução de toxidade de rejeitos de longo termo. Tem-se aumentado a atenção para atividades em curto prazo no ciclo combustível, que é dirigido pelos limites de capacidade declarada do repositório de rejeitos em Yucca Mountain. Estas atividades também incluem a investigação de sistemas inovadores dedicados à incineração de AM e transmutação de PFLV (por exemplo, ADS). As principais atividades do AFCI incluem o desenvolvimento de combustíveis e engenharia de transmutação. Resultados indicam que a redução de radioatidade é o objetivo mais difícil para alcançar. O tratamento do combustível gasto no Reator Experimental Regenerador II (EBR-II) tem sido integrado no programa AFCI. 
Devido a todas estas atividades detectou-se necessidade do aprimoramento dos cálculos de Física de subcriticalidade, assim como devido aos novos experimentos de potência zero, o grupo técnico em sistemas rápidos (TWG-FR) da Agência Internacional de Energia Atômica (IAEA) propôs um Projeto Coordenado de Pesquisa (CRP) para contribuir nos esforços em P\&D nos vários campos comuns no desenvolvimento de sistemas inovadores de nêutrons rápidos. O CRP teve seu início em 2006. Algumas das áreas que o CRP abrange são: (a) avaliação de modelos teóricos de reações nucleares; (b) medidas e avaliação de dados nucleares para transmutação; e (c) desenvolvimento e validação de métodos computacionais e códigos. Dentro deste CRP este trabalho está inserido. O CRP também tem como objetivo integrar alguns dos projetos de demonstração experimentais planejados, tais como a YALINA Booster, o experimento TRADE (foi projetado para ser o primeiro ADS de potência, um experimento intermediário entre o ADS de potência zero e o XADS) e o Projeto SAD em JINR, Dubna.

Também, devido à preocupação do DOE (Departamento de Energia dos Estados Unidos) e o Programa RERTR ("Reduced Enrichment for Research and Test Reactor") com a utilização de Urânio altamente enriquecido em ADS, surgiu um trabalho colaborativo onde se destacou a utilização de Urânio de baixo enriquecimento (LEU). Destaca-se neste contexto o reator de pesquisa na Ucrânia, que utiliza acelerador de fótons-nêutrons. O reator IPEN/MB-01 também foi colocado neste contexto de utilização de LEU [17] e cálculos preliminares dessa proposta serão realizados posteriormente.

\section{2- Revisão dos Métodos de Cálculo de ADS, "Benchmarks"s Numéricos e Experimentais}

\subsubsection{Métodos de Cálculo de ADS}

No cálculo de ADS são realizados três tipos de cálculos: fonte, acoplamento da fonte com o ADS e da queima e transmutação. Este trabalho não se preocupará com os cálculos com o termo fonte, que está sendo motivo de estudo de outro trabalho [18], nem com queima e transmutação, que também está sendo alvo de outro trabalho [19]. 
Nos cálculos iniciais (anos 90) nos Estados Unidos utilizava-se acoplados o código LAHET ("High Energy Particle Transport Calculations") [20], para calcular o termo fonte, e o código MCNP4. Um dos primeiros trabalhos publicados utilizando este sistema foi publicado por Bowman's em Los Alamos [7], em 1992. No CERN eram utilizados acoplados os códigos FLUKA [21] e EA-MC [22].

Na Europa foi desenvolvido um sistema de dados chamado ERANOS [23] que acopla cálculos de parâmetros físicos. A finalidade deste sistema é estabelecer uma base apropriada para cálculos determinísticos confiáveis de reatores rápidos. Este sistema contém as funções necessárias para cálculos de projetos de reatores rápidos a metal líquido (LMFR) e reatores rápidos refrigerados a gás (GCFR).

Uma de suas principais características é a biblioteca de dados nucleares ECCO/ERANOS 2.1. Este pacote contém diversas bibliotecas de seções de choque, derivadas das bibliotecas de dados nucleares JEFF-3.1, JENDL3.3 e ENDF/B6.8. As bibliotecas do código são obtidas processando os arquivos de dados com os códigos NJOY [24] e CALENDF [25]. O Código ECCO prepara as seções de choque autobilindadas pela combinação do tratamento de "slowing down" em muitos grupos de energia (1968 grupos) com o método de subgrupo em cada grupo fino. O método de subgrupo leva em consideração a estrutura de ressonância dos nuclídeos pesados pelas médias das tabelas de probabilidades e assume que a fonte de nêutrons é uniforme na letargia em um dado grupo fino. O código BISTRO [26] é um código $S_{N}$ de transporte com geometria em 1-D ou 2-D que calcula autoblindagens.

Um método de cálculo utilizado no ERANOS é o método de transporte nodal variacional 2-D e 3-D cartesiano (usado para a MASURCA) e hexagonal (para PHENIX e SUPERPHENIX), com o código “TGV/VARIANT”. Estes códigos resolvem as equações homogêneas e não homogêneas (com fonte externa) e geram soluções diretas e adjuntas.

Nos Estados Unidos os códigos utilizados para calcular parâmetros estáticos são o SCALE 5.1 [27] e o TORT [28].

Um código que acopla cálculo de parâmetros com geração de seções de choque e transmutação é o DRAGON [29]. A versão mais recente do código é a 3.05 B. 
O código realiza cálculos em uma, duas e três dimensões geométricas e resolve a equação multigrupo de transporte em geometria geral; avalia a população de nêutrons em um reator; resolve a equação de Bateman para queima de combustível e depleção isotópica: prediz a concentração de cada isótopo no reator. Ele também processa bibliotecas de seções de choque microscópicas; realiza autoblindagens de ressonâncias de isótopos; realiza cálculos de fugas e calcula coeficientes de difusão; gera propriedades homogeneizadas e condensadas para cálculos de reatores finitos em transporte ou difusão; não há limites para cálculos de arranjos. Este código foi desenvolvido por pesquisadores canadenses e a versão para ser usada é "free".

Neste trabalho quando calculados alguns parâmetros do reator IPEN/MB-01 com a inserção de uma fonte externa de nêutrons utilizou-se o código TORT. Este é um código determinístico de transporte de radiação que calcula fluxos ou fluências através de geometrias tridimensionais devido às partículas incidentes de fontes externas ou geradas internamente como resultado de interações das partículas com os materiais do sistema.

Em relação à queima e transmutação utilizava-se o código CINDER [30] para calcular as curvas de transmutação em função do tempo para alguns actinídeos. Outro código utilizado na década passada para análise de transmutações de nuclídeos foi o ORIGEM-JR [31], que foi desenvolvido a partir do código ORIGEN [32]. Recentemente surgiu o código MCB [33]: código Monte Carlo de queima e transmutação que calcula a densidade do nuclídeo com a queima ou decaimento. Este código é acoplado ao MCNP [34] e inclui cálculos de autovalores de sistemas críticos e subcríticos como também cálculos de transporte de nêutrons no modo de fonte fixa ou modo de "k-code" para obter taxas de reação e depósito de energia que são necessários para cálculos de queima.

\subsection{2 "Benchmarks” Experimentais}

Em 1995, na instalação MASURCA em CADARACHE começou uma série de experimentos chamados MUSE. O princípio destes experimentos eram as hipóteses da separabilidade dos efeitos da fonte e da multiplicação no núcleo subcrítico. Vários experimentos MUSE foram realizados (1-4). A TAB. 1 mostra os tipos de experimentos realizados. 
TABELA 1 - Experimentos MUSE realizados na Instalação MASURCA.

\begin{tabular}{|c|c|c|c|}
\hline & Tipo de fonte & $\begin{array}{c}\text { Alcance da } \\
\text { subcriticalidade }\end{array}$ & $\begin{array}{l}\text { Área de difusão } \\
\text { ao redor da fonte }\end{array}$ \\
\hline $\begin{array}{l}\text { MUSE-1 } \\
\text { (1995) }\end{array}$ & $\begin{array}{l}{ }^{252} \mathrm{Cf} \\
\text { Fissão espontânea }\end{array}$ & $-1,5 \%$ & Nenhum \\
\hline $\begin{array}{l}\text { MUSE-2 } \\
\text { (1996) }\end{array}$ & $\begin{array}{l}{ }^{252} \mathrm{Cf} \\
\text { Fissão espontânea }\end{array}$ & $-3.0 \pm 3,5 \%$ & $\begin{array}{l}\text { Sódio } \\
\text { Aço }\end{array}$ \\
\hline $\begin{array}{l}\text { MUSE-3 } \\
\text { (1998) }\end{array}$ & $\begin{array}{c}\text { Fonte pulsada de } \\
\text { nêutrons da reação }(\mathrm{D}, \mathrm{T})\end{array}$ & $-0.5 \pm 6 \%$ & $\begin{array}{l}\text { Sódio } \\
\text { Aço }\end{array}$ \\
\hline $\begin{array}{l}\text { MUSE-4 } \\
(2000-2001)\end{array}$ & $\begin{array}{l}\text { Fonte pulsada de } \\
\text { nêutrons das reações } \\
(D, D) \text { e }(D, T)\end{array}$ & $-1 \pm 4 \%$ & Chumbo \\
\hline
\end{tabular}

Os experimentos MUSE-3 e MUSE-4 foram os principais experimentos realizados. O experimento MUSE-3 consistiu na introdução de uma fonte pulsada de nêutrons (reação nuclear D-T) no centro do núcleo em diferentes configurações subcríticas. Os resultados obtidos por técnicas experimentais foram comparados com os cálculos obtidos com os dados nucleares gerados pelos códigos ERALIB1/ECCO/ERANOS [35, 36]. Nas TAB. 2 e 3, da Referência 37 são mostrados alguns destes resultados para cálculos de reatividade e variações na potência com o gerador de nêutrons ligado e desligado.

Quando comparadas as técnicas experimentais com o código ERANOS os valores concordam relativamente bem, e as incertezas nos valores do código ERANOS são creditadas aos dados nucleares e ao modelamento da fonte e combustível. Em cálculos de parâmetros dinâmicos (medidas de nêutrons de fonte pulsados para diferentes níveis de sub criticalidade) [37], os dados experimentais foram comparados com simulações do código MCNP. O parâmetro tempo de vida do nêutron calculado foi compatível com o valor encontrado pelo código ERANOS.

O experimento MUSE-4 foi o último experimento realizado (2000-2001) e utilizou uma fonte pulsada de nêutrons de reações nucleares (D-D) e (D-T). Os cálculos foram realizados utilizando o sistema de códigos ERANOS com os arquivos de dados 
nucleares das bibliotecas JEF2.2 [38], ENDF/B-V e ENDF/B-VI. As seções de choque foram processadas com os códigos ECCO (com JEF2.2) e MC2-2 [39] (ENDF-B/V, ENDF-B/VI e JEF2.2). Os cálculos de autovalores foram realizados pelo código VARIANT [40] (código nodal de transporte, 3-D) implementado no sistema de códigos ERANOS. Os cálculos de dinâmica foram realizados com módulo de cinética KIND3D [41] do sistema ERANOS. Após a realização dos cálculos pode-se chegar a algumas conclusões tais como que dificuldades significantes na execução de cálculos determinísticos com um grande número de grupos de energia: recursos computacionais, tempo, espaço de disco e memória. Diferentes métodos têm sido propostos a fim de processar corretamente as seções de choque na estrutura de grupo largo, capaz de reproduzir os mesmos resultados de um cálculo espacial fino.

O impacto no cálculo de reatividade devido ao uso de diferentes dados nucleares pode ser observado quando as seções de choque são processadas com o código MC2-2, movendo-se da biblioteca ENDF/B-V para a ENDF-B-VI há uma diferença nos resultados de reatividade de cerca de $700 \mathrm{pcm}$. Enquanto a comparação entre os resultados para as bibliotecas JEF2.2-ECCO e JEF2.2-MC2-2 permitem estimar o efeito devido ao uso de diferentes códigos (ECCO vs MC2-2) quando os dados nucleares são os mesmos: este efeito é cerca de $150 \mathrm{pcm}$.

Nos cálculos de taxa de fissão mostrou-se um bom acordo entre os cálculos e o experimento na margem de incerteza nas medidas se o número de grupos de energia é suficientemente grande. Em relação aos cálculos de dinâmica o acordo com as medidas foram satisfatórios para cada configuração analisada.

Em 2001 foi desenvolvida por Carlo Rubbia a idéia do experimento TRADE (“TRiga Accelerator Driven Experiment") [42]. Este experimento foi proposto para ser realizado no reator TRIGA da ENEA (Itália), e tendo como proposta principal a validação de conceitos em ADS, no qual os três principais componentes de um ADS - o acelerador, o alvo de spallation e o núcleo subcrítico - seriam acoplados em um nível de potência suficiente para calcular os efeitos de reatividade. Alguns dos parâmetros que o "benchmark" se propôs a calcular foram: o comportamento do sistema dinâmico de um ADS versus a importância neutrônica da fonte externa em diferentes níveis de subcriticalidade, correlação entre potência do reator e corrente de prótons, controle de 
reatividade, etc. Atualmente usa-se fontes de reações nucleares D-D e DT para calcular quais são correções que precisam ser feitas em relação aos efeitos espaciais relacionados aos detectores colocados na instalação.

\subsection{3 “Benchmarks” Numéricos}

O primeiro "benchmark" numérico para diferentes conceitos de transmutação foi publicado pela Agência de Energia Nuclear (NEA) no ano 2000. Este "benchmark" foi estabelecido porque cálculos de transmutação de actinídeos menores na década passada não estavam bem estabelecidos. Nesta mesma época os dados nucleares para actinídeos menores eram menos precisos e as cadeias de decaimento de queima não estavam completamente modeladas na computação.

Um dos objetivos do "benchmark" foi avaliar o estado dos cálculos de transmutação de actinídeos menores para diferentes sistemas de reatores (rápidos, ADS e PWR). Neste trabalho só serão considerados os resultados encontrados para os reatores rápidos e $\mathrm{ADS}$.

O "benchmark" do reator rápido foi para um reator rápido regenerador de 1000 MWe com uma taxa de regeneração de 1,25 [43]. O núcleo consistia em duas zonas combustíveis com diferentes enriquecimentos. Seis soluções foram submetidas para o "benchmark".

A TAB. 2 mostra um resumo dos participantes, dados básicos e códigos usados na solução do problema. 
TABELA 2 - Resumo do "benchmark" de reatores rápidos

\begin{tabular}{|c|c|c|c|c|}
\hline $\begin{array}{c}\text { Instituição } \\
\text { (país) }\end{array}$ & Participantes & Dados Básicos & $\begin{array}{c}\text { Número de grupos } \\
\text { de energia }\end{array}$ & Códigos \\
\hline $\begin{array}{l}\text { JAERI } \\
\text { (Japão) }\end{array}$ & $\begin{array}{l}\text { K. Tsujimoto } \\
\text { H. Oigawa } \\
\text { T. Mukaiyama }\end{array}$ & JENDL-3.2 & $\begin{array}{c}70 \\
1 \text { (cálculo de } \\
\text { queima) }\end{array}$ & $\begin{array}{l}\text { ABC-SC } \\
\text { - SLAROM } \\
\text { - CITATION-FBR } \\
\text { - ORILIB } \\
\text { - ORIGEN-2 } \\
\text { - F-CHANGE } \\
\text { - PERKY } \\
\text { - RADAMES }\end{array}$ \\
\hline $\begin{array}{c}\text { CEA } \\
\text { (França) }\end{array}$ & J. Tommasi & $\begin{array}{c}\text { CARNAVAL- } \\
\text { IV + JEF-1 }\end{array}$ & 25 & - ERANOS \\
\hline $\begin{array}{c}\text { JNC } \\
\text { (Japão) }\end{array}$ & T. Wakabayashi & JENDL-3.2 & $\begin{array}{c}70 \\
7 \text { (cálculo de } \\
\text { queima) }\end{array}$ & $\begin{array}{l}\text { - SLAROM } \\
\text { - CITATION-FBR } \\
\text { - ORIGEN-2 } \\
\text { - PERKY }\end{array}$ \\
\hline $\begin{array}{l}\text { MITSUBISHI } \\
\text { (Japão) }\end{array}$ & M. Yano & JENDL-3.2 18 & $\begin{array}{c}7 \text { (cálculo de } \\
\text { queima) }\end{array}$ & $\begin{array}{l}\cdot \text { ODDBURN } \\
\cdot \text { 2DBURN } \\
\cdot \text { HANYO }\end{array}$ \\
\hline $\begin{array}{l}\text { TOSHIBA } \\
\text { (Japão) }\end{array}$ & $\begin{array}{l}\text { M. Kawashima } \\
\text { M. Yamaoka }\end{array}$ & JENDL-3.2 70 & $\begin{array}{c}7 \text { (cálculo de } \\
\text { queima) }\end{array}$ & - STANBRE-V3 \\
\hline $\begin{array}{l}\text { IPPE } \\
\text { (Rússia) }\end{array}$ & $\begin{array}{l}\text { M. Semenov } \\
\text { A. Tsiboulia }\end{array}$ & FOND-2 & 26 & $\begin{array}{l}\text { - CONSYST2 } \\
\text { - TRIGEX } \\
\text { - CARE }\end{array}$ \\
\hline
\end{tabular}

Seis soluções foram submetidas para este "benchmark", conforme a Referência 43. Chegou - se às seguintes conclusões:

1. Os valores observados para o fator de multiplicação, índices espectrais, perda de reatividade, reatividade Doppler, fontes de nêutrons e taxa de transmutação concordam satisfatoriamente.

2. As discrepâncias principais são observadas nas variações de composição isotópica dos elementos ${ }^{238} \mathrm{Pu},{ }^{240} \mathrm{Pu},{ }^{242} \mathrm{Pu},{ }^{241} \mathrm{Am},{ }^{243} \mathrm{Am},{ }^{244} \mathrm{Cm}$ e ${ }^{237} \mathrm{~Np}$. Estas discrepâncias são creditadas as diferenças de seções de choque.

3. As discrepâncias menores são notadas no decaimento de calor e atividades dos rejeitos.

4. Sistemas de códigos de cálculos dos participantes têm um bom acordo geral nas previsões das características nucleares do núcleo do reator rápido carregado com actinídeos menores. 
O "benchmark" em ADS foi desenvolvido para a validação de códigos e dados nucleares, em um sistema refrigerado à Sódio dirigido por um feixe de prótons de $1 \mathrm{GeV}$ e $10 \mathrm{~mA}$. O "benchmark" foi baseado em um projeto conceitual da JAERI. O fator de multiplicação de nêutrons utilizado nos cálculos é $\mathrm{k}=0,98$. Na Referência 43 é encontrada uma descrição completa do "benchmark" em ADS. A lista de participantes, dados básicos e códigos utilizados para cada estágio dos cálculos estão apresentados na TAB. 3.

TABELA 3 - Resumo do "benchmark" em ADS

\begin{tabular}{|c|c|c|c|}
\hline Instituição (país) & Participantes & $\begin{array}{l}\text { Dados } \\
\text { básicos }\end{array}$ & Códigos \\
\hline JAERI (Japão) & $\begin{array}{l}\text { T. Nishida } \\
\text { T. Takizuda } \\
\text { T. Sasa }\end{array}$ & JENDL-3.2 & $\begin{array}{l}> \\
\text { - } 20 \mathrm{MMTCV} \\
<20 \mathrm{MeV} \\
\text { - TWODANT } \\
\text { (transporte de nêutrons: } 73 \text { grupos) } \\
\text { - BURNER (queima) } \\
\text { - } \text { NJOY-91.38/NILER/BONAMI-S } \\
\text { (seções de choque) }\end{array}$ \\
\hline PSI (Suíça) & $\begin{array}{l}\text { G. Youinou } \\
\text { S. Pelloni } \\
\text { P. Wyder }\end{array}$ & JEF-2.2 & $\begin{array}{l}>15 \mathrm{MeV} \\
\text { - HETC-PSI } \\
<15 \mathrm{MeV} \\
\text { - TWODANT } \\
\text { (transporte de nêutrons: } 33 \text { grupos) } \\
\text { - } \quad \text { 2DTB (queima) } \\
\text { - NJOY-89.62/MICROR/MICROX-2 } \\
\text { (seções de choque) }\end{array}$ \\
\hline IPPE (Rússia) & $\begin{array}{l}\text { T. T. Ivanova } \\
\text { V.F. Batyaev } \\
\text { A.A. Tsiboulia }\end{array}$ & $\begin{array}{l}\text { ABBN-93 da } \\
\text { FOND-2 }\end{array}$ & $\begin{array}{l}>20 \mathrm{MeV} \\
\text { - HETC } \\
<20 \mathrm{MeV} \\
\text { - TWODANT } \\
\text { (transporte de nêutrons: } 28 \text { grupos) } \\
\text { - CARE (queima) } \\
\text { - CONSYST2 (seções de choque) }\end{array}$ \\
\hline
\end{tabular}


Três soluções foram submetidas para este "benchmark". As seguintes conclusões foram encontradas:

1. Acordos satisfatórios foram observados no número de nêutrons de spallation por próton incidente e a distribuição axial da fuga de nêutrons do alvo de spallation ( $>$ $15 \mathrm{MeV})$.

2. Grandes discrepâncias foram encontradas nas densidades de potências médias e máximas nas partes finas e espessas do disco do alvo.

3. Os resultados do espectro médio de nêutrons mostram um bom acordo entre os participantes. Discrepâncias essenciais foram encontradas no fator de multiplicação e nos aspectos característicos da queima.

4. As discrepâncias no fator de multiplicação e nas características da queima podem ser atribuídas principalmente ao espectro de energia dos nêutrons de fissão, ao tratamento dos produtos de fissão, e as seções de choque usadas para os actinídeos menores em diferentes bibliotecas de dados nucleares.

Os resultados deste "benchmark" foram muito discrepantes e inconclusivos. Portanto, percebeu-se a necessidade de outros "benchmarks" e a utilização destes estudos realizados como ponto de partida para novos estudos. Também se concluiu que é importante aumentar a credibilidade na validação de códigos e dados nucleares, principalmente de seções de choque acima de $20 \mathrm{MeV}$.

\section{3- Objetivos e Divisão do Trabalho}

A equação de transporte de radiação, ou equação de Boltzmann gera uma descrição exata de um campo de radiação de partículas neutras em termos da posição, direção de movimento e energia de cada partícula no campo. Cálculos de fonte fixa geralmente são realizados por formas estocásticas (simulação Monte Carlo) tal como o MCNP. Tal método utiliza amostragem aleatória para solucionar um problema físico ou matemático, onde um modelo estatístico é construído de tal forma que a amostragem de distribuições de probabilidades apropriadas leva à respostas através de médias das grandezas de interesse. Os códigos Monte Carlo são extremamente efetivos para problemas com geometrias complexas onde cálculos de quantidades integrais tais como taxas de radiação e fatores de multiplicação de nêutrons são desejados. Entretanto, 
cálculos para obter informações diferenciais precisas tais como, fluxos de nêutrons em função do espaço e energia, podem ser difíceis ou dispendiosos e são predispostos à imprecisões (mesmo se a grandeza integral está correta).

Por outro lado, técnicas determinísticas de transporte, tais como transporte integral, probabilidade de colisão, teoria da difusão e métodos de Ordenadas Discretas são mais bem apropriadas para problemas onde quantidades diferenciais, tais como o fluxo de nêutrons em função da energia ou espaço é desejado. Além das informações globais, quando executado apenas uma vez, em um programa determinístico podem ser obtidos todos os parâmetros estáticos. Obviamente, o tempo de processamento depende da complexidade geométrica de cada programa. Os códigos determinísticos têm suas vantagens e desvantagens: o código TORT, por exemplo, demanda um longo tempo de processamento no cálculo de fator de multiplicação de nêutrons, porém em cálculos de outras grandezas estáticas de fonte fixa o tempo de processamento é muito menor, pois apenas uma iteração externa é necessária. Algumas das desvantagens dos métodos determinísticos de transporte de nêutrons são: a flexibilidade para descrever sistemas geométricos complexos e o processamento dos dados nucleares, que precisam passar por um longo processo de tratamento até poderem ser usados pelos códigos determinísticos.

O objetivo específico de pesquisa do Projeto Coordenado de Pesquisa (CRP) atual da Agência Internacional de Energia Atômica (IAEA) [44] é melhorar o entendimento do acoplamento de fontes de spallation em ADS com núcleos subcríticos. Dentro deste objetivo pretende-se implementar e validar uma metodologia de cálculo de constantes de Multigrupo (que ainda são uma questão em aberto para cálculos de ADS, mas cujo estudo mais detalhado neste momento está além do nosso alcance). No presente trabalho objetiva-se estudar a Física de sistemas multiplicativos subcríticos acionados por fontes externas e a aplicação de Métodos Determinísticos de cálculos na solução de parâmetros associados a estes sistemas.

No Capítulo 2, na primeira parte, será feita uma apresentação da equação de transporte de nêutrons. Na segunda parte do capítulo serão descritos alguns métodos numéricos de solução da equação de transporte. 
No Capítulo 3 será realizada uma descrição da Física dos sistemas acionados por fontes. Serão descritos sucintamente os parâmetros estáticos e dinâmicos deduzidos por Gandini e Dulla. Para ilustrar alguns destes parâmetros serão realizados alguns cálculos utilizando o código determinístico ANISN [45] (geometria unidimensional).

No Capítulo 4 utiliza-se o código TORT para calcular alguns parâmetros subcríticos físicos do reator IPEN/MB-01. O reator IPEN/MB-01 tem objetivo definido dentro do CRP, onde se fará a primeira tentativa de calcular alguns parâmetros de interesse, sem as barras de controle e com a remoção de duas linhas e duas colunas da configuração crítica.

No capítulo 5 será analisada a geração de constantes de Multigrupo para cálculos de parâmetros de Física de reatores acionados por fontes. Será mostrada a forma atual de geração destas constantes pelo grupo de pesquisa do IPEN, assim como os programas utilizados por estes.

No Capitulo 6 são apresentadas as conclusões e sugestões. No Apêndice A são apresentadas as constantes Multigrupo utilizadas na execução do código ANISN. No Apêndice B, é feita uma breve descrição dos códigos ANISN e TORT, que foram utilizados na solução dos parâmetros estáticos relacionados ao reator IPEN/MB-01 e Yalina Booster e no apêndice C será analisada a geração de constantes de Multigrupo para cálculos de parâmetros de Física de reatores acionados por fontes. Será mostrada a forma de geração destas constantes pelo grupo de pesquisa do IPEN, assim como os programas utilizados por estes. 


\section{A EQUAÇÃO DE TRANSPORTE NA SOLUÇÃO DE CÁLCULOS DE PARÂMETROS DE FÍSICA DE REATORES}

\subsection{Introdução}

A equação de Boltzmann linearizada é a equação básica da teoria de transporte de nêutrons em meios multiplicativos, com a aplicação em projeto de reatores nucleares e análise de criticalidade, teoria de transferência radiativa, aplicação em transferência de calor radiativo, cálculos estelares e atmosferas planetárias, blindagens de radiação, etc.

No espaço de fases $(\vec{r}, \vec{\Omega}, E, t)$, a equação de transporte, pode ser escrita na forma:

$$
\begin{aligned}
& \frac{1}{V} \frac{\partial \Phi(\vec{r}, \hat{\Omega}, E, t)}{\partial t}=-\hat{\Omega} \cdot \vec{\nabla} \Phi(\vec{r}, \hat{\Omega}, E, t)-\Sigma_{t}(\vec{r}, E) \Phi(\vec{r}, \hat{\Omega}, E, t)+ \\
& \int_{0}^{\infty} d E^{\prime} \int_{4 \pi} d \hat{\Omega}^{\prime} \Sigma_{s}\left(\vec{r} ; E^{\prime}, \hat{\Omega}^{\prime} \rightarrow \hat{\Omega}, E, t\right) \Phi\left(\vec{r}, \hat{\Omega}^{\prime}, E^{\prime}, t\right)+ \\
& \frac{\chi(E)}{4 \pi} \int_{0}^{\infty} d E^{\prime} \int_{4 \pi} d \hat{\Omega}^{\prime} v\left(E^{\prime}\right) \Sigma_{f}\left(\vec{r}, E^{\prime}, t\right) \Phi\left(\vec{r}, \hat{\Omega}, E^{\prime}, t\right)+S_{e x t}(\vec{r}, \hat{\Omega}, E, t)
\end{aligned}
$$

Na Equação (1) $\Phi(\vec{r}, \hat{\Omega}, E, t)$ representa o fluxo angular; $\Sigma_{t}(\vec{r}, E)$ a seção de choque macroscópica total; $\Sigma_{S}\left(\vec{r}, E^{\prime}, \hat{\Omega}^{\prime} \rightarrow \hat{\Omega}, E\right)$ a seção de choque macroscópica de transferência, que descreve a probabilidade que uma partícula com uma energia inicial $E^{\prime}$ e direção $\hat{\Omega}^{\prime}$ sofra uma colisão em $\vec{r}$ no tempo $t$, resultando em uma mudança de direção e energia; $S_{e x t}$ é a fonte externa de nêutrons; $\chi(E)$ a distribuição de energia dos nêutrons de fissão (espectro), assumida isotrópica; $v(E)$ é o número médio de nêutrons liberados por fissão e, $\Sigma_{f}\left(\vec{r}, E^{\prime}\right)$ é a seção de choque macroscópica de fissão, assumida como isotrópica.

A Equação (1) também pode ser escrita na sua forma independente do tempo sem o termo fonte e com a introdução do autovalor $k$ : 


$$
\begin{aligned}
& \hat{\Omega} \cdot \vec{\nabla} \Phi(\vec{r}, \hat{\Omega}, E)+\Sigma(\vec{r}, E) \Phi(\vec{r}, E, \hat{\Omega})= \\
& \int_{0}^{\infty} \int_{4 \pi} \Sigma_{S}\left(\vec{r}, \hat{\Omega}^{\prime} \rightarrow \hat{\Omega}, E^{\prime} \rightarrow E\right) \Phi\left(\vec{r}, \hat{\Omega}^{\prime}, E^{\prime}\right) d \hat{\Omega}^{\prime} d E^{\prime} \\
& +\frac{1}{k} \int_{0}^{\infty} \int_{4 \pi} \frac{\chi(E)}{4 \pi} v\left(E^{\prime}\right) \Sigma_{f}\left(\vec{r}, E^{\prime}\right) \Phi\left(\vec{r}, \hat{\Omega}^{\prime}, E^{\prime}\right) d \hat{\Omega}^{\prime} d E^{\prime} .
\end{aligned}
$$

O autovalor $k$, também é conhecido como fator de multiplicação de nêutrons. Integrando-se a Equação (2) em todo o espaço de fases, verifica-se que este autovalor relaciona a produção de nêutrons pelo desaparecimento de nêutrons. Este fator está relacionado à geometria e composição dos materiais que compõem um determinado sistema. Em meios multiplicativos os sistemas contendo nuclídeos físseis podem ser considerados como sistemas subcríticos, críticos ou supercríticos. Um sistema é considerado supercrítico quando o fator de multiplicação é maior que a unidade, i.e., as reações divergem, ou seja, de um nêutron inicial obtém-se um número final de nêutrons que tende ao infinito. Uma divergência controlada permite ligar um reator nuclear. Quando o fator de multiplicação é mantido igual à unidade obtém-se um reator crítico. Este sistema é possível devido à presença de uma pequena fração de nêutrons atrasados que permitem a correção do desvio do coeficiente de criticalidade da unidade. Quando o fator de multiplicação é menor que a unidade o sistema é dito subcrítico e neste sistema nasce um número finito de nêutrons secundários.

Em pesquisas de criticalidade (2) não é considerada a fonte externa de nêutrons, pois tais pesquisas dependem apenas dos materiais e geometria do sistema.

Na Equação (2) há um termo, na seção de choque de espalhamento, que representa o núcleo de espalhamento de nêutrons, que depende da interação física. Este termo geralmente é expandido em polinômios de Legendre do ângulo de espalhamento $\left(\hat{\Omega} \cdot \hat{\Omega}^{\prime}=\mu_{0}\right)$, i.e.,

$$
\Sigma_{s}\left(\vec{r}, E^{\prime} \rightarrow E, \mu_{0}\right)=\sum_{l=0}^{L} \frac{2 l+1}{2} \Sigma_{s}^{l}\left(\vec{r}, E^{\prime} \rightarrow E\right) P_{l}\left(\mu_{0}\right)
$$


A dependência da energia na equação de transporte é tratada através de uma formulação de Multigrupo, na qual o alcance de energia é dividido em um número finito, $\mathrm{G}$, de intervalos separados pelas energias $E_{g}, g=1,2,3, \ldots, G$ [46]. Nessa formulação o primeiro grupo representa o grupo com maior energia e o grupo $\mathrm{G}$ representa o grupo com a menor energia. Esta representação é usada porque a maior parte das partículas nasce nas altas energias e sofrem interações que fazem que haja perda de energia destas partículas quando entram em equilíbrio térmico com o meio. Dessa forma, a equação de transporte Multigrupo com espalhamento anisotrópico, sem dependência temporal, pode ser escrita na forma

$$
\begin{aligned}
& \hat{\Omega} \cdot \vec{\nabla} \Phi_{g}(\vec{r}, \hat{\Omega})+\sum_{t g}(\vec{r}) \Phi_{g}(\vec{r}, \hat{\Omega})= \\
& \sum_{m=0}^{M} \sum_{g^{\prime}}^{G} \int_{4 \pi} d \hat{\Omega}^{\prime}\left(\frac{2 l+1}{2}\right) \sum_{g^{\prime} \rightarrow g}^{(l)}(\vec{r}) P_{l}\left(\mu_{0}\right) \Phi_{g^{\prime}}\left(\vec{r}, \hat{\Omega}^{\prime}\right) \\
& +\frac{1}{k} \int d \hat{\Omega}^{\prime} \chi_{g} \sum_{g^{\prime}}^{G}\left(\frac{v \Sigma_{f}}{4 \pi}\right)_{g^{\prime}} \Phi_{g^{\prime}}\left(\vec{r}, \hat{\Omega}^{\prime}\right)+S_{e x t}^{g}\left(\vec{r}, \hat{\Omega}^{\prime}\right), \quad g=1,2,3, \ldots, G .
\end{aligned}
$$

Onde $\Phi_{g}(\vec{r}, \hat{\Omega})$ representa o fluxo angular de nêutrons do grupo $g$. O fluxo angular pode ser definido como

$$
\Phi_{g}(\vec{r}, \hat{\Omega})=\int_{E_{g}}^{E_{g+1}} \Phi(\vec{r}, E, \hat{\Omega}) d E
$$

As seções de choque de grupo, ou constantes de grupo, $\left(\Sigma_{t g}, \Sigma_{g^{\prime} \rightarrow g}^{(l)},\left(v \Sigma_{f}\right)_{g}\right)$ são seções de choque médias ponderadas pelo fluxo no intervalo do grupo de energia, i.e.

$$
\Sigma_{g}(\vec{r})=\frac{\int_{g} \Sigma(\vec{r}, E) \Phi(\vec{r}, E) d E}{\Phi_{g}(\vec{r})}
$$




$$
\Sigma_{g^{\prime} \rightarrow g}^{(l)}(\vec{r})=\frac{\int_{g} d E \int_{g^{\prime}} \Sigma\left(\vec{r}, E^{\prime} \rightarrow E\right) \int_{4 \pi} \Phi\left(r, E^{\prime}, \hat{\Omega}^{\prime}\right) P_{l}\left(\mu_{0}\right) d E^{\prime} d \Omega^{\prime}}{\int_{g^{\prime}} \int_{4 \pi} \Phi\left(\vec{r}, E^{\prime}, \hat{\Omega}^{\prime}\right) P_{l}\left(\mu_{0}\right) d E^{\prime} d \Omega^{\prime}}
$$

As quantidades definidas na Equação (7) são conhecidas como seções de choque de transferência, uma vez que estas quantidades se referem à transferência de nêutrons do grupo $g$ ' para o grupo $g$, incluindo $g=g$ '.

A equação linear de transporte em estado estacionário quando aplicada a problemas físicos é um típico problema de valor de fronteira. Nos cálculos realizados neste trabalho a equação de transporte é resolvida em estado estacionário na subcriticalidade e com uma fonte externa de nêutrons. Para se obter uma solução única e positiva é necessário haver certas condições de fronteira bem definidas que estabeleçam as condições físicas do problema a ser resolvido. As condições de fronteira mais usadas são:

(a) Vácuo (ou superfície livre): esta condição é válida quando não há partículas que entram no meio, i.e., uma partícula que deixa a superfície do meio não pode retornar, e, portanto ela pode ser chamada de superfície livre,

(b) Reflexão: nesta condição de fronteira assume-se que as partículas são refletidas na fronteira de superfície com ângulos iguais de incidência e reflexão,

(c) Periódico: esta condição de contorno assume que o fluxo angular que deixa certa fronteira é equiparado com o fluxo que re-entra em outra fronteira. Por exemplo, no código ANISN o fluxo angular que deixa a fronteira esquerda re-entra na fronteira direita,

(d) White: nesta condição o fluxo angular que deixa a fronteira especificada é integrado na variável angular, e este mesmo fluxo total retorna isotropicamente para a mesma fronteira como função da energia e ângulo, e

(e) Albedo: geralmente esta condição é interpretada como uma generalização da condição de fronteira White. Ela é obtida assumindo-se que o fluxo angular que retornou isotropicamente é multiplicado pelo Albedo, i.e., 


$$
\Phi\left(\vec{r}_{s}, \hat{\Omega}, E\right)=\frac{\alpha}{4 \pi} \int_{2 \pi} \Phi\left(\vec{r}_{s}, \hat{\Omega}^{\prime}, E\right) d \hat{\Omega}^{\prime}
$$

onde $\hat{\Omega} \cdot \hat{n}<0 ; \quad \hat{\Omega}^{\prime} \cdot \hat{n}>0 ; \alpha$ é o Albedo $(0<\alpha<1)$.

\subsection{Métodos Numéricos de Solução da Equação de Transporte}

\subsubsection{Métodos dos Elementos Finitos}

O Método dos Elementos Finitos, MEF, ao contrário de outros métodos que eram utilizados no passado só tem utilidade prática se dispuser de um computador digital. Ele tem sido vastamente utilizado nos últimos 20-30 anos, graças aos avanços tecnológicos ocorridos nos equipamentos computacionais. Este método é uma análise matemática que consiste na discretização de um meio contínuo em pequenos elementos, mantendo as mesmas propriedades do meio original. Esses elementos são descritos por equações diferenciais e resolvidos por modelos matemáticos, para que sejam obtidos os resultados desejados. Devido às suas características de flexibilidade e estabilidade numérica, ele pode ser implementado na forma de um sistema computacional (programa de computador) de forma consistente e sistemática para a resolução de grandes sistemas de equações lineares.

Os métodos de elementos finitos consistem em dividir o domínio da solução em um número finito de subdomínios simples, os elementos finitos. Esquemas variacionais empregando uma aproximação residual pesada ou uma aproximação baseada em princípios extremos são usados para construir uma solução aproximada no conjunto de elementos finitos.

O uso de método de elementos finitos em problemas de transporte tem dado uma maior flexibilidade geométrica para os métodos determinísticos. Em contraste aos métodos antigos de diferenças finitas que são geralmente baseadas em formulações diferenciais, o método de diferenças finitas é baseado em formulações integrais. Em um elemento a solução é aproximada pelas chamadas funções "local piece-wise polynomial 
trial functions". Os coeficientes da expansão então são determinados, ou pela aplicação da aproximação de resíduos pesados ou pela aproximação variacional.

Aparte da flexibilidade geométrica do método, estes métodos também são vantajosos porque eles geram o fluxo angular em qualquer ponto do sistema. Também os erros na fronteiras em algumas das características globais e locais podem ser preditas de forma sistemática através destes métodos. Podem-se citar alguns códigos que resolvem problemas de transporte utilizando os métodos de diferenças finitas: FELTRAN, MARC e EVENT. Estes códigos são capazes de solucionar a equação de transporte em estado estacionário ou dependente do tempo, problemas com espalhamento isotrópico e anisotrópico e em multiregiões.

Em algumas formulações envolvendo métodos de elementos finitos a aproximação de resíduos pesados é usada, enquanto que em outras as aproximações variacionais são adotadas, com uma combinação das aplicações dos elementos finitos para uma ou mais das variáveis independentes. A aproximação variacional inclui o método clássico de Euler-Lagrange, método da funcional bilinear e método dos mínimos quadrados generalizados.

$\mathrm{Na}$ aproximação residual pesada a forma fraca (integral) da equação íntegro diferencial é considerada e expandida em um conjunto de funções base de elementos finitos. A forma fraca é obtida pela multiplicação da equação original por uma função peso arbitrária. Se as funções arbitrárias são as funções bases do elemento finito, então esta aproximação é chamada de técnica Galerkin. Esta aproximação foi usada por Martin et al (1981) para resolver a equação de Boltzmann de primeira ordem em estado estacionário e dependente do tempo para problemas de transporte de nêutrons. Outros pesquisadores também utilizaram este mesmo método, como por exemplo, Mordant, que desenvolveu um código para geometrias irregulares X-Y e R-Z.

Como exemplo da aproximação variacional, pode ser utilizado o método de Euler-Lagrange, onde uma funcional é desenvolvida para uma dada equação diferencial parcial, que quando é minimizada ou maximizada dá a equação original como equação de Euler-Lagrange na primeira variação dela. Para desenvolver tal funcional, a equação diferencial parcial tem que ser auto adjunto (Duderstad e Martin) [47]. Portanto, para 
aplicar este método no transporte de nêutrons, deve-se usar as formas de segunda ordem da equação de Boltzmann. Um tratamento desta teoria é dada em detalhes por Duderstad e Martin e Lewis e Miller [48].

\subsubsection{Métodos dos Harmônicos Esféricos}

Para entender o método dos harmônicos esféricos pode-se começar explicitando que equação de Laplace é uma equação diferencial linear de segunda ordem que impõe restrições em alguma função $\varphi(x, y, z)$. A solução da equação de Laplace é chamada de harmônico sólido. Quando $\varphi$ pode ser escrito como o produto de uma função de r, R(r), e uma função dos ângulos $\theta$ e $\psi, \Theta(\theta, \psi)$, a função $\Theta$ é chamada de esférico harmônico.

O princípio geral de solução da equação de transporte através do método dos harmônicos esféricos, ou aproximação $\mathrm{P}_{\mathrm{L}}$, é expandi-la em um conjunto completo de funções elementares, tais como uma série de polinômios, a dependência angular do fluxo e seção de choque diferencial de espalhamento. Para geometria geral, harmônicos esféricos é uma escolha lógica, mas para geometrias planas ou esféricas estes se reduzem à polinômios de Legendre. Em problemas multigrupo reais de transporte o espalhamento é anisotrópico e o efeito de tais espalhamentos nas soluções da equação de transporte deve ser examinado.

Os harmônicos esféricos podem ser escritos em termos das funções associadas de Legendre como

$$
Y_{l m}(\mu, \varphi)=\frac{\sqrt{(l-m) !}}{\sqrt{(l+m) !}} P_{l}^{m}(\mu) \exp (\operatorname{im} \varphi)
$$

Denotando o complexo conjugado por um asterisco, segue-se que

$$
Y_{l,-m}(\mu, \varphi)=(-1)^{m} Y_{l m}^{*}(\mu, \varphi)
$$


Os harmônicos esféricos também podem ser gerados usando a relação de recorrência das funções associadas de Legendre. Eles também devem satisfazer a relação de ortogonalidade.

Expandindo-se a dependência angular do fluxo de nêutrons da equação de transporte em coordenadas cartesianas em harmônicos esféricos obtém-se

$$
\Phi(r, \hat{\Omega})=\sum_{l=0}^{L} \frac{2 l+1}{4 \pi} \sum_{m=-l}^{l} \phi_{l m}(r) Y_{l m}(\mu, \varphi)
$$

A expansão da seção de choque diferencial de espalhamento torna-se

$$
\Sigma_{s}\left(r, \mu_{0}\right)=\sum_{l^{\prime}=0}^{L^{\prime}} \frac{2 l^{\prime}+1}{4 \pi} \Sigma_{s l^{\prime}}(r) P_{l^{\prime}}\left(\mu_{0}\right) .
$$

Substituindo estas expansões acima na equação de transporte obtém-se

$$
\begin{aligned}
\hat{\Omega} \cdot \nabla \varphi(r, \hat{\Omega})+\Sigma_{t}(r, \hat{\Omega}) \varphi(r, \hat{\Omega}) & =\frac{1}{4 \pi} \int_{4 \pi} d \hat{\Omega}^{\prime} v \Sigma_{f}(r) \varphi\left(r, \hat{\Omega}^{\prime}\right) \\
& +\int_{4 \pi} d \hat{\Omega}^{\prime} \Sigma_{s}\left(r, \hat{\Omega} \cdot \hat{\Omega}^{\prime}\right) \varphi\left(r, \hat{\Omega}^{\prime}\right)+S(r, \hat{\Omega})
\end{aligned}
$$

Quando se multiplica por cada $Y_{l m}^{*}$ por sua vez, e integrando em $d \hat{\Omega}$, e fazendo uso da ortogonalidade, relação de recorrência e do teorema da adição produz-se as equações de harmônicos esféricos para os momentos de fluxo $\phi_{l m}$ : 


$$
\begin{aligned}
& \frac{1}{2 l+1}\left\{\frac{1}{2} \sqrt{(l+m+2)(l+m+1)}\left(-\frac{\partial}{\partial x}-i \frac{\partial}{\partial y}\right) \phi_{l+1, m+1}\right. \\
& +\frac{1}{2} \sqrt{(l-m+2)(l-m+1)}\left(\frac{\partial}{\partial x}-i \frac{\partial}{\partial y}\right) \phi_{l+1, m-1} \\
& +\frac{1}{2} \sqrt{(l-m-1)(l-m+1)}\left(\frac{\partial}{\partial x}-i \frac{\partial}{\partial y}\right) \phi_{l-1, m+1} \\
& +\frac{1}{2} \sqrt{(l+m-1)(l+m)}\left(-\frac{\partial}{\partial x}+i \frac{\partial}{\partial y}\right) \phi_{l-1, m-1} \\
& +\sqrt{(l+m+1)(l+m-1)} \frac{\partial}{\partial z} \phi_{l+1, m} \\
& \left.+\sqrt{(l+m)(l-m)} \frac{\partial}{\partial z} \phi_{l-1, m}\right\}+\Sigma_{t} \phi_{l m} \\
& =\Sigma_{s l} \phi_{l m}+\delta_{l 0} v \Sigma_{f} \phi_{00}+Q_{l m} \quad l=0, \ldots L, m=-l \ldots l
\end{aligned}
$$

Neste conjunto de Equação $Q_{l m}$ é o $Y_{l m}^{*}$ momento da fonte externa.

Este conjunto de equações raramente é resolvido da forma como ele aparece na Equação (14); entretanto, ele gera a base para o desenvolvimento de um número de aproximações úteis. Nota-se que a equação para cada momento do fluxo $\phi_{l m}$ contém termos de espalhamento envolvendo apenas aquele momento de fluxo, a fim de que o acoplamento entre as equações para diferentes momentos de fluxo é inteiramente através dos termos "streaming" do termo $\hat{\Omega} \cdot \nabla \Phi$.

Para problemas unidimensionais, um subconjunto dos harmônicos esféricos pode ser usado, os polinômios de Legendre, que consistem num conjunto ortogonal de funções.

Os polinômios de Legendre podem ser gerados pela relação de recorrência

$$
(2 n+1) \mu P_{n}(\mu)=(n+1) P_{n+1}(\mu)+n P_{n-1}(\mu)
$$

Os polinômios de Legendre também devem satisfazer a relação de ortogonalidade 


$$
\int_{-1}^{+1} d \mu P_{m}(\mu) P_{n}(\mu)=\frac{2 \delta_{m n}}{2 n+1}
$$

Os polinômios de Legendre de $\mu_{0}=\cos \theta$, o cosseno do ângulo entre $\mu^{\prime}$ e $\mu$, podem ser expressos em termos dos polinômios de Legendre de $\mu$ ' e $\mu$ pelo teorema da adição

$$
P_{n}\left(\mu_{0}\right)=P_{n}(\mu) P_{n}\left(\mu^{\prime}\right)+2 \sum_{m=1}^{M} \frac{(n-m) !}{(n+m) !} P_{n}^{m}\left(\mu^{\prime}\right) P_{n}^{m}(\mu) \cos m\left(\phi-\phi^{\prime}\right)
$$

Onde as funções associadas de Legendre são definidas por

$$
P_{n}^{m}(\mu)=\left(1-\mu^{2}\right)^{m / 2} \frac{d^{m} P_{n}(\mu)}{d \mu^{m}}
$$

Pode-se escrever a equação de transporte de Boltzmann em estado estacionário, para nêutrons monoenergéticos, como:

$$
\mu \frac{\partial \Phi(x, \mu)}{\partial x}+\Sigma_{t}(x, \mu) \Phi(x, \mu)=\int_{-1}^{1} \Sigma_{s}\left(x, \mu^{\prime} \rightarrow \mu\right) \Phi\left(x, \mu^{\prime}\right) d \mu^{\prime}+S(x, \mu)
$$

Quando se considera a variável $\cos \theta_{0} \equiv \mu_{0}$, a Equação (19) também pode ser escrita como

$$
\mu \frac{\partial \Phi(x, \mu)}{\partial x}+\Sigma_{t}(x, \mu) \Phi(x, \mu)=\int_{-1}^{1} \Sigma_{s}\left(x, \mu_{0}\right) \Phi\left(x, \mu^{\prime}\right) d \mu^{\prime}+S(x, \mu)
$$

As Equações $\mathrm{P}_{\mathrm{L}}$ são baseadas na aproximação da dependência angular do fluxo de nêutrons que pode ser expandido nos primeiros $\mathrm{L}+1$ polinômios de Legendre:

$$
\varphi(x, \mu)=\sum_{l=0}^{L} \frac{2 l+1}{2} \phi_{l}(x) P_{l}(\mu)
$$


A dependência angular da seção de choque diferencial também pode ser expandida em polinômios de Legendre:

$$
\Sigma_{s}\left(x, \mu_{0}\right)=\sum_{m=0}^{M} \frac{2 m+1}{2} \Sigma_{s m}(x) P_{m}\left(\mu_{0}\right)
$$

Quando estas expansões são usadas na Equação (20), o teorema da adição da Equação (17) é usado para substituir $P_{m}\left(\mu_{0}\right) \operatorname{com} P_{m}(\mu)$ e $P_{m}\left(\mu^{\prime}\right)$. A relação de recorrência da Equação (15) é usada para substituir os termos $\mu P_{n}(\mu)$ com os termos $P_{n+1}(\mu)$. A equação resultante é multiplicada vez por $P_{k}(\mu)(\mathrm{k}=0$ para $\mathrm{L})$ e integrada em $-1 \leq \mu \leq 1$, e a relação de ortogonalidade da Equação (16) é usada, as $\mathrm{L}+1$ Equações $\mathrm{P}_{\mathrm{L}}$ obtidas são:

$$
\begin{gathered}
\frac{d \phi_{1}(x)}{d x}+\left(\Sigma_{t}-\Sigma_{s o}\right) \phi_{0}(x)=S_{0}(x), \quad n=0 \\
\frac{n+1}{2 n+1} \frac{d \phi_{n+1}(x)}{d x}+\frac{n}{2 n+1} \frac{d \phi_{n-1}(x)}{d x}+\left(\Sigma_{t}-\Sigma_{s n}\right) \phi_{n}(x)=S_{n}(x), \quad n=1, \ldots, L
\end{gathered}
$$

O subscrito $n$ indica o $n^{\text {th }}$ momento de Legendre da quantidade dependente angular:

$$
\begin{aligned}
& \phi_{n}(x) \equiv \int_{-1}^{1} d \mu P_{n}(\mu) \varphi(x, \mu) \\
& S_{n}(x) \equiv \int_{-1}^{1} d \mu P_{n}(\mu) S(x, \mu)
\end{aligned}
$$

e

$$
\Sigma_{s n}(x) \equiv \int_{-1}^{1} d \mu P_{n}\left(\mu_{0}\right) \Sigma_{s}\left(x, \mu_{0}\right)
$$

Este conjunto de $\mathrm{L}+1$ equações tem um problema de fechamento, pois eles envolvem $\mathrm{L}+2$ desconhecidos. Este problema é geralmente resolvido ignorando o termo $\mathrm{d} \phi_{\mathrm{L}+1} / \mathrm{dx}$ que aparece na equação quando $\mathrm{n}=\mathrm{L}$. As primeiras $\mathrm{L}+1$ equações são então usadas. O conjunto resultante de equações é conhecido como as Equações $\mathrm{P}_{\mathrm{L}}$. 


\subsubsection{Métodos das Características}

A aplicação dos métodos de ordenadas discretas é difícil quando se trata de geometrias complicadas, não ortogonais, devido a natureza das aproximações de diferenças finitas para derivadas espaciais. Uma alternativa para a representação discreta da variável espacial é obtida no método das características, na qual a equação de transporte é resolvida analiticamente ao longo das direções características na célula computacional. Este método usa representações planas ou lineares de distribuição espacial das fontes nas células e fluxos na fronteira das células.

O fluxo angular $\Phi$ é resolvido ao longo do eixo s, onde este eixo é orientado ao longo da direção característica $\hat{\Omega}$. Uma vez que apenas o fluxo angular na direção $\hat{\Omega}$ é de interesse, o termo de streaming na equação de transporte pode ser escrito como:

$$
\widehat{\Omega} \cdot \vec{\nabla} \Phi(\vec{r}, \widehat{\Omega}, E)=\frac{d \Phi(s, E)}{d s}
$$

Portanto, a equação de transporte pode ser escrita na forma característica (omitindo E por clareza) como:

$$
\frac{d \Phi(s)}{d s}+\Sigma_{t}(s) \Phi(s)=Q(s)
$$

A Equação (29) tem solução na forma

$$
\Phi(s)=\Phi_{0} e^{-\Sigma_{t} s}+e^{-\Sigma_{t} s} \int_{0}^{s} Q e^{\Sigma_{t} s^{\prime}} d s^{\prime}
$$

Onde s é a distância ao longo da direção característica $\hat{\Omega}$, e $\Phi_{0}$ é o fluxo angular conhecido em $\mathrm{s}=0$. A variável $\Phi_{0}$ é dada pelas condições de fronteira dos lados conhecidos da célula e os fluxos angulares nos lados desconhecidos são computados usando a Equação (30). Existem vários métodos para a determinação de $\Phi_{0}$ e para a avaliação do termo integral, em diferentes técnicas de solução. 
Entre os vários esquemas que empregam o Método das Características pode-se destacar o "Step Characteristic" (SC) (desenvolvido por Lathrop [49]). Nesta aproximação, a fonte $\mathrm{Q}$ e a seção de choque macroscópica total $\Sigma_{t}$ são assumidas constantes na célula computacional. Realiza-se a integração da Equação (30):

$$
\Phi(s)=\Phi_{0} e^{-\Sigma_{t} s}+\frac{Q}{\Sigma_{t}}\left(1-e^{-\Sigma_{t} s}\right)
$$

A FIG. (5) mostra uma célula computacional na qual o método SC pode ser aplicado. Para uma dada direção característica $\hat{\Omega}$, o fluxo angular em qualquer lado desconhecido pode ser expresso em termos de uma média apropriada dos fluxos dos lados conhecidos, que contribuem para o lado desconhecido. Para a direção característica $\hat{\Omega}$, o fluxo "top" desconhecido $\Phi_{T}$ pode ser calculado com uma média pesada linearmente das contribuições dos lados conhecidos $\Phi_{B}$ e $\Phi_{L}$. Os fluxos em cada um dos dois lados conhecidos são considerados como constantes ao logo do comprimento de cada lado, representando o fluxo angular médio em cada direção $\hat{\Omega}$ e deve ser especificado das condições de contorno externas ou de um cálculo completo em uma célula adjacente.

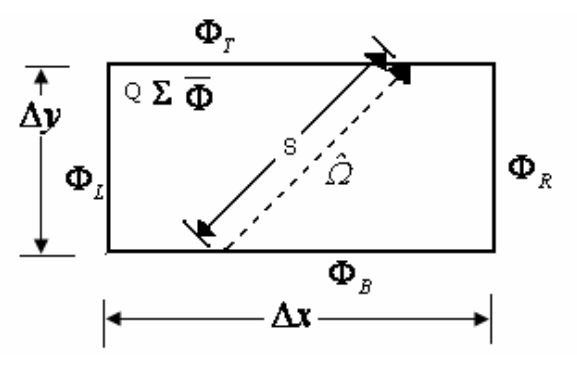

FIGURA 5 - Célula retangular típica usada na aproximação característica "step".

Um conjunto de direções características é escolhido de um conjunto de quadraturas, a fim de que os fluxos angulares resultantes possam ser numericamente integrados para obter um fluxo escalar. Conhecendo os comprimentos dos lados de uma célula retangular ( $\Delta x$ e $\Delta y)$ e os cossenos direção de $\hat{\Omega}$ no plano x-y $(\mu$ e $\eta)$ uma função dos comprimentos pode ser determinada. A solução para $\Phi(s)$ pode então ser integrada ao longo do comprimento de cada lado desconhecido para determinar o fluxo angular médio dos lados desconhecidos. 
Apesar do método SC descrito ser baseado em células retangulares, a derivação da Equação (30) não faz suposições sobre a forma da célula. Ela simplesmente requer conhecimento das relações entre as fronteiras da célula ao longo da direção da característica. Daí, o método não ser restrito a alguma geometria particular. Por isso ela é uma extensão da aproximação SC em células generalizadas, o Método Extended Step Characteristic (ESC).

Algumas definições da aproximação "Extended Step Characteristic" (ESC) são: (1) que as propriedades de todas as células computacionais, i.e., $\Sigma_{t} \mathrm{e} Q$, são uniformes, e (2) as fronteiras da célula são definidas por linhas retas. A restrição de uma célula computacional para as fronteiras consiste de um conjunto de linhas retas nas células computacionais que são limitadas a polígonos. Nenhuma restrição é colocada na forma do polígono, nem no número de lados do polígono. Entretanto, o tamanho do polígono é limitado. Em aplicações práticas, as propriedades são diferentes para permanecer constantes em volumes significantes, portanto, esta aproximação é uma aproximação pobre quando os volumes das células tornam-se muito grandes. Apesar de $\Sigma_{t}$ ser uma propriedade do material e poder permanecer espacialmente constante, o termo de fonte $\mathrm{Q}$, que depende do fluxo de nêutrons, irá variar com a posição. Uma vez que a solução pode se tornar exata quando uma célula tende a se tornar muito pequena, é esperado que a aproximação seja razoável para células computacionais em que a mudança no fluxo (e, portanto a fonte) é pequena no domínio da célula.

Como resultado desta configuração geométrica, cada lado de uma célula tem um dos três possíveis atributos relativos ao fluxo de partículas em uma dada direção característica, como é ilustrado na FIG. 6: (1) pode entrar na célula quando atravessa um lado (como mostrado pelos lados E e F na figura); (2) pode sair da célula quando atravessa um lado (lados B e C); ou (3) pode ser paralelo à orientação de um dado lado (lados A e D). 


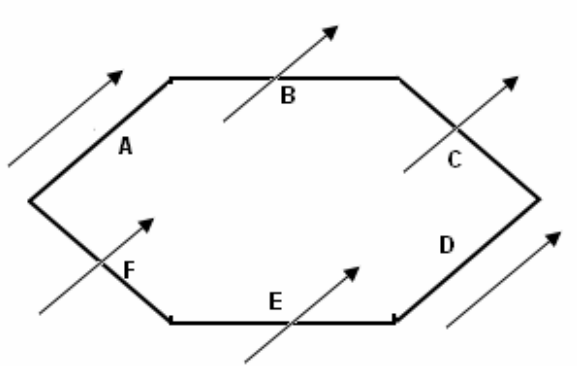

FIGURA 6 - Orientação dos lados de uma célula com relação à um dado vetor direção.

Para que seja capaz de resolver os fluxos nos lados de saída de uma célula, os fluxos nos lados de entrada têm que ser conhecidos. Cada lado de entrada de cada célula será dado a partir de uma condição de fronteira ou será o lado saída de uma célula adjacente.

\subsubsection{Métodos de Probabilidade de Colisão}

A teoria da difusão e a aproximação $\mathrm{P}_{1}$ falham se a dependência angular do fluxo é complicada ou varia rapidamente no ângulo $(\hat{\Omega})$ ou distância $(\vec{r})$. Tais casos podem ocorrer próximos de fontes localizadas e fronteiras ou em meios fortemente absorvedores. Ao invés de usar aproximações de alta ordem em tais situações, alguns métodos baseados no uso das probabilidades de colisões em meios puramente absorvedores podem ser úteis.

Nos métodos de probabilidades de colisões considera-se que o combustível do reator é rodeado por moderador, onde um nêutron que aparece em alguma região tem a probabilidade de ter a sua próxima colisão na outra região. Por exemplo, um nêutron de fissão pode nascer mais ou menos uniformemente em uma vara combustível, e para cálculo da multiplicação rápida, é necessário determinar a probabilidade que este nêutron tem de sofrer colisões na vara combustível antes de escapar. Para cálculos de absorção de ressonância, a probabilidade de escape pode ser determinada de tal forma que os nêutrons moderados tenham a próxima colisão no combustível.

O objetivo é determinar a probabilidade que os nêutrons têm de ter a próxima colisão na região da fonte ou em alguma das outras regiões. 
A equação de transporte (1) em estado estacionário pode ser escrita como

$$
\frac{d}{d R} \Phi(\vec{r}, \hat{\Omega}) d \vec{r} d \hat{\Omega}+\Sigma_{t}(\vec{r}) \Phi(\vec{r}, \hat{\Omega}) d \vec{r} d \hat{\Omega}=S(\vec{r}, \hat{\Omega}) d \vec{r} d \hat{\Omega}
$$

Onde $d R$ é o comprimento diferencial ao longo da direção $\hat{\Omega}($ i,e., $\hat{\Omega} \cdot \nabla=d / d R)$. Integrando-se esta equação ao longo da direção $\hat{\Omega}$ de $\vec{r}_{0}$ a $\vec{r}$, obtém-se

$$
\Phi(\vec{r}, \hat{\Omega}) d \vec{r}=e^{-\alpha\left(\vec{r}_{0}, \vec{r}\right)} \Phi\left(\vec{r}_{0}, \hat{\Omega}\right) d \vec{r}_{0}+\int_{r_{0}}^{r} e^{-\alpha\left(\vec{r}^{\prime}, \vec{r}\right)} S\left(\vec{r}^{\prime}, \hat{\Omega}\right) d \vec{r}^{\prime}
$$

Na Equação (33) $\alpha\left(\vec{r}, \vec{r}^{\prime}\right)$ representa o comprimento da trajetória óptica ao longo da direção $\hat{\Omega}$ entre $\vec{r}^{\prime}$ e $\vec{r}$, ou seja,

$$
\alpha\left(\vec{r}^{\prime}, \vec{r}\right)=\left|\int_{\vec{r}^{\prime}}^{\vec{r}} \Sigma_{t}(R) d R\right|
$$

Em cálculos de probabilidades de colisão, o espaço é dividido em um número finito de regiões e assume-se que os nêutrons são produzidos uniformemente e isotropicamente em uma destas regiões. Se o volume do problema de interesse é dividido em volumes discretos, $V_{i}$, dentro dos quais seções de choque médias uniformes e um fluxo plano é assumido, a equação para o fluxo,

$$
\begin{aligned}
& \Phi(r)=\int d \vec{r}^{\prime} \frac{\left[\sum_{s}\left(\vec{r}^{\prime}\right)+v \sum_{f}\left(\vec{r}^{\prime}\right)\right] \Phi\left(\vec{r}^{\prime}\right) e^{-\alpha\left(r, r^{\prime}\right)}}{4 \pi\left|\vec{r}^{\prime}-\vec{r}\right|^{2}}+\Phi_{u n}\left(\vec{r}^{\prime}\right)= \\
& \int d \vec{r}^{\prime}\left\{\left[\sum_{s}\left(\vec{r}^{\prime}\right)+v \Sigma_{f}\left(\vec{r}^{\prime}\right)\right] \Phi\left(\vec{r}^{\prime}\right)+S_{0}\left(\vec{r}^{\prime}\right)\right\} \frac{e^{-\alpha\left(\vec{r}, \vec{r}^{\prime}\right)}}{4 \pi\left|\vec{r}^{\prime}-\vec{r}\right|^{2}}
\end{aligned}
$$

pode ser integrada em $V_{i}$, e a equação resultante pode ser dividida em $V_{i}$, para obter 


$$
\Phi_{i}=\sum_{j} T^{j \rightarrow i}\left[\left(\Sigma_{s j}+v \Sigma_{f j}\right) \Phi_{j}+S_{0 j}\right]
$$

onde $T$ é a probabilidade de transmissão e está relacionada à probabilidade de absorção da seguinte forma: $A=1-T$. A Equação (36) relaciona os fluxos nos vários volumes pelas probabilidades de transmissão $T^{j \rightarrow i}$

$$
T^{j \rightarrow i}=\frac{1}{V_{i}} \int_{V_{i}} d \vec{r}_{i} \int_{V_{j}} d \vec{r}_{j} \frac{e^{-\alpha\left(\vec{r}_{i}, \vec{r}_{j}\right)}}{4 \pi\left|\vec{r}_{i}-\vec{r}_{j}\right|^{2}}
$$

\subsubsection{Métodos de Ordenadas Discretas}

O Método original de Ordenadas Discretas foi desenvolvido por Wick [50] e Chandrasekkar [51] que aplicaram este método para problemas de transferência de radiatividade em geometria plana. Posteriormente, Carlson introduziu neste método a generalização para geometrias esféricas e cilíndricas, assim como também a partir dele o método passou a ser conhecido como Método $\mathrm{S}_{\mathrm{N}}$.

Este método é uma técnica essencialmente numérica de solução da equação de transporte linear de Boltzmann. A base dele é o cálculo da equação de transporte linear em um conjunto discreto da componente direcional $(\vec{\Omega})$ das partículas e a integração numérica da integral de colisões usando fórmulas de quadraturas. A variável espacial $(\vec{r})$ é discretizada através de esquemas de Diferenças Finitas e a variável energia (E) é manipulada através do tratamento de Multigrupo. Portanto, todas as variáveis independentes da equação de transporte linear no estado estacionário podem ser discretizadas.

Para exemplificar estas discretizações pode-se escrever a equação de transporte monoenergética em geometria plana com espalhamento isotrópico sem fissão e fontes externas: 


$$
\mu \frac{\partial \Phi}{\partial x}(x, \mu)+\Sigma_{t} \Phi(x, \mu)=\frac{1}{2} \Sigma_{s} \int_{-1}^{1} \Phi\left(x, \mu^{\prime}\right) d \mu
$$

Se a integral da equação do fluxo angular é aproximada por uma fórmula de quadratura obtém-se

$$
\int_{-1}^{1} \Phi\left(x, \mu^{\prime}\right) d \mu^{\prime}=\sum_{m^{\prime}=1}^{N} \Phi\left(x, \mu_{m^{\prime}}\right) w_{m^{\prime}}
$$

Onde $N$ é o número total de pontos de quadratura e $\mu_{m^{\prime}}$ e $w_{m^{\prime}}$ são as abscissas e os pesos das quadraturas. Quando a Equação (39) é introduzida na Equação (38), obtémse

$$
\mu_{m} \frac{\partial \Phi}{\partial x}\left(x, \mu_{m}\right)+\Sigma_{t} \Phi\left(x, \mu_{m}\right)=\frac{1}{2} \Sigma_{s} \sum_{m^{\prime}=1}^{N} \Phi\left(x, \mu_{m^{\prime}}\right) w_{m^{\prime}}
$$

para $m=1,2, \ldots, N$.

As Equações (40) representam um conjunto de $N$ equações diferenciais acopladas para os fluxos angulares discretos.

Em relação as direções angulares, $\mu_{m}$, e pesos angulares, $w_{m}$, algumas condições mínimas devem ser estabelecidas. Em geometria unidimensional estas condições são:

(a) Invariância de projeção: as direções, $\mu_{m}$ e pesos, $w_{m}$, devem ser simétricos em relação $\mu_{m}=0$, i.e., para cada $\mu$ e $w$ há também um $-\mu$ e um $-w$.

(b) Positividade da solução, i.e., $w_{m}>0, \quad \quad \sum_{m=1}^{M} w_{m}=1$.

Das condições (a) e (b), a condição a ser satisfeita é $\quad \sum_{m=1}^{M} w_{m} \mu_{m}=0$; 
(c) Avaliação precisa das integrais. Um conjunto de quadraturas Gaussianas integra exatamente um polinômio de Legendre de grau $2 \mathrm{~N}-1$, i.e.,

$$
\sum_{m=1}^{N} w_{i} \mu_{i}^{N}=\frac{2}{N+1} ; \quad \text { N par }
$$

e

$$
\sum_{m=1}^{N} w_{i} \mu_{i}^{N}=0 ; \quad \text { N ímpar }
$$

(d) Nos limites da teoria da difusão, é necessário impor a condição

$$
\sum_{m=1}^{N} w_{m} \mu_{m}^{2}=\frac{1}{3}
$$

Apesar destas condições, ainda há uma liberdade considerável nas escolhas das direções, $\mu_{m}$, e pesos $w_{m}$.

Um problema que pode ocorrer devido a discretização angular é o efeito raio, que é uma conseqüência da forma das equações discretas em duas ou mais dimensões espaciais. Desta forma, o resultado da discretização angular $\hat{\Omega}$, permite o fluxo de partículas somente em direções selecionadas $\hat{\Omega}_{m}$. Assim, de uma fonte isolada em um dado sistema, os nêutrons só podem alcançar um número limitado de células espaciais. Portanto, não se pode esperar que o fluxo de partículas seja suave, a menos que a fonte de partículas seja razoavelmente bem distribuída. Atualmente se tem muitas maneiras de se mitigar o efeito raio, mas não saná-lo por completo.

A dependência da energia no método é tratada através da Formulação de Multigrupo, onde o alcance de energia do nêutron é dividido em um número finito, $G$, de intervalos separados pelas energias $E_{g}$, onde $g=1,2, \ldots, G$, ou seja, $E_{\min } \leq E \leq E_{\max }$. A integral em E' é expressa como a soma de integrais em todos os grupos de energia, i.e., 


$$
\int d E^{\prime}=\sum_{g^{\prime}} \int_{E_{g^{\prime}}}^{E_{g^{\prime}-1}} d E^{\prime}
$$

A dependência espacial é solucionada através do Método de Diferenças Finitas. Pode-se exemplificar a aplicação deste método na equação de transporte em geometria unidimensional plana, assumindo-se que o operador $\vec{\nabla}$ pode ser substituído por $d / d x$. A direção $\hat{\Omega}$ pode ser substituída por $\mu=\cos \theta$ e a variável espacial $\vec{r}$ pode ser substituída por $x$. A equação de transporte pode ser escrita na forma,

$$
\mu \frac{d \Phi(x)}{d x}+\Sigma_{t} \Phi(x)=Q
$$

onde $Q$ inclui a fonte de fissão, fonte de espalhamento e fontes fixas.

Introduzindo-se a aproximação de diferenças finitas na Equação (42) obtém-se a equação

$$
\mu\left(\frac{\Phi_{i+1 / 2}-\Phi_{i-1 / 2}}{\Delta x}\right)+\Sigma_{t} \Phi(x)=Q, \quad 1, \ldots, I M
$$

Na Equação (43) $\Phi$ representa o fluxo angular de grupo na direção atual para o nó i; $\Phi_{1+1 / 2}$ representa o fluxo angular de grupo na direção atual para a borda do nó i; $\Phi_{1-1 / 2}$ representa o fluxo angular de grupo na direção atual para a borda do nó i; $\Delta \mathrm{x}$ representa a largura espacial do nó i; $\mu$ representa o ângulo longitudinal, para a direção atual e, $\Sigma_{\mathrm{t}}$ representa a seção de choque de colisão média no nó i para o grupo atual.

Há dois fluxos desconhecidos na Equação (43), $\Phi$ e $\Phi_{1+1 / 2}$, uma vez que $\Phi_{1-1 / 2}$ é conhecido das condições de fronteira do nó espacial anterior ou externo. Há, portanto, uma relação adicional entre $\Phi$ e $\Phi_{1+1 / 2}$ que têm que ser definida para que seja resolvida a Equação (43), e ao mesmo tempo gerar o fluxo de entrada $\Phi_{1-1 / 2}$ para o próximo nó espacial. 
Três diferentes relações entre $\Phi$ e $\Phi_{1+1 / 2}$ podem ser utilizadas nesta configuração geométrica. Na primeira conhecida como modelo de diferenças lineares, $\Phi$ é posto como uma média aritmética entre $\Phi_{1+1 / 2}$ e $\Phi_{1-1 / 2}$ :

$$
\Phi=\frac{1}{2}\left(\Phi_{i+1 / 2}+\Phi_{i-1 / 2}\right)
$$

Na segunda relação, que é conhecida como modelo de diferenças "step”, temse que

$$
\Phi=\Phi_{i+1 / 2}
$$

E na terceira relação, tem-se o modelo conhecido como modelo de diferenças pesadas, onde $\Phi$ é posto como uma média pesada de $\Phi_{1+1 / 2}$ e $\Phi_{1-1 / 2}$ :

$$
\Phi=\alpha_{s} \Phi_{i+1 / 2}+\left(1-\alpha_{s}\right) \Phi_{i-1 / 2}
$$

onde $\alpha_{\mathrm{s}}$ é o fator peso, que é limitado aos valores entre 0,5 e 1,0.

Este é o método de ordenadas discretas, que como descrito anteriormente, consiste na discretização das componentes. 


\section{A FÍSICA DE SISTEMAS SUBCRÍTICOS ACIONADOS POR FONTES}

\subsection{Introdução}

Como descrito anteriormente se o fator de multiplicação de nêutrons for menor que a unidade, a reação em cadeia não pode ser sustentada. Entretanto, quando uma fonte de nêutrons é introduzida num meio multiplicativo o número inicial de nêutrons pode ser multiplicado por um fator que pode ser muito grande. Em sistemas subcríticos pode ser gerado um grande número de nêutrons desde que uma fonte externa de nêutrons seja inserida.

Se $\mathrm{N}_{0}$ é o número de nêutrons primários, a interação de uma partícula com um alvo rodeado por um meio multiplicativo infinito, caracterizado por um fator de multiplicação $k$, o número total de nêutrons gerados, após a multiplicação é

$$
N=\frac{N_{0}}{(1-k)}
$$

e o número de nêutrons secundários produzidos após uma multiplicação (desconsiderando as reações do tipo $(\mathrm{n}, 2 \mathrm{n}))$, é

$$
\frac{k N_{0}}{(1-k)} \text {. }
$$

A importância de reatores do tipo subcríticos acionados por fonte (ADS) consiste no fato de que estes podem ao mesmo tempo produzir energia e com o excesso de nêutrons transmutar actinídeos menores e produtos de fissão de longa vida. Por isso é importante avaliar qual o ganho de energia produzida no meio multiplicativo. 
Cada nêutron secundário é produzido por uma fissão, que produz $v$ nêutrons. Portanto, o número de nêutrons secundários no sistema é

$$
\frac{k N_{0}}{v(1-k)}
$$

e uma vez que cada fissão libera cerca de $0,18 \mathrm{GeV}$ de energia, a energia térmica produzida no meio é

$$
\frac{0,18 k N_{0}}{v(1-k)} \text {. }
$$

Esta energia deve ser comparada com a energia da partícula incidente (e.g. prótons) $E_{p}$ para definir o ganho de energia do sistema:

$$
G=\frac{0,18 k N_{0}}{v(1-k) E_{p}}=\frac{G_{0} k}{1-k} .
$$

Cálculos experimentais no experimento FEAT CERN encontraram um valor constante de $G_{0} k=3$ para um próton incidente de energia maior que $1 \mathrm{GeV}$ e alvo de Urânio. Este experimento também mostrou que o valor mínimo do fator de multiplicação para a obtenção de um ganho positivo de energia (ignição) é $k_{m}=0,68$. A Equação (51) mostra, por exemplo, que quando $k=0,98$ um ganho líquido de 150 pode ser obtido. Também foi demonstrado neste experimento que um grande ganho de energia não significa alta capacidade de transmutação. Concluiu-se também que se deve tentar conciliar a capacidade de geração de energia com o poder de transmutação do sistema.

Um reator padrão libera na fissão aproximadamente $200 \mathrm{MeV}$ de energia e 2,5 nêutrons, ou seja, são necessários cerca de $80 \mathrm{MeV}$ para produzir um nêutron. No processo de "spallation" precisa-se apenas de $30 \mathrm{MeV}$ para produzir um nêutron. Se os $200 \mathrm{MeV}$ de energia liberados na fissão estivessem disponíveis para a aceleração de uma partícula, então no processo de "spallation" ele conseguiria a produção de mais de 9 nêutrons por fissão (2,5 liberados na fissão mais 6,6 produzidos pelos $200 \mathrm{MeV}$ de 
energia). Assumindo-se que a eficiência é $40 \%$ e a eficiência de aceleração é $40 \%$, ou seja, uma eficiência total de $16 \%$, para acelerar uma partícula de $1 \mathrm{GeV}$ são necessários cerca de $6 \mathrm{GeV}$. Com esta eficiência, 40\%, é possível obter aproximadamente 3,5 nêutrons por fisssão.

O número de nêutrons secundários produzidos em um reator é dado pela Equação (49), enquanto que o número de fissões é, como anteriormente dito,

$$
N_{F}=\frac{N_{0} k}{v(1-k)}
$$

onde em média uma fissão é produzida por $\left(\sigma_{\mathrm{F}}+\sigma_{\mathrm{C}}\right) / \sigma_{\mathrm{F}}$ nêutrons. O número total de nêutrons necessários para produzir $N_{F}$ fissões é

$$
N_{N F}=N_{F} \frac{\sigma_{F}+\sigma_{C}}{\sigma_{F}}=N_{F}(1+\alpha)=\frac{N_{0} k}{\eta(1-k)},
$$

onde $\eta$ é o número de nêutrons produzidos após a captura de um nêutron inicial por um núcleo físsil. O número total de nêutrons disponível para transmutação é, portanto

$$
N_{D T}=N-N_{N F}=\frac{N_{0}}{1-k}\left(1-\frac{k}{\eta}\right)
$$

Em reatores rápidos o valor de $\eta$ é aproximadamente 3. Verifica-se na Equação (53) que deve haver um $k$ ideal para que haja ao mesmo tempo um número razoável de nêutrons para a transmutação e ao mesmo tempo para a produção de energia. Existe um compromisso ante gerar energia pela Equação (51) e transmutação pela Equação (54).

Considera-se agora um reator crítico acoplado à um acelerador. Sendo $N_{D R} \mathrm{O}$ número de nêutrons disponíveis quando o reator produz $N_{F}$ fissões, além dos $N_{0}$ nêutrons de "spallation". O número de nêutrons necessários por fissão é 


$$
\frac{\sigma_{F}+\sigma_{C}}{\sigma_{F}}=1+\alpha
$$

enquanto o número de nêutrons produzidos por fissão é v. Portanto, o número de nêutrons disponíveis por fissão é $v-1-\alpha$. O número total de nêutrons disponíveis no reator é então

$$
N_{D F}=N_{F}(v-1-\alpha)=\frac{N_{0} k}{\eta(1-k)}(v-1-\alpha)
$$

e o número de nêutrons disponíveis para o sistema reator mais acelerador é

$$
N_{D R}=N_{0}\left(1+\frac{k}{v(1-k)}(v-1-\alpha)\right)=\frac{N_{0}}{1-k}\left(1-\frac{k}{\eta}\right)
$$

Portanto,

$$
N_{D T}=N_{D R}
$$

Logo, a escolha de um valor especifico de $k$ é irrelevante quando a capacidade de transmutação está envolvida, pois é preciso fazer a relação energia x transmutação.

Da discussão anterior verifica-se que quando se usa $10 \%$ da energia disponível pode-se obter aproximadamente 0,1 nêutrons adicionais por fissão. Apesar de pequeno, este número deve ser comparado com o número de nêutrons que são efetivamente disponíveis no reator. Sabe-se que o número máximo de nêutrons disponíveis equivale à $v-1-\alpha$. Na prática o número real é menor que este valor devido as capturas nos materiais estruturais e as transmutações dos núcleos férteis. Se o número de nêutrons de captura é $v_{C}$, o número de nêutrons disponíveis é então $v-1-\alpha-v_{C}$. Para cada núcleo de fissão $\alpha$ núcleos físseis sofrem captura de nêutron, em geral, para um núcleo fértil. Quando se trata de regeneração do combustível nuclear, precisa-se de no mínimo $v_{\mathrm{C}}=0,2$ $+1+\alpha$. O número de nêutrons disponíveis equivale à $v-2(1+\alpha)-0,2$. Como exemplo considera-se quatro casos: 
1. Um sistema térmico $\mathrm{U}^{238}-\mathrm{Pu}^{239}$. Neste caso $v=2,871, \alpha=0,36$. O número de nêutrons disponíveis é $2,871-(2 \times 1,36)-0,2=-0,05$. A regeneração não é possível e não há nêutrons disponíveis para transmutação;

2. Um sistema térmico $T h^{232}-U^{233}$. Neste caso $v=2,492, \alpha=0,09$. O número de nêutrons disponíveis é $2,492-(2 \times 1,09)-0,2=0,11$. A regeneração é possível e 0,1 nêutrons estão disponíveis para transmutação. O número adicional de nêutrons que um acelerador pode produzir neste sistema é significante;

3. Um sistema rápido de $\mathrm{U}^{238}-\mathrm{Pu}^{239}$. Neste caso $v=2,98$ e $\alpha=0,14$. O número de nêutrons disponíveis é $2,98-(2 \times 1,14)-0,2=0,5$. A regeneração neste sistema é fácil; e

4. Um sistema rápido de $\mathrm{Th}^{232}-\mathrm{U}^{233}$. Neste caso $v=2,492$ e $\alpha=0,093$. O número de nêutrons disponíveis é $2,492-(2$ x 1,093 $)-0,2=0,10$. A regeneração é possível. $\mathrm{O}$ número adicional de nêutrons que um acelerador pode produzir para este sistema é significante.

Como se pode perceber os cálculos da Física de sistemas subcríticos acionados por fontes diferenciam-se dos cálculos de criticalidade devido à inserção do termo fonte. Novos aspectos nestes sistemas devem ser avaliados, pois o interesse nestes sistemas além da produção de energia também é a transmutação. Também devem ser analisados alguns aspectos com relação aos parâmetros estáticos e dinâmicos de um sistema acionado por fonte. A seguir será feita uma breve descrição dos parâmetros estáticos e dinâmicos destes sistemas.

\subsection{Parâmetros Estáticos de Reator}

A equação de transporte de nêutrons em termos dos operadores $\mathrm{L}_{o p}$ (fuga, absorção e transferência por espalhamento) e $\mathrm{M}_{o p}$ (fissão) pode ser escrita na forma

$$
L_{o p} \Phi+M_{o p} \Phi=0
$$

Esta equação relaciona a produção e a destruição dos nêutrons. Quando se tem um meio homogêneo e infinito, por exemplo, considera-se que a produção de nêutrons 
seja $\mathrm{k}_{\infty}$. Porém, para reatores finitos, alguns nêutrons escapam do meio, e, portanto o coeficiente de multiplicação efetivo $k_{e f f}$ é menor que $\mathrm{k}_{\infty}$.

A criticalidade é alcançada quando $k_{\text {eff }}=1$. Quando se deseja fazer uma pesquisa de criticalidade deve-se resolver o problema de autovalores; para tais casos a equação a ser resolvida é

$$
L_{o p} \Phi=-\frac{1}{k_{\text {eff }}} M_{o p} \Phi .
$$

Neste caso o fator de multiplicação de nêutrons para este sistema pode ser definido como

$$
k_{e f f}=\frac{\left\langle\Phi^{*}, M_{o p} \Phi\right\rangle}{\left\langle\Phi, L_{o p}{ }^{*} \Phi\right\rangle},
$$

onde $\langle\cdot\rangle$ representa a integração no espaço e ângulo em todo o sistema. Em um sistema finito subcrítico a descendência de um nêutron gerado no centro não é a mesma que a de um nêutron gerado próximo à fronteira. Vários pesquisadores perceberam que estas considerações levavam para a o conceito de um fator de multiplicação de fonte: $k_{S}(\mathrm{r}, \mathrm{E})$. Este fator depende da posição inicial e energia dos nêutrons, e a "descendência" neutrônica deste é $\mathrm{k}_{\mathrm{S}} /\left(1-\mathrm{k}_{\mathrm{S}}\right)$. O número de descendentes é chamado a importância do nêutron, que é relacionado com a função importância ou função adjunta,

$$
\Phi^{*}=\frac{k_{S}}{1-k_{S}}
$$

O parâmetro $\mathrm{k}_{\mathrm{S}}$ pode ser visto quando definido pela expansão

$$
\frac{k_{S}}{1-k_{S}}=k_{1}+k_{1} k_{2}+\cdots+k_{1} k_{2} \cdots k_{i}+\cdots
$$

O número de nêutrons de primeira geração $k_{1}$ também depende da posição e energia do nêutron, e de certa forma está relacionado com a função importância (fluxo adjunto): 


$$
\Phi^{*}=k_{1}
$$

Com base nestas novas formulações, Gandini e Salvatores [52] decidiram definir o fator de multiplicação de nêutrons em sistemas com fontes, para cálculos não muitos distantes da condição de criticalidade, como sendo

$$
k_{s} \equiv \frac{\left\langle u, M_{o p} \Phi_{s}\right\rangle}{\left\langle u, M_{o p} \Phi\right\rangle+\left\langle u, S_{e x t}\right\rangle} .
$$

Onde o fluxo $\Phi$ é assumido como uma aproximação do fluxo que é solução da equação com o termo fonte:

$$
L_{o p} \Phi+M_{o p} \Phi=S_{e x t}
$$

A função $u$ na Equação (65) tem sido motivo de investigação por parte da comunidade internacional em ADS, sendo que uma sugestão é a solução do problema adjunto com $S=v \Sigma_{f}$, ou seja:

$$
\left(L_{o p}^{*}+M_{o p}^{*}\right) u+v \Sigma_{f}=0
$$

Realizaram-se para esta dissertação dois cálculos do fator de multiplicação de fonte, $k_{S}$, Equação (65), onde utilizou-se dois valores diferentes para a função $u$. Primeiro com a solução do problema adjunto com $S=v \Sigma_{f}$, e depois com a função $u=1$. O resultado encontrado foi o mesmo em ambos os casos. Pode-se então concluir, preliminarmente, que é indiferente usar a função $u$ como solução do problema adjunto, ou com valor unitário. Esta conclusão é importante, pois em cálculos com simulação Monte Carlo usa-se a função $u$ com o valor unitário. 
Dulla [53] definiu o fator de multiplicação de fonte $k_{S}$ com a função $u$ da Equação (65) igual à unidade. Portanto, a definição de $k_{S}$ de Gandini e Salvatores torna-se igual a definição dada por Dulla quando a função $u=1$.

Uma definição mais satisfatória para a Equação (65) também foi proposta por Gandini e Salvatores [54]. Nesta definição é introduzida uma função importância $n_{0}^{*}$ associada com o nível de potência relativa no sistema subcrítico. Esta função importância é obtida da equação:

$$
L_{o p}^{*} n_{0}^{*}+M_{o p} n_{0}^{*}+\frac{\gamma}{w_{0}} \Sigma_{f}=0
$$

onde $\gamma$ é o número de unidades de energia por fissão, $W_{0}$ é a potência do reator e $\Sigma_{f}$ é o vetor das seções de choque macroscópicas de fissão correspondentes. O termo $\gamma / w_{0}$ assume a unidade de $v$, que desta forma se reduz ao formalismo de Dulla.

Outro parâmetro definido por Gandini e Salvatores é o parâmetro $\varphi^{*}$, que é a avaliação da importância relativa dos nêutrons de fonte com relação a importância média dos nêutrons de fissão gerados no núcleo subcrítico, i.e.,

$$
\varphi^{*}=\left(\frac{1}{k_{e f f}}-1\right) /\left(\frac{1}{k_{s}}-1\right)
$$

A relevância do cálculo deste parâmetro em ADS é grande, pois a relação entre a intensidade do feixe de prótons, da potência no núcleo subcrítico e a subcriticalidade é dada por [52]:

$$
i_{p}=\frac{\bar{v}\left(\frac{1}{k}-1\right)}{\varphi^{*} Z} \cdot \frac{w}{\varepsilon_{f}},
$$


onde $i_{p}$ representa a intensidade do feixe de prótons, $w$ a potência do núcleo subcrítico em megawatts, $\mathcal{E}_{f}$ a energia por fissão $(\mathrm{em} \mathrm{MeV})$ e $Z$ o número de nêutrons por próton incidente. Da Equação (70) percebe-se que quando o valor de $\varphi^{*}$ é maior que 1, pode reduzir proporcionalmente o feixe de próton, para um dado nível de subcriticalidade.

A fim de dimensionar alguns dos parâmetros descritos anteriormente foram realizados alguns cálculos. O objetivo principal destes cálculos é utilizar um código determinístico em uma dimensão, ANISN, para reproduzir aproximadamente um sistema subcrítico rápido (e.g.Yalina Booster [55]) e calcular numericamente alguns dos parâmetros estáticos. Os cálculos foram divididos em duas partes: (a) cálculos unidimensionais em uma região (U36\%) com um e três grupos de energia, (b) cálculos em uma dimensão e três regiões ( $\mathrm{Pb}, \mathrm{U} 90 \%, \mathrm{U} 36 \%)$ com três grupos de energia.

A motivação para o cálculo destes parâmetros utilizando as definições de Gandini e Salvatores e Dulla é que as definições e aplicações de muitos destes parâmetros ainda estão em discussão na comunidade internacional.

Toma-se como exemplo um sistema composto por uma zona rápida com uma geometria do núcleo subcrítico apresentada na FIG. 7. Esta geometria é composta por três regiões: Urânio altamente enriquecido (90\%), Urânio com 36\% de enriquecimento e alvo $(\mathrm{Pb})$.

$$
\text { Pb } \mid \text { U90 } \% \text { U36\% }
$$

FIGURA 7 - Geometria aproximada da configuração subcrítica (meio plano).

As constantes de grupo utilizadas nos cálculos são apresentadas no Anexo A desta dissertação. A metodologia empregada na geração destas constantes multigrupo é a que já está descrita no anexo C. Apesar do sistema em questão ser rápido, as seções de 
choque utilizadas foram as mesmas empregadas para cálculo de reatores térmicos. Estas constantes multigrupo foram publicadas em 2006 para cálculos de "benchmarks" em cinética de reatores com dependência temporal no "Joint International Topical Meeting on Mathematics \& Computation and Supercomputing in Nuclear Applications (M\&C + SNA 2007)", Monterey, California, Abril 15-19, 2007 [56]. Na geração das constantes multigrupo utilizou-se a aproximação $\mathrm{P}_{0}$ e $\mathrm{S}_{2}$.

A espessura crítica encontrada para o problema com uma região (U36\%) foi $20,032 \mathrm{~cm}$. Para encontrar a dimensão crítica variou-se a espessura até encontrar o $k$ desejado. Para o meio heterogêneo com três regiões as espessuras críticas foram: $8,0 \mathrm{~cm}$ (Chumbo), 7,98372 cm (U90\%) e 20,55948 cm (U36\%). As espessuras da região com Chumbo e da região com Urânio $36 \%$ foram fixadas e variou-se a espessura da região com Urânio 90\% até encontrar o fator de multiplicação desejado.

Na TAB. 4 são apresentados os valores de três diferentes parâmetros: $k, k_{s} e$ $\Phi^{*}$. Nestes cálculos considera-se primeiro a região que possui Urânio com $36 \%$ de enriquecimento e um grupo de energia; depois, a mesma região, com três grupos de energia e, por último é considerada as três regiões do sistema subcrítico, com três grupos de energia. Os cálculos foram realizados para seis níveis de subcriticalidade: 0,90, 0,95, $0,98,0,99,0,999$ e 1,0, com a aproximação $\mathrm{P}_{0}$ e $\mathrm{S}_{2}$.

TABELA 4 - Parâmetros estáticos de reator, para três diferentes situações, com $\mathrm{S}_{2}$

\begin{tabular}{|c|c|c|c|c|c|c|}
\hline \multicolumn{2}{|c|}{1 Região e 1 grupo de energia } & \multicolumn{2}{|c|}{$\begin{array}{c}\text { Região e 3 grupos de } \\
\text { energia }\end{array}$} & $\begin{array}{c}\text { Regiões e 3 grupos de } \\
\text { energia }\end{array}$ \\
\hline $\mathrm{k}$ & $\mathrm{k}_{\mathrm{s}}$ & $\Phi^{*}$ & $\mathrm{k}_{\mathrm{s}}$ & $\Phi^{*}$ & $\mathrm{k}_{\mathrm{s}}$ & $\Phi^{*}$ \\
\hline 0,9 & 0,9175989 & 0,017599 & 0,9169761 & 0,016976 & 0,90811633 & 0,008116 \\
\hline 0,95 & 0,9590172 & 0,009017 & 0,9590824 & 0,009082 & 0,95425580 & 0,004256 \\
\hline 0,98 & 0,9837518 & 0,003752 & 0,9838057 & 0,0038057 & 0,98176142 & 0,001761 \\
\hline 0,99 & 0,9919087 & 0,001908 & 0,9919144 & 0,0019144 & 0,99090246 & 0,000902 \\
\hline 0,999 & 0,9992125 & 0,0002125 & 0,9991951 & 0,0001951 & 0,99910691 & 0,000106 \\
\hline 1 & 1 & 0 & 1 & 0 & 1 & 0 \\
\hline
\end{tabular}


Os valores encontrados na TAB. 4 era o que realmente se esperava. Que à medida que o $k$ fosse aumentando, a importância dos nêutrons de fonte fossem diminuindo. Em relação ao $k_{\mathrm{S}}$ ele sempre será maior que o $k$ devido á contribuição dos nêutrons de fonte.

A fim de verificar a variação dos parâmetros calculados com o modelo adotado foram calculados os mesmos parâmetros da TAB. 4, mas com um modelo diferente: $\mathrm{S}_{12} \mathrm{e}$ $\mathrm{P}_{0}$. Sabe-se que quando se tem $\mathrm{P}_{0}$ e $\mathrm{S}_{2}$ tem-se aproximadamente a teoria $\mathrm{P}_{1}$. Para calcular como um problema de transporte variou-se o valor de $\mathrm{N}\left(\mathrm{S}_{\mathrm{N}}\right)$. $\mathrm{O}$ valor $\mathrm{P}_{0}$ não foi modificado, pois para modificá-lo seria necessário gerar um novo conjunto de seções de choque, que devido ao prazo seria muito difícil realizar. Na TAB. 5 são mostrados os valores dos parâmetros calculados. Verifica-se que o valor do fator de multiplicação varia com o $\mathrm{S}_{\mathrm{N}}$. A variação maior aconteceu para $k=0,90$ e à medida que $k$ aumenta a variação vai diminuindo. Percebe-se que para $k=0,98\left(\mathrm{~S}_{2}\right)$ o valor de $k$ para $\mathrm{S}_{12}$ já ultrapassa a criticalidade. Para $k=0,98$ já se percebe que o reator ficou supercrítico. Para $\mathrm{S}_{12}$ foram realizados apenas os cálculos para os valores de $k$ menores que a criticalidade, pois apenas cálculos de sistemas subcríticos nos interessam.

TABELA 5 - Parâmetros estáticos de reator, para três diferentes situações, com $\mathrm{S}_{12}$

\begin{tabular}{|c|c|c|c|c|c|c|c|}
\hline & \multicolumn{3}{|c|}{1 Região e 1 grupo de energia } & \multicolumn{2}{c|}{$\begin{array}{r}\text { Região e 3 grupos } \\
\text { de energia }\end{array}$} & \multicolumn{2}{c|}{$\begin{array}{c}\text { Regiões e 3 grupos } \\
\text { de energia }\end{array}$} \\
\hline $\mathrm{k}-\mathrm{S}_{2}$ & $\mathrm{k}-\mathrm{S}_{12}$ & $\mathrm{~K}_{\mathrm{s}}$ & $\Phi^{*}$ & $\mathrm{~K}_{\mathrm{s}}$ & $\Phi^{*}$ & $\mathrm{~K}_{\mathrm{s}}$ & $\Phi^{*}$ \\
\hline 0,90 & 0,952024 & 0,961558 & 0,009534 & 0,961120 & 0,009096 & 0,959925 & 0,007901 \\
\hline 0,95 & 0,999727 & 0,9999235 & 0,0001965 & 0,9999100 & 0,00183 & 0,9999012 & 0,000172 \\
\hline 0,98 & 1,02832 & - & - & - & - & - & - \\
\hline 0,99 & 1,03785 & - & - & - & - & - & - \\
\hline 0,999 & 1,04641 & - & - & - & - & - & - \\
\hline 1 & 1,04737 & - & - & - & - & - & - \\
\hline
\end{tabular}


Através das TAB. 4 e 5 verifica-se que os valores dos parâmetros estáticos também dependem do modelo adotado. Quando se varia o modelo os parâmetros também variam.

Para ilustrar o comportamento do fluxo neutrônico serão apresentados alguns gráficos. Para calcular o fluxo com o código ANISN, na geometria apresentada na FIG. 7, as 3 regiões foram discretizadas em um número de intervalos e uma fonte externa de nêutrons foi localizada em um destes intervalos no centro da região que contém Chumbo. Para calcular o fator de multiplicação das três regiões procedeu-se da mesma forma que para encontrar a espessura crítica: fixou-se a espessura da região que contém U36\%, e da região que contém $\mathrm{Pb}$, e variou-se a espessura da região com U90\% até encontrar o fator de multiplicação desejado. Nestes gráficos usa-se a aproximação $\mathrm{S}_{2}$. Os gráficos a seguir estão separados por região e número de grupos de energia para seis diferentes níveis de subcriticalidade. Os fluxos estão normalizados pelo fluxo total e a figura mostra apenas o fluxo para meio plano, portanto, a dimensão não é apenas $9 \mathrm{~cm}$ mas, $18 \mathrm{~cm}$.

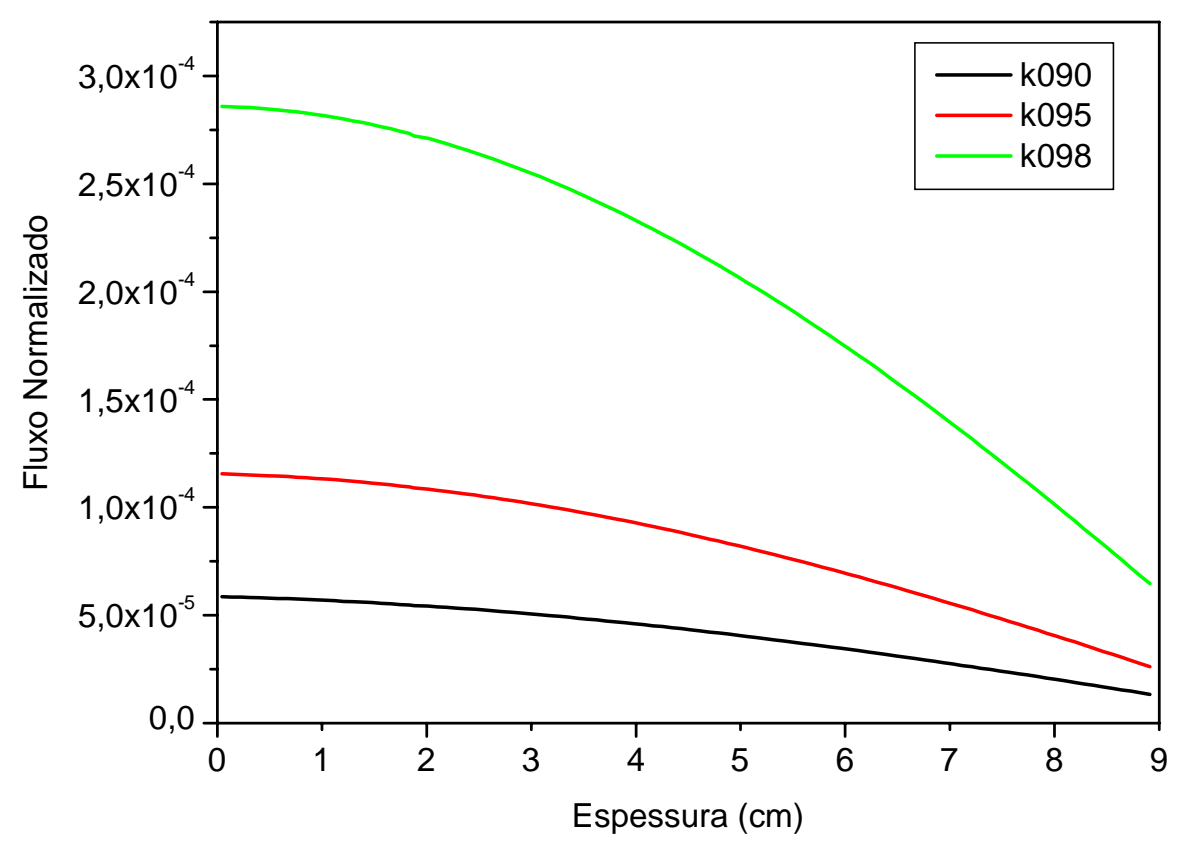

FIGURA 8 - Uma região e um grupo de energia ( $k$ de 0,90 até 0,98$)$. 


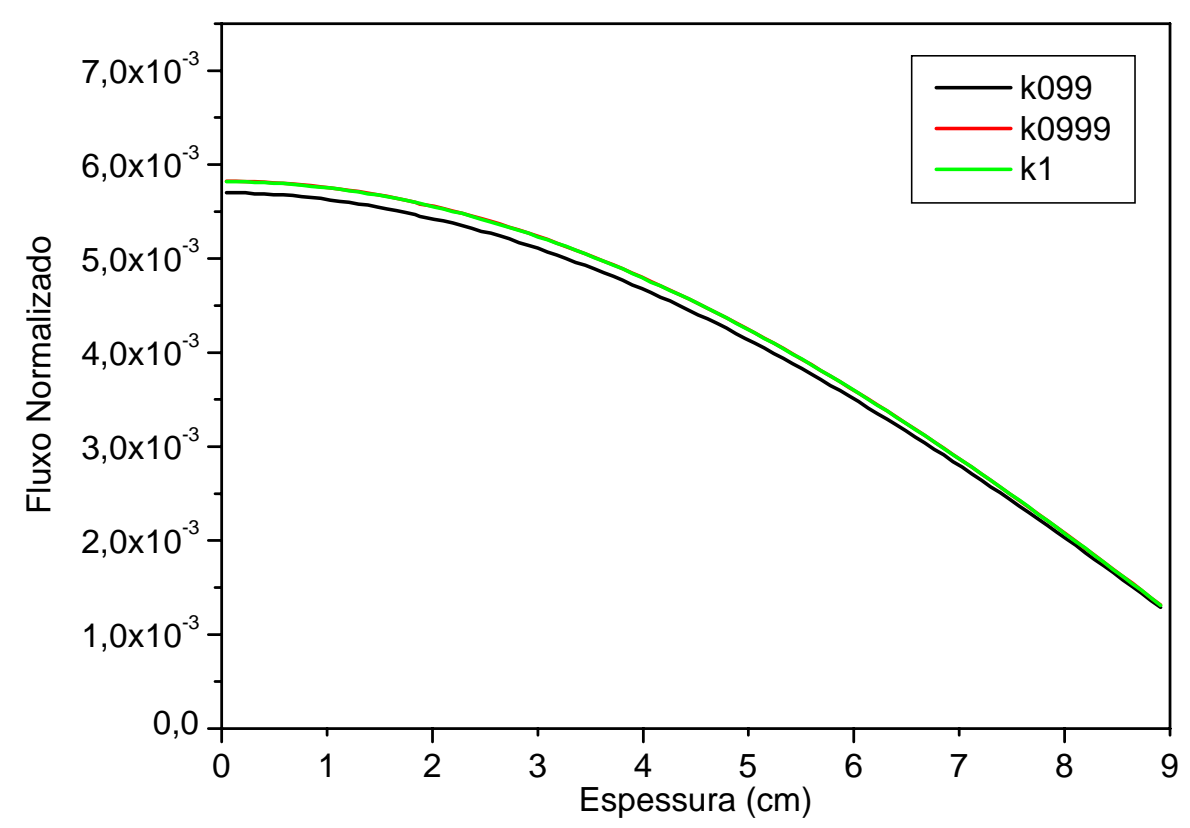

FIGURA 9 - Uma região e um grupo de energia $(k$ de 0,99 até 1,0$)$.

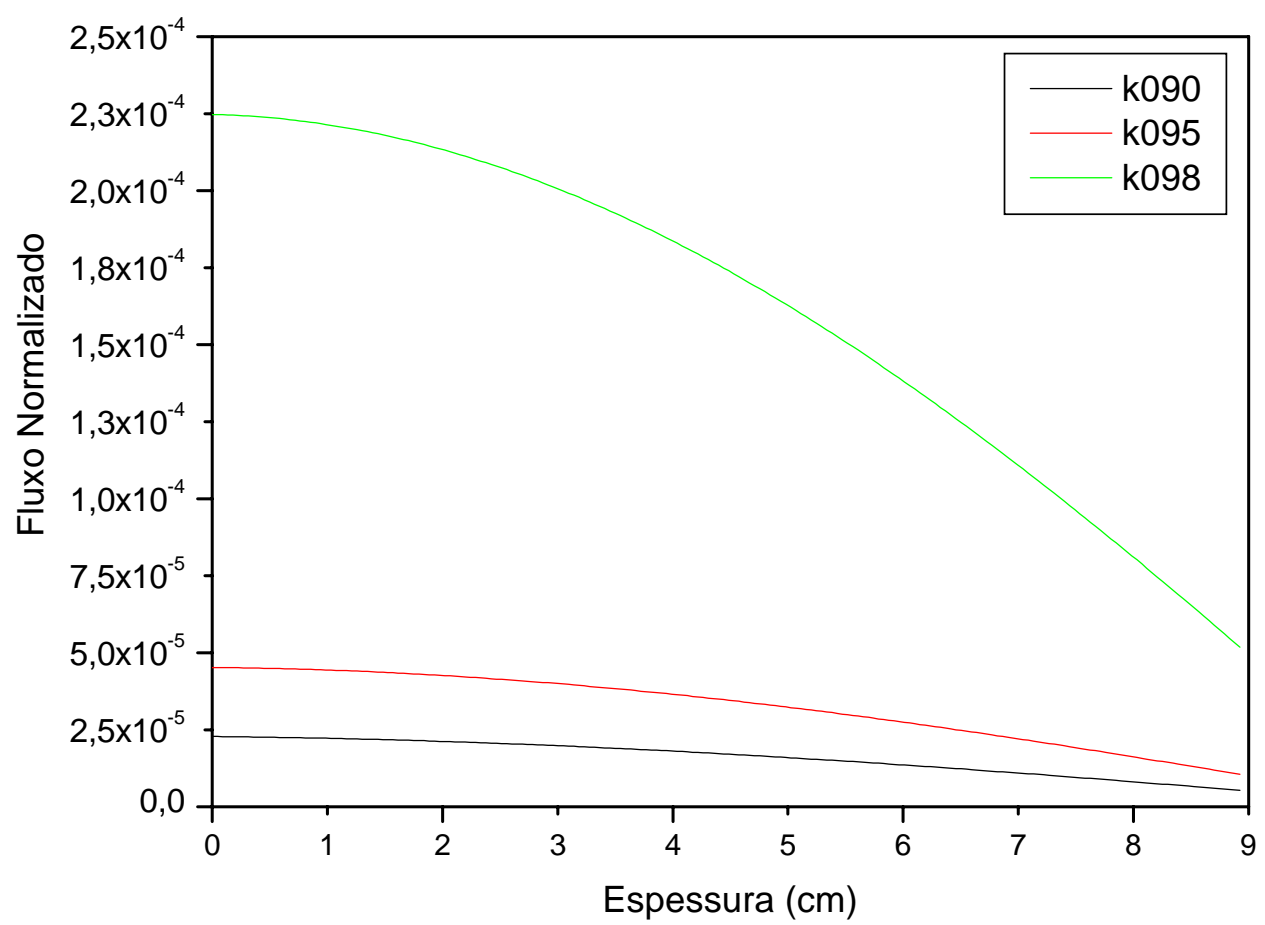

FIGURA 10 - Uma região e três grupos de energia ( $k$ de 0,90 até 0,98$)$. 


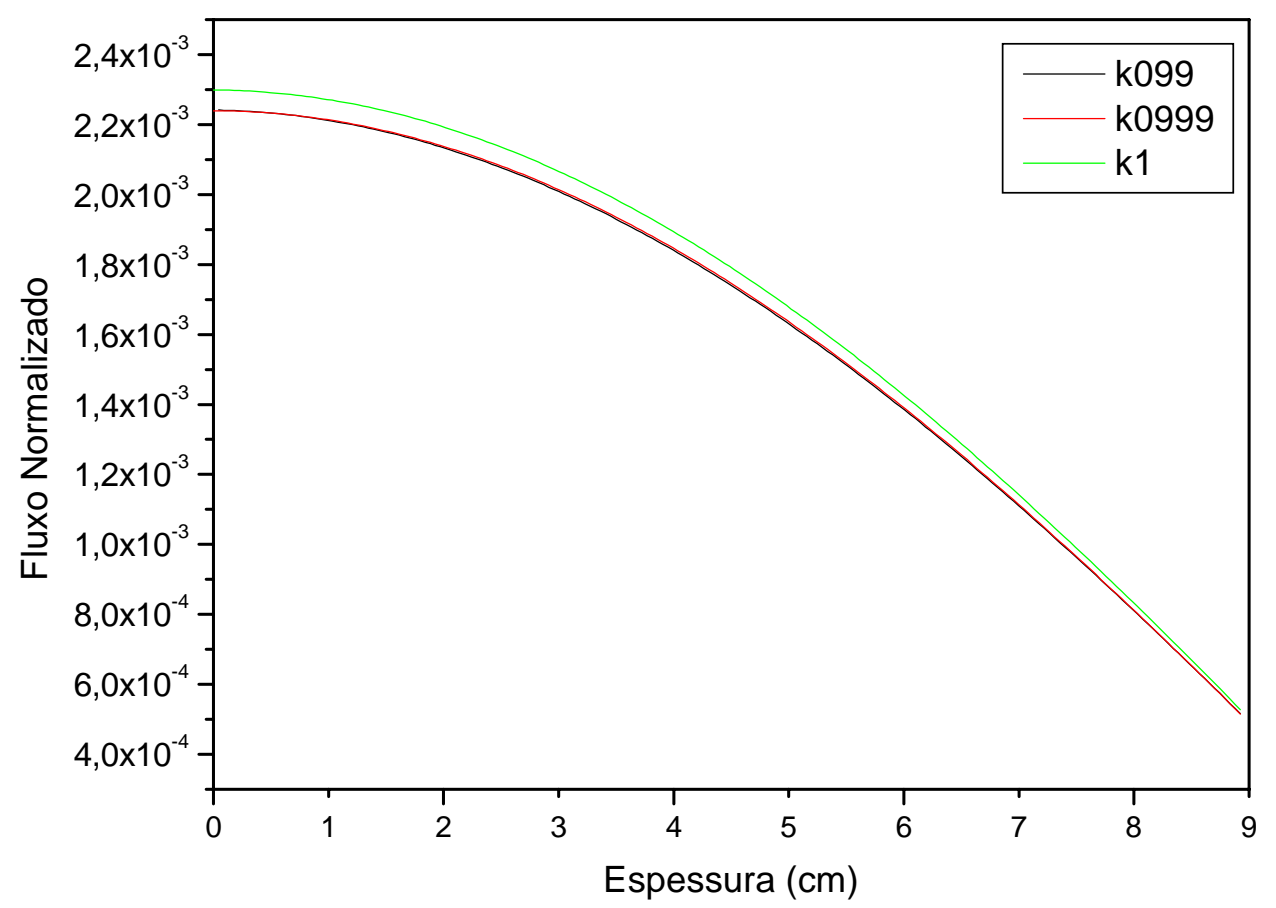

FIGURA 11 - Uma região e três grupos de energia ( $k$ de 0,99 até 1,0$)$.

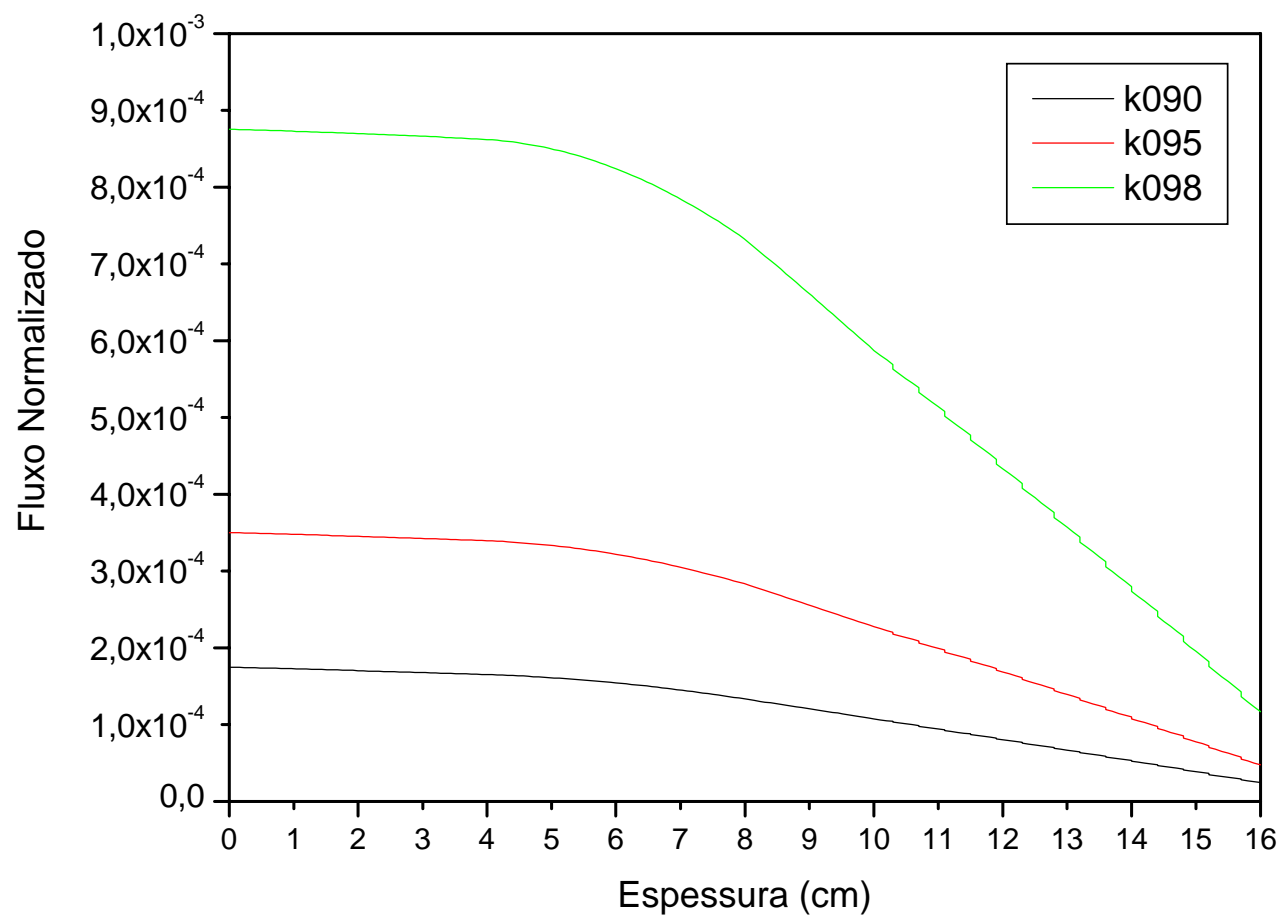

FIGURA 12 - Três regiões e três grupos de energia ( $k$ de 0,90 até 0,98$)$. 


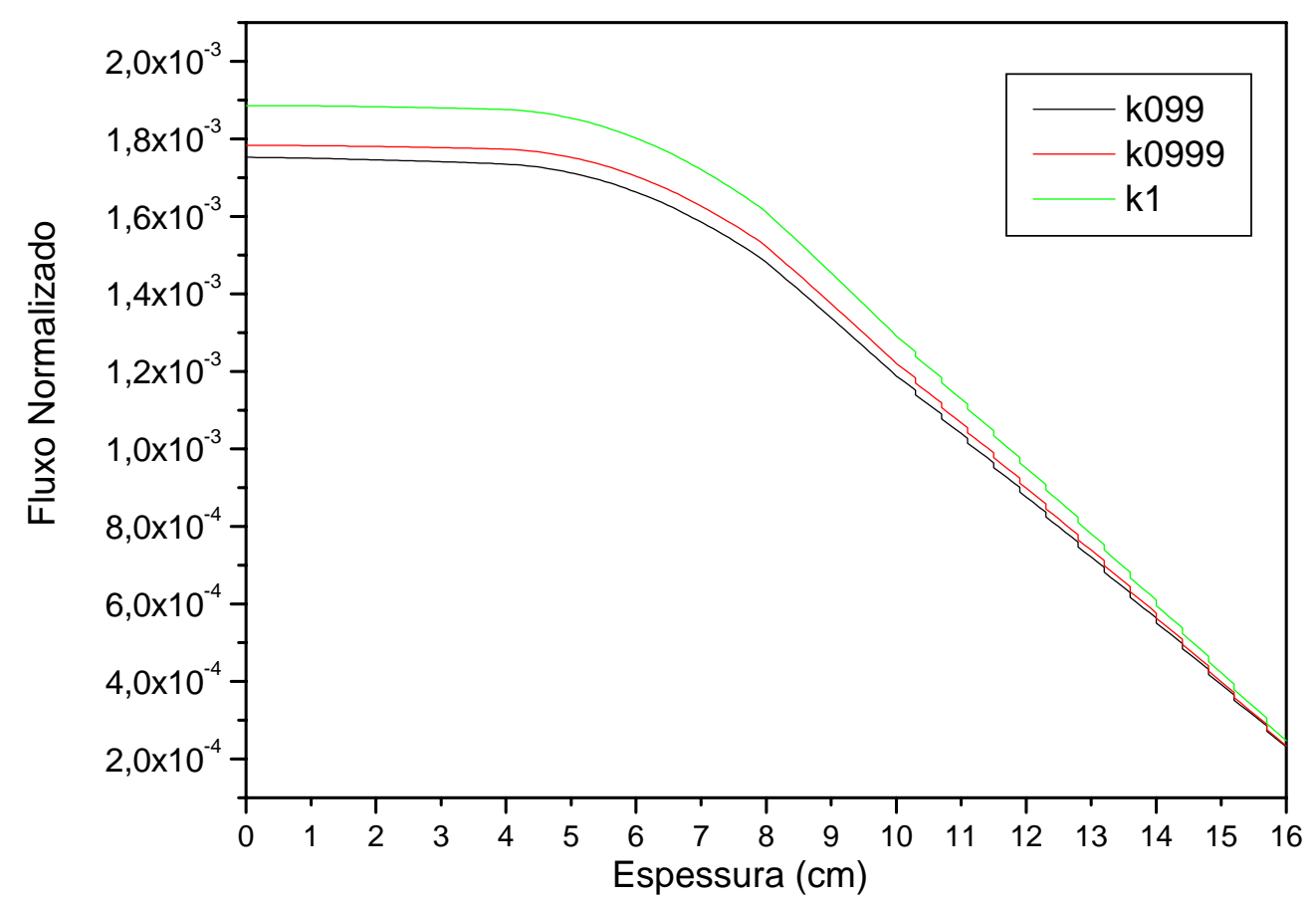

FIGURA 13 - Três regiões e três grupos de energia ( $k$ de 0,99 até 1,0$)$.

As formas dos fluxos apresentados nos gráficos acima mostram que para valores de $k$ que se aproximam da criticalidade as formas destes também se aproximam da forma cossenoidal, o que já era esperado.

Nos gráficos a seguir serão mostrados como o fluxo neutrônico varia com a aproximação $\mathrm{P}_{1}\left(\mathrm{~S}_{2}\right)$. Os gráficos estão divididos por número de regiões de número de grupos de energia. Os fluxos estão normalizados pelo fluxo total. 


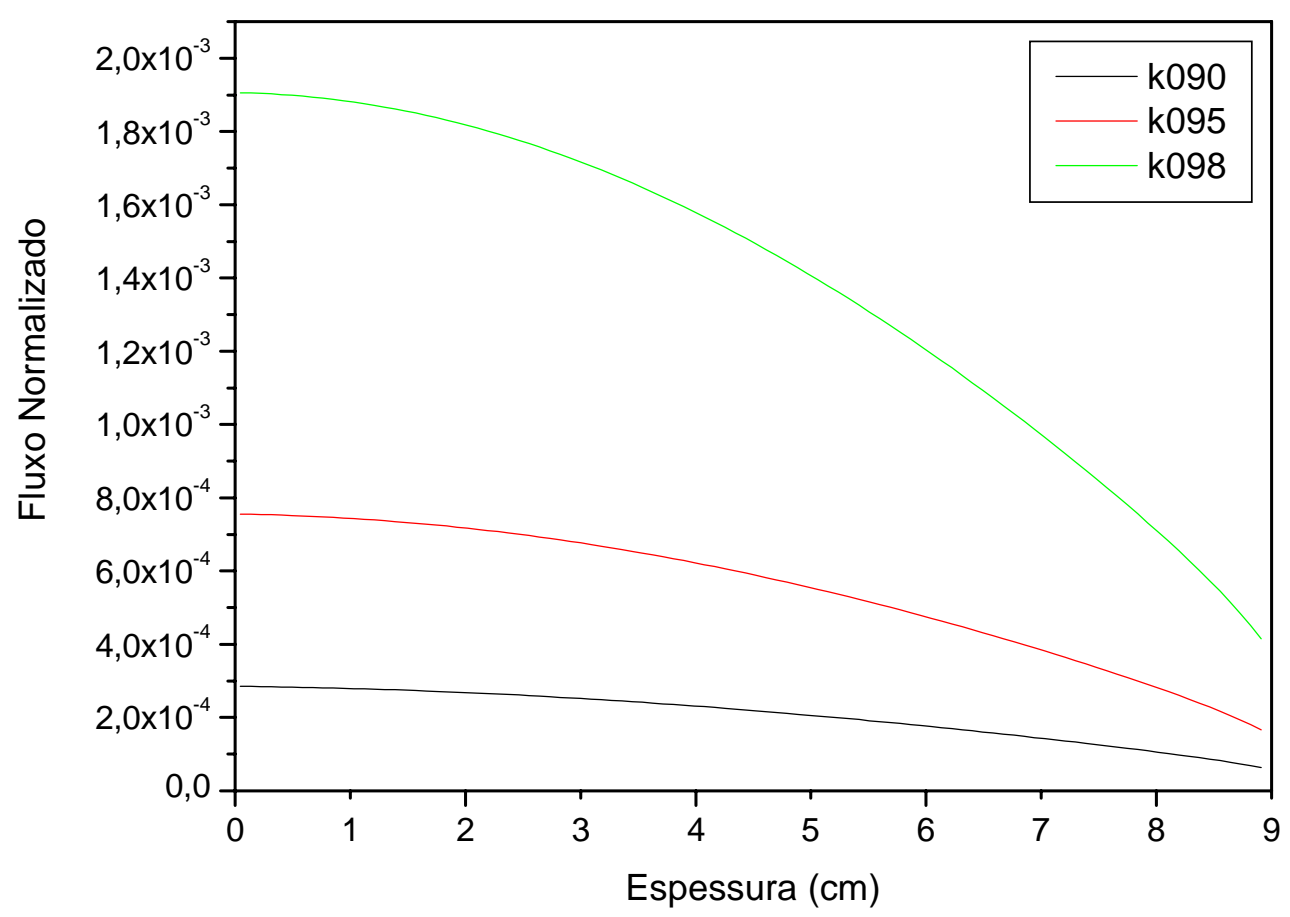

FIGURA 14 - Uma região e um grupo de energia $(k=0,90$ até 0,95$)$.

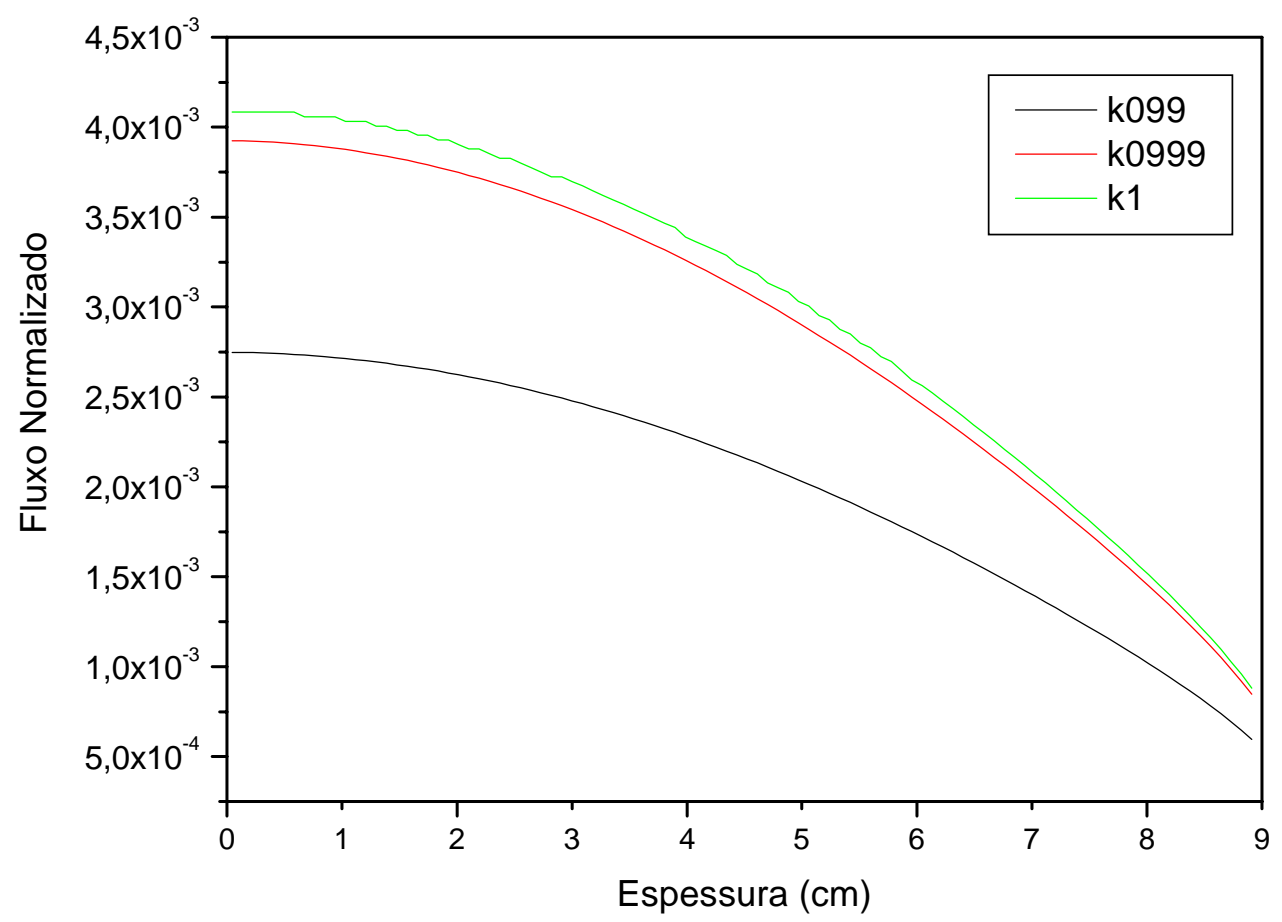

FIGURA 15 - Uma região e um grupo de energia $(k=0,99$ até 1,0$)$. 


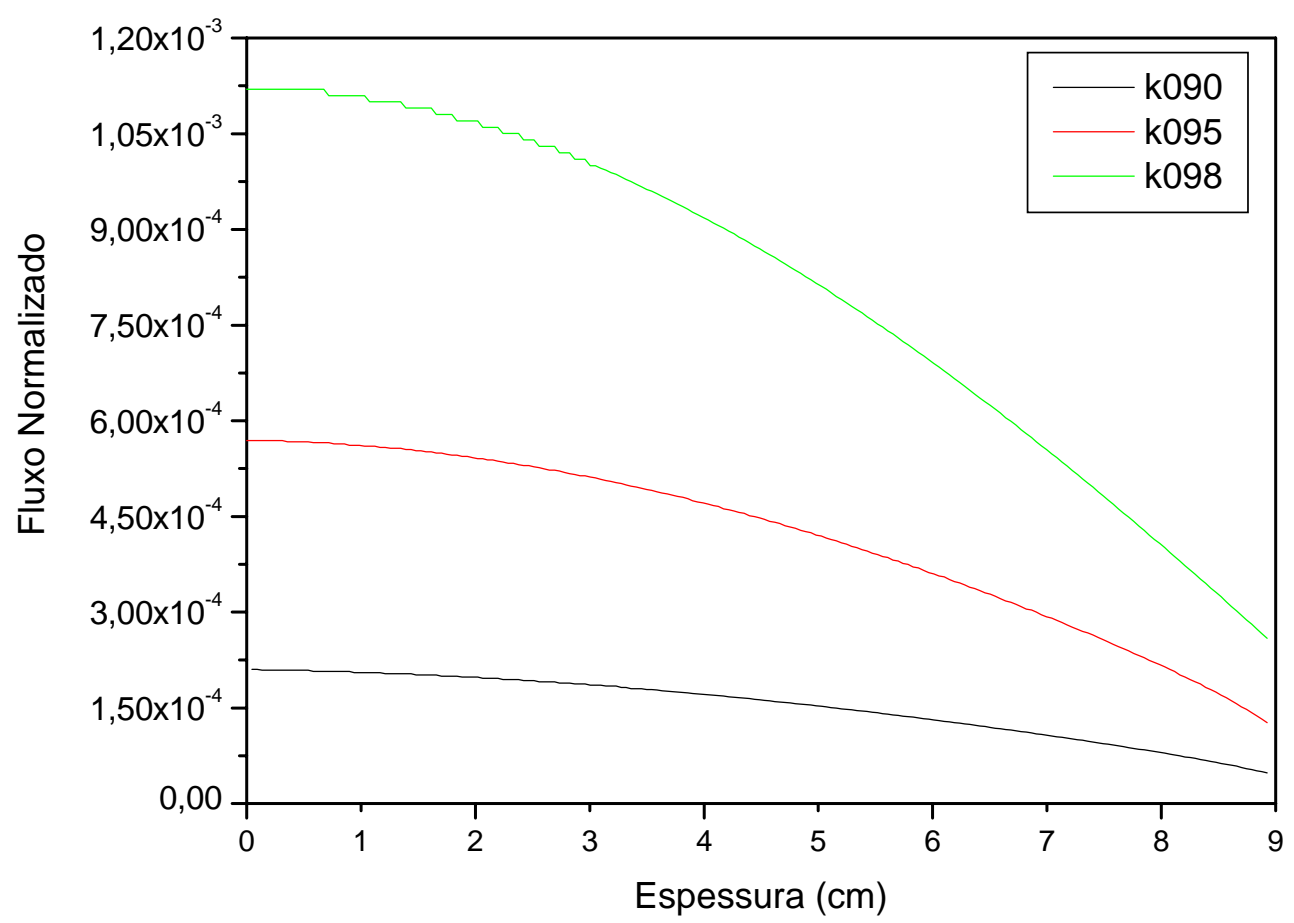

FIGURA 16 - Uma região e três grupos de energia $(\mathrm{k}=0,90$ até 0,95$)$.

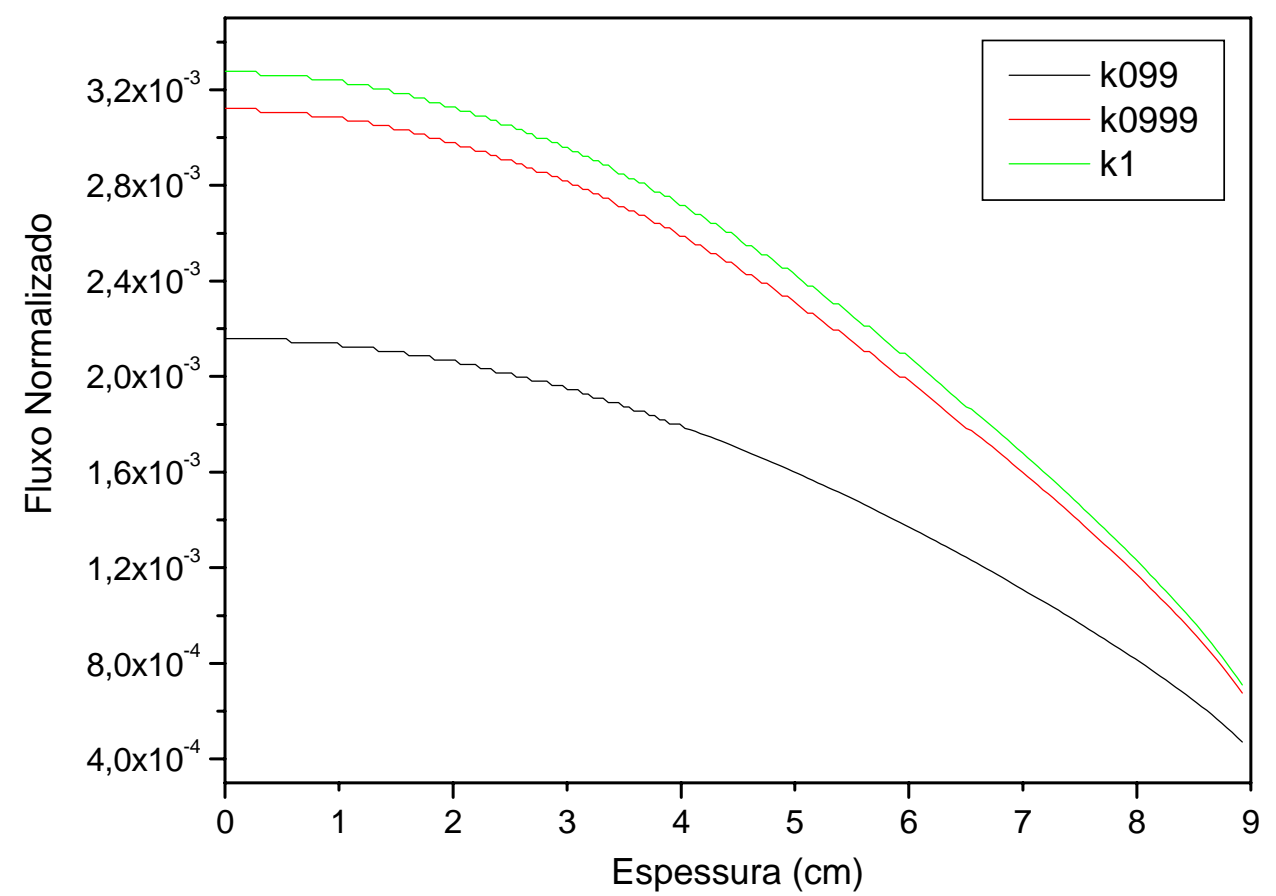

FIGURA 17 - Uma região e três grupos de energia $(k=0,99$ até 1,0$)$. 


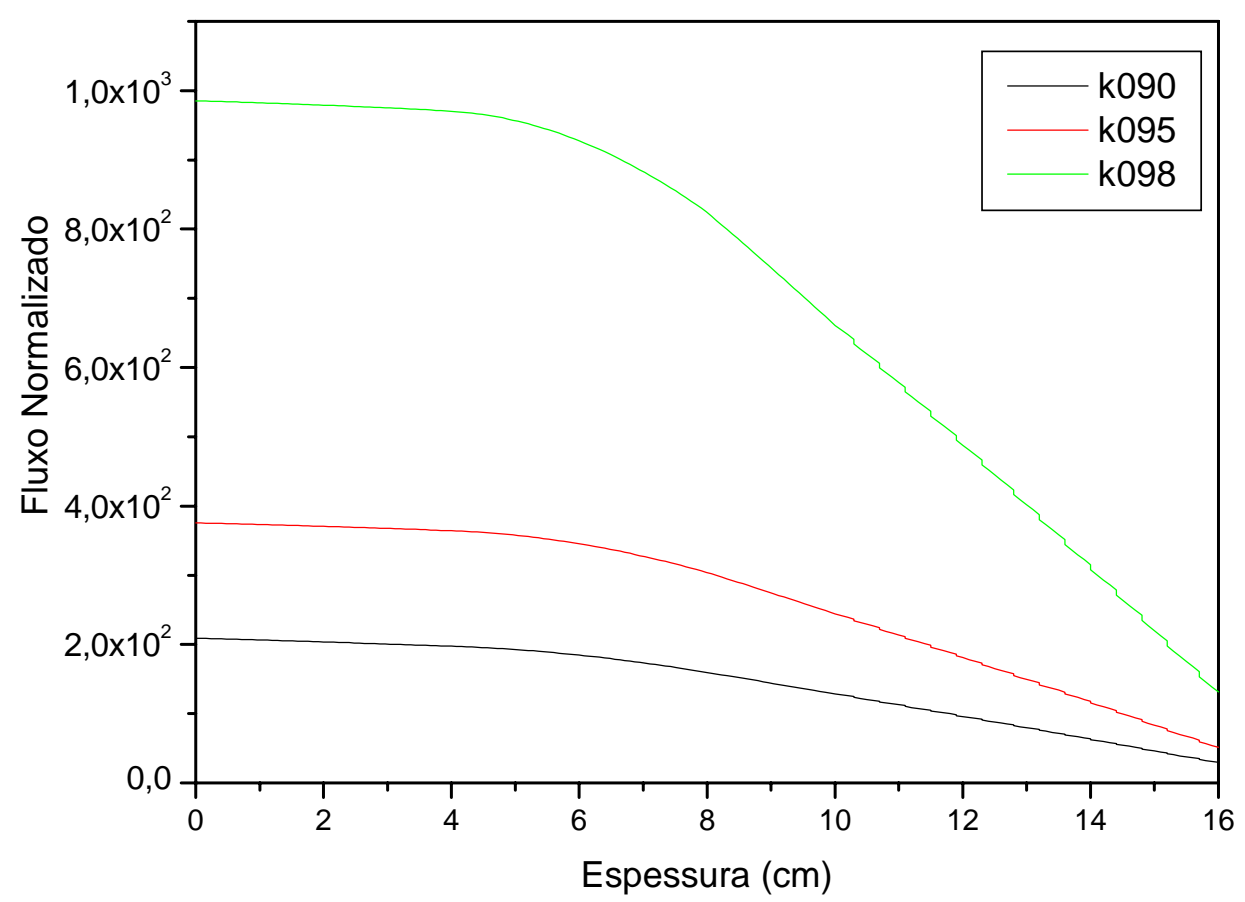

FIGURA 18 - Três regiões e três grupos de energia $(k=0,90$ até 0,95$)$.

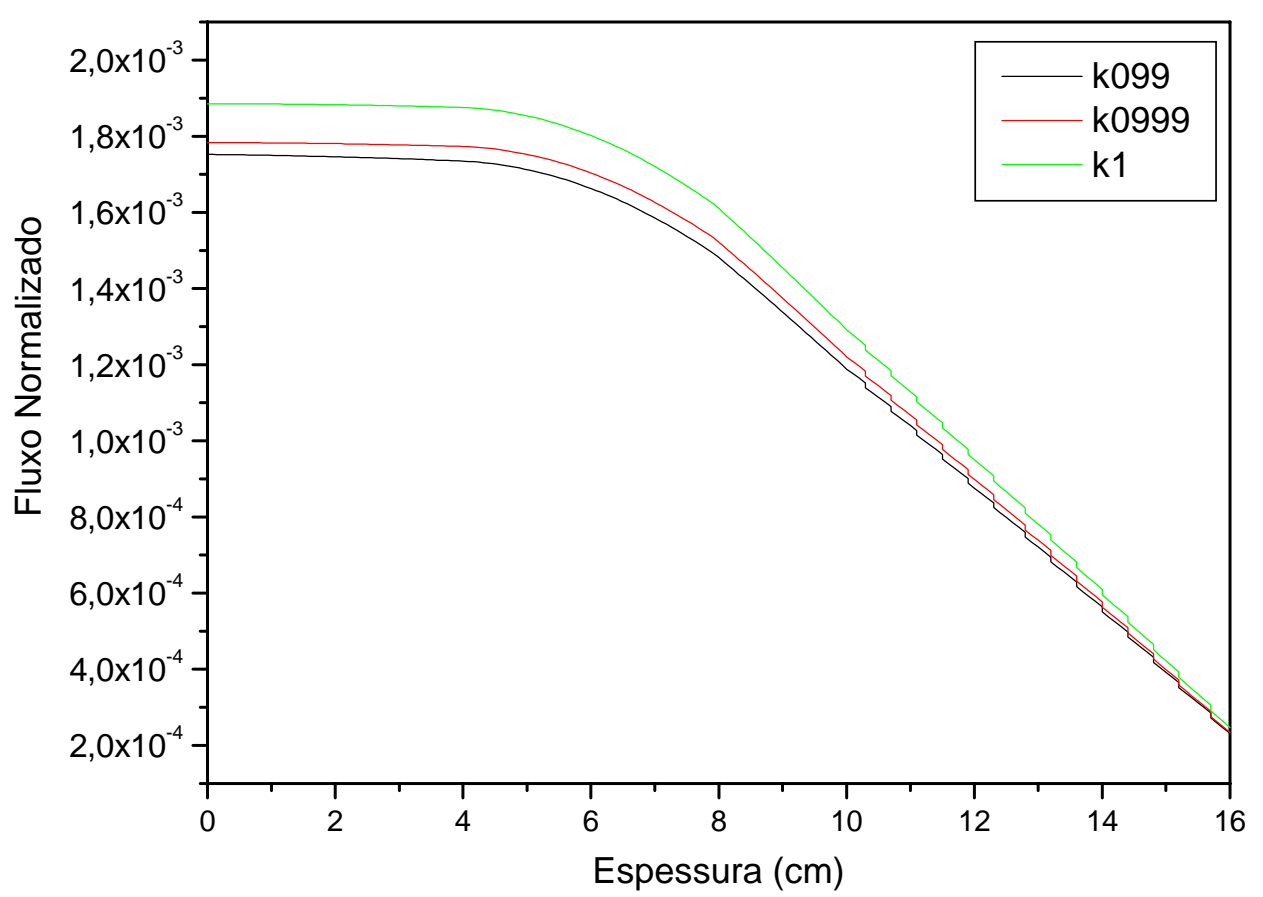

FIGURA 19 - Três regiões e três grupos de energia $(k=0,99$ até 1,0$)$. 
A forma dos gráficos é similar à dos encontrados para a aproximação $\mathrm{S}_{2}$, apesar de haver uma diferença um pouco maior quando o fluxo se aproxima da criticalidade.

\subsection{Parâmetros Cinéticos de Reator}

O estudo da evolução neutrônica em sistemas nucleares múltiplos é de grande importância quando se estuda reatores nucleares. A evolução dos nêutrons num reator nuclear é fortemente afetada pelas emissões de nêutrons atrasados do decaimento radiativo de alguns produtos de fissão. Apesar destas frações serem pequenas, o efeito destas é que permite o sistema ser controlado. Diferentes precursores têm sido identificados e eles são agrupados de acordo com as características do decaimento em seis famílias. Cada família é caracterizada pelas grandezas físicas que dependem do nuclídeo físsil que é considerado:

(i) A fração de nêutrons de fissão $\beta_{i}$, que aparecem na ith família $\left(\beta=\sum_{i=1}^{6} \beta_{i}\right)$;

(ii) A constante de decaimento $\lambda_{i}\left(s^{-1}\right) \mathrm{e}$

(iii) $\mathrm{O}$ espectro de emissão $\chi_{i}$.

A equação de transporte dependente do tempo acoplada com a equação de concentração de precursores pode ser escrita na seguinte forma:

$$
\begin{aligned}
& \frac{1}{V} \frac{\partial \Phi(\vec{r}, \hat{\Omega}, E, t)}{\partial t}+\hat{\Omega} \cdot \vec{\nabla} \Phi(\vec{r}, \hat{\Omega}, E, t)+\Sigma_{t}(\vec{r}, E) \Phi(\vec{r}, \hat{\Omega}, E, t)= \\
& \iint \sum_{x \neq f} \Sigma_{x} f_{x}\left(\vec{r} ; E^{\prime}, \hat{\Omega}^{\prime} \rightarrow \hat{\Omega}, E, t\right) \Phi^{\prime}\left(\vec{r}, \hat{\Omega}^{\prime}, E^{\prime}, t\right) d \hat{\Omega}^{\prime} d E^{\prime}+ \\
& \sum_{j} \frac{\chi_{i}^{j}(E)}{4 \pi} \iint\left(1-\beta^{j}\right) v^{j}\left(\vec{r}, E^{\prime}\right) \Sigma_{f}^{j}\left(\vec{r}, E^{\prime}, t\right) \Phi^{\prime} d \hat{\Omega}^{\prime} d E^{\prime}+\sum_{j} \lambda_{j} C_{j}(\vec{r}, t) \frac{\chi_{j}}{4 \pi}+Q
\end{aligned}
$$

e

$$
\frac{\partial C_{j}(r, t)}{\partial t}+\lambda_{j} C_{j}(\vec{r}, t)=\iint \beta_{j} v \Sigma_{f}(\vec{r}, E) \Phi^{\prime}\left(\vec{r}, \hat{\Omega}, E^{\prime}, t\right) d \Omega^{\prime} d E^{\prime} \quad j=1,2, \ldots, 6
$$


As Equações (71) e (72) geram uma formulação exata da variação do fluxo angular de nêutrons com a variação do tempo levando em consideração os nêutrons atrasados. Estas equações podem ser resolvidas numericamente e fornecem a variação do fluxo angular no espaço de fases, embora de extrema dificuldade.

Em termos de operadores as Equações (71) e (72) podem ser escritas na forma simplificada:

$$
\left\{\begin{array}{c}
\frac{1}{v} \frac{\partial \Phi}{\partial t}=\hat{L} \Phi+\hat{M}_{P} \Phi+\lambda C \\
\frac{\partial C}{\partial t}=\hat{M}_{i} \Phi-\lambda C
\end{array}\right.
$$

onde

(i) L é o operador que inclui o termo o "streaming" de nêutrons e a contribuição no espaço de fases:

$$
\begin{aligned}
\hat{L}(t)=-\hat{\Omega} \cdot \vec{\nabla} \Phi(E)-\Sigma_{t}(\vec{r}, E, t) \Phi(E)+ \\
\quad \int d E^{\prime} \oint d \hat{\Omega}^{\prime} \Phi\left(E^{\prime}\right) \Sigma_{S}\left(\vec{r} ; E^{\prime}, \hat{\Omega}^{\prime} \rightarrow \hat{\Omega}, E, t\right) \Phi^{\prime}\left(\vec{r}, \hat{\Omega}^{\prime}, E^{\prime}, t\right)
\end{aligned}
$$

(ii) $M_{p}$ o operador multiplicação de fissão,

$$
\hat{M}_{p}=\sum_{j} \frac{\chi_{i}^{j}(E)}{4 \pi} \int d E^{\prime \prime} \oint d \hat{\Omega}^{\prime} \Phi^{\prime}\left(1-\beta^{j}\right) v\left(\vec{r}, E^{\prime}\right) \Sigma_{f}\left(\vec{r}, E^{\prime}, t\right)
$$

(iv) $M_{i}$ é o operador multiplicação de nêutrons atrasados,

$$
\hat{M}_{i}=\sum_{j} \frac{\chi_{i}^{j}(E)}{4 \pi} \int d E^{\prime} \oint d \hat{\Omega}^{\prime} \Phi\left(E^{\prime}\right) \beta_{i}^{j} v\left(E^{\prime}\right) \Sigma_{f}\left(\vec{r}, E^{\prime}, t\right)
$$

(v) $M_{0}$ é o operador multiplicação total de nêutrons, 


$$
\hat{M}_{0}(t)=\hat{M}_{p}(t)+\sum_{i=1}^{6} \hat{M}_{i}(t)
$$

(vi) e o espectro de emissão de nêutrons para cada nuclídeo físsil é dado por

$$
\chi^{j}(E)=\left(1-\beta^{j}\right) \chi_{p}^{j}(E)+\sum_{i=1}^{6} \beta_{i}^{j} \chi_{i}^{j}(E)
$$

A forma como os termos são apresentados nas equações anteriores, assim como as Equações (71) e (72) são a forma clássica de apresentação das equações de cinética. Uma derivação completa para as equações de cinética são dadas por Bell e Glasstone [57] para sistemas críticos, ou então, muito próximos da criticalidade. Porém, quando se trata de sistemas subcríticos acionados por fontes é necessário que no meio multiplicativo subcrítico sejam considerados também os nêutrons da fonte externa. Neste caso a solução pode ser obtida a partir da equação:

$$
\hat{L} \Phi_{S}+\hat{M}_{0} \Phi_{S}+S_{0}=0
$$

onde os operadores nesta equação têm a mesma definição dada para a Equação (73).

Da mesma forma que para os parâmetros estáticos, Dulla, Gandini e Salvatores deram uma importante contribuição para a definição dos parâmetros cinéticos para sistemas subcríticos acionados por fontes externas.

Diferentemente dos parâmetros cinéticos clássicos, Dulla sugere dividir os termos de cinética $\left(\rho_{\mathrm{s}}, \beta_{\mathrm{s}}, \Lambda_{\mathrm{s}}\right)$ por uma importância total dos nêutrons de primeira geração introduzidos no sistema pela fissão e emissões da fonte:

$$
I=\left\langle\Phi_{S}^{*} \mid \hat{M}_{0} \Phi_{S}\right\rangle+\left\langle\Phi_{S}^{*} \mid S_{0}\right\rangle
$$

Esta escolha tem conseqüências diretas na definição dos parâmetros cinéticos, com atenção particular no tempo de vida do nêutron. Na derivação dos parâmetros Dulla divide todos os termos por esta integral para descrever o seu modelo. Estes termos 
também são determinados pela forma do fluxo dirigido pela fonte e pela função importância correspondente:

$$
\hat{L}^{*} \Phi_{S}^{*}+\hat{M}_{0}^{*} \Phi_{S}^{*}+S_{0}^{*}=0
$$

A partir das Equações (71) e (72), com as técnicas clássicas de projeção e perturbação de primeira ordem pode-se escolher uma equação equivalente na forma das equações de cinética pontual com uma redefinição dos parâmetros cinéticos.

O termo de fração de nêutrons atrasados de um sistema dirigido por fonte foi apresentado por Dulla como

$$
\beta_{S}=\frac{\left\langle\Phi_{S}^{*} \hat{M}_{d} \Phi_{S}\right\rangle}{I}
$$

e o tempo de geração efetivo:

$$
\Lambda_{S}=\frac{\left\langle\Phi_{S}^{*} \mid \frac{1}{V} \Phi_{S}\right\rangle}{I}
$$

Dulla definiu estes parâmetros de tal forma que quando se aproxima a criticalidade, também os parâmetros $\beta_{\mathrm{S}}$ e $\Lambda_{\mathrm{S}}$ se aproximam dos parâmetros usuais para sistemas críticos.

A reatividade de um sistema com fonte é introduzida por Dulla como a seguinte soma:

$$
\rho_{S}=\widetilde{\rho}_{S}+\rho_{S, 0}
$$

onde os termos que compõem a Equação (79) são definidos como 


$$
\rho_{S}=\frac{\left\langle\Phi_{S}^{+} \mid(\delta \hat{M}+\delta \hat{L}) \Phi_{S}\right\rangle}{I}
$$

e

$$
\rho_{S, 0}=-\frac{\left\langle\Phi_{S}^{+} \mid \Phi_{S}\right\rangle}{I} .
$$

O primeiro termo de reatividade pode ser relacionado ao fator de multiplicação de fonte que é introduzido pela seguinte equação:

$$
k_{S}=\frac{\left\langle\hat{M} \Phi_{S}\right\rangle}{\left\langle\hat{M} \Phi_{S}+S\right\rangle}
$$

Como conseqüência das definições anteriores o termo de reatividade generalizada dirigida por fonte é escrita como:

$$
\widetilde{\rho}_{S}=\frac{\delta k_{S}}{k_{S}} \frac{\left\langle\hat{M}_{0} \Phi_{S}\right\rangle}{I} .
$$

Todos os termos de reatividade definidos por Dulla são diferentes daqueles obtidos pelas definições de reatividade usuais, pois estes termos são determinados pela forma do fluxo do sistema e pela função importância do sistema dirigido por fonte.

Gandini e Salvatores também definiram os mesmos parâmetros que Dulla definiu, partindo das equações de cinética com o termo fonte. Assim como Dulla eles também definiram uma integral de normalização pela qual os termos cinéticos são definidos:

$$
I=\left\langle n^{*}, M \Phi_{0}\right\rangle
$$


A função $n^{*}$ tem gerado discussão, pois Gandini e Salvatores a definem como sendo uma função importância associada com o nível de potência em um sistema subcrítico. Esta função importância é obtida da equação

$$
L^{*} n_{0}^{*}+M^{*} n_{0}^{*}+\frac{\gamma}{W_{0}} \Sigma_{f}=0
$$

onde $\gamma$ é o número de unidades de energia por fissão, $W_{0}$ é a potência do reator, e $\Sigma_{\mathrm{f}}$ é a seção de choque macroscópica de fissão. O termo que envolve estas três constantes é discutido se este representa a fonte de nêutrons, pois se este a representa faz sentido solucionar a Equação (85) para encontrar a variável $n^{*}$.

A reatividade generalizada é derivada por Gandini e Salvatores relacionada à uma perturbação em $\mathrm{t}=0: L \rightarrow L+\delta L, M \rightarrow M+\delta M$ (L é o operador perdas e M é o operador produção) é dada como

$$
\rho_{\text {gen }}=\frac{\left\langle n_{s, 0}^{*}(\delta L+\bar{\chi} \delta M) \Phi_{0}\right\rangle}{\left\langle n_{s, 0}^{*}, M_{0} \Phi_{0}\right\rangle}
$$

O coeficiente de reatividade de fonte relacionado à uma perturbação na fonte: $S \rightarrow S+\delta S$, em $\mathrm{t}=0$, foi definido por Gandini como

$$
\rho_{S}=\frac{\left\langle n_{0}^{*}, \delta s\right\rangle}{I} .
$$

Gandini e Salvatores também definiram o tempo de geração de nêutrons como

$$
\Lambda_{S}=\frac{\left\langle n_{0}^{*}, V^{-1} \Phi\right\rangle}{I},
$$

e a fração de nêutrons atrasado foi definida da forma: 


$$
\begin{gathered}
\beta_{i, e f f}=\frac{\sum_{g=1}^{G} \sum_{j=1}^{J}\left\langle n_{s, 0, g}^{*} c_{j} \chi_{D, g}^{j} \beta_{i, g}^{j} v \sigma_{f, g} \Phi_{g}\right\rangle}{\sum_{g=1}^{G} \sum_{j=1}^{J} \sum_{i=1}^{I}\left\langle n_{s, 0, g}^{*} c_{j} v \sigma_{f, g} \Phi_{g}\right\rangle} \\
\beta_{e f f}=\sum_{i=1} \beta_{i, e f f} .
\end{gathered}
$$

A seguir serão apresentadas algumas tabelas que mostram alguns valores de parâmetros cinéticos que foram calculados utilizando as definições de Dulla e Gandini e Salvatores com $\mathrm{S}_{2}$. A motivação para o cálculo destes parâmetros é que o uso, aplicação e definição de alguns destes parâmetros ainda é uma questão em aberto para a comunidade que estuda ADS. O objetivo não é demonstrar fisicamente algum parâmetro, mas apenas mostrar valores de parâmetros à fim de comparação das duas metodologias para as equações apresentadas acima. As TAB. 6, 7 e 8 apresentam os parâmetros $\Lambda_{\mathrm{s}}$ e $\beta_{\mathrm{s}}$ para 6 diferentes níveis de criticalidade $(0,90 ; 0,95 ; 0,98 ; 0,99 ; 0,999$ e 1,0$)$. Cálculos para uma região e um grupo de energia e com esta mesma aproximação foram realizados por Seung Min Lee e apresentados no seminário de área [58].

TABELA 6 - 1 Região e 1 grupo de energia, $\mathrm{S}_{2}$

\begin{tabular}{|c|c|c|c|c|}
\hline $\mathrm{K}$ & $\Lambda_{\mathrm{S}}$ (Dulla) & $\Lambda_{\mathrm{S}}$ (Gandini) & $\beta_{\mathrm{S}}$ (Dulla) & $\beta_{\mathrm{S}}$ (Gandini) \\
\hline 0,90 & $2,652357 \mathrm{E}-6$ & $2,672111 \mathrm{E}-6$ & $4,38625 \mathrm{E}-3$ & $4,39224 \mathrm{E}-3$ \\
\hline 0,95 & $2,712389 \mathrm{E}-6$ & $2,725850 \mathrm{E}-6$ & $4,48553 \mathrm{E}-3$ & $4,489093-3$ \\
\hline 0,98 & $2,738851 \mathrm{E}-6$ & $2,741328 \mathrm{E}-6$ & $4,53929 \mathrm{E}-3$ & $4,54007 \mathrm{E}-3$ \\
\hline 0,99 & $2,742389 \mathrm{E}-6$ & $2,761132 \mathrm{E}-6$ & $4,54514 \mathrm{E}-3$ & $4,54721 \mathrm{E}-3$ \\
\hline 0,999 & $2,745225 \mathrm{E}-6$ & $2,7641328 \mathrm{E}-6$ & $4,54886 \mathrm{E}-3$ & $4,54989-3$ \\
\hline 1,0 & $2,745850 \mathrm{E}-6$ & $2,7643325 \mathrm{E}-6$ & $4,55 \mathrm{E}-3$ & $4,55 \mathrm{E}-3$ \\
\hline
\end{tabular}

Na TAB. 6 percebe-se que há discrepâncias nos valores encontrados pelas duas metodologias. Quando $k=0,90$, por exemplo, para $\Lambda_{\mathrm{S}}$ é encontrada uma diferença de $0,74 \%$, enquanto que para $k=1$, a diferença é de $0,66 \%$. Percebe-se que a diferença 
diminuiu na medida em que $k$ se aproxima da criticalidade. Para o parâmetro $\beta_{\mathrm{S}}$ a diferença quando $k=090$ é $0,13 \%$, que tende a ser nula esta diferença quando o fator de multiplicação tende à um.

TABELA 7 - 1 Região e 3 grupos de energia, $\mathrm{S}_{2}$

\begin{tabular}{|c|c|c|c|c|}
\hline$k$ & $\Lambda_{\mathrm{S}}$ (Dulla) & $\Lambda_{\mathrm{S}}$ (Gandini) & $\beta_{\mathrm{S}}$ (Dulla) & $\beta_{\mathrm{S}}$ (Gandini) \\
\hline 0,90 & $2,662350 \mathrm{E}-6$ & $2,684321 \mathrm{E}-6$ & $4,38838 \mathrm{E}-03$ & $4,41826 \mathrm{E}-3$ \\
\hline 0,95 & $2,724317 \mathrm{E}-6$ & $2,73762 \mathrm{E}-6$ & $4,48632 \mathrm{E}-03$ & $4,491901-3$ \\
\hline 0,98 & $2,7393560-6$ & $2,749689 \mathrm{E}-6$ & $4,541699 \mathrm{E}-03$ & $4,54175 \mathrm{E}-3$ \\
\hline 0,99 & $2,751581 \mathrm{E}-6$ & $2,760035 \mathrm{E}-6$ & $4,545872 \mathrm{E}-03$ & $4,54626 \mathrm{E}-3$ \\
\hline 0,999 & $2,752250 \mathrm{E}-6$ & $2,760122 \mathrm{E}-6$ & $4,547821 \mathrm{E}-03$ & $4,54987-3$ \\
\hline 1,0 & $2,755998 \mathrm{E}-6$ & $2,760124 \mathrm{E}-6$ & $4,55 \mathrm{E}-3$ & $4,55 \mathrm{E}-3$ \\
\hline
\end{tabular}

Na TAB. 7 pode-se perceber que quando $k=0,90$ é encontrada a maior discrepância $(0,82 \%)$ para $\Lambda_{\mathrm{S}}$ que vai diminuindo na medida em que $k$ vai tendendo a criticalidade (quando $k=1$, a diferença é $0,14 \%$ ). Para o valor de $\beta_{\mathrm{S}}$ foram encontrados os valores esperados, que longe da criticalidade houvesse uma maior discrepância $(0,67 \%)$, mas que os valores tenderiam ao mesmo valor quando se aproximassem da criticalidade.

TABELA 8 - 3 Regiões e 3 grupos de energia, $\mathrm{S}_{2}$

\begin{tabular}{|c|c|c|c|c|}
\hline$K$ & $\Lambda_{S}$ (Dulla) & $\Lambda_{\mathrm{S}}$ (Gandini) & $\beta_{\mathrm{S}}$ (Dulla) & $\beta_{\mathrm{S}}$ (Gandini) \\
\hline 0,90 & $5,45182 \mathrm{E}-6$ & $5,70025 \mathrm{E}-6$ & $4,363331 \mathrm{E}-3$ & $4,38633 \mathrm{E}-3$ \\
\hline 0,95 & $7,23643 \mathrm{E}-6$ & $7,37611 \mathrm{E}-6$ & $4,452002 \mathrm{E}-3$ & $4,461010-3$ \\
\hline 0,98 & $8,78307 \mathrm{E}-6$ & $8,79073 \mathrm{E}-6$ & $4,476998 \mathrm{E}-3$ & $4,478411 \mathrm{E}-3$ \\
\hline 0,99 & $9,41477 \mathrm{E}-6$ & $9,42169 \mathrm{E}-6$ & $4,487775 \mathrm{E}-3$ & $4,48889 \mathrm{E}-3$ \\
\hline 0,999 & $9,41678 \mathrm{E}-6$ & $9,42174 \mathrm{E}-6$ & $4,497821 \mathrm{E}-3$ & $4,498733-3$ \\
\hline 1,0 & $9,417002 \mathrm{E}-6$ & $9,42175 \mathrm{E}-6$ & $4,5 \mathrm{E}-3$ & $4,50 \mathrm{E}-3$ \\
\hline
\end{tabular}


Na TAB. 8 pode-se perceber que as maiores diferenças encontradas nos valores são para os primeiros parâmetros. No primeiro valor de $\Lambda_{\mathrm{s}}$, por exemplo, a diferença entre as duas metodologias é de 4,35\% enquanto que para o último valor a diferença é de 1,89\%. Portanto, a diferença vai diminuindo na medida em que os valores de $k$ vão tendendo à criticalidade. Em relação ao parâmetro $\beta_{\mathrm{s}}$ a diferença nos valores quando comparadas as duas metodologias é muito menor. A maior diferença é encontrada para $k=0,90$ onde a diferença é de $0,5 \%$. Quando $k$ tende à criticalidade $\beta_{\mathrm{s}}$ tende ao $\beta$ crítico.

Nas três tabelas parte da discrepância pode ser creditada ao fato que as integrais de normalização definidas por Dulla e Gandini e Salvatores não são iguais. Elas divergem por um termo nas Equações (84) e (75). Observando estas duas equações se percebe que Gandini e Salvatores não consideram a segunda parte da Equação (75), que foi definida por Dulla. No entanto, as duas metodologias convergem para o valor encontrado para o sistema crítico. Os valores encontrados nas tabelas acima são muito próximos dos valores encontrados nos cálculos apresentados por Seung Min Lee no seu seminário de área [58].

A fim de verificar a variação dos parâmetros com o modelo foram calculados os mesmos parâmetros das tabelas acima, mas com um modelo diferente: $\mathrm{S}_{12}$. O valor $\mathrm{P}_{0}$ não foi modificado, pois para modificá-lo seria necessário gerar um novo conjunto de seções de choque, que devido ao prazo de tempo seria muito difícil realizar. Nas TAB. 9, 10 e 11 são mostrados os valores dos parâmetros calculados. Nestas tabelas percebe-se que há apenas três níveis de criticalidade, pois com a aproximação $\mathrm{S}_{12}$ há apenas dois valores de $k$ abaixo da criticalidade.

TABELA 9 - 1 Região e 1 grupo de energia, $\mathrm{S}_{12}$

\begin{tabular}{|c|c|c|c|c|}
\hline $\mathrm{K}$ & $\Lambda_{\mathrm{S}}$ (Dulla) & $\Lambda_{\mathrm{S}}$ (Gandini) & $\beta_{\mathrm{S}}$ (Dulla) & $\beta_{\mathrm{S}}$ (Gandini) \\
\hline 0,952024 & $2,661965-6$ & $2,672111 \mathrm{E}-6$ & $4,38625 \mathrm{E}-3$ & $4,39224 \mathrm{E}-3$ \\
\hline 0,999727 & $2,746555 \mathrm{E}-6$ & $2,725850 \mathrm{E}-6$ & $4,48553 \mathrm{E}-3$ & $4,489093-3$ \\
\hline 1,0 & $2,745850 \mathrm{E}-6$ & $2,7643325 \mathrm{E}-6$ & $4,55 \mathrm{E}-3$ & $4,55 \mathrm{E}-3$ \\
\hline
\end{tabular}


TABELA 10 - 1 Região (U36\%) e 3 grupos de energia, $\mathrm{S}_{12}$

\begin{tabular}{|c|c|c|c|c|}
\hline$K$ & $\Lambda$ S (Dulla) & $\Lambda$ S (Gandini) & $\beta S$ (Dulla) & $\beta S$ (Gandini) \\
\hline 0,952024 & $2,662350 \mathrm{E}-6$ & $2,684321 \mathrm{E}-6$ & $4,38838 \mathrm{E}-03$ & $4,41826 \mathrm{E}-3$ \\
\hline 0,999727 & $2,724317 \mathrm{E}-6$ & $2,73762 \mathrm{E}-6$ & $4,48632 \mathrm{E}-03$ & $4,491901-3$ \\
\hline 1 & $2,755998 \mathrm{E}-6$ & $2,760124 \mathrm{E}-6$ & $4,55 \mathrm{E}-3$ & $4,55 \mathrm{E}-3$ \\
\hline
\end{tabular}

TABELA 11 - 3 Regiões e 3 grupos de energia, $\mathrm{S}_{12}$

\begin{tabular}{|c|c|c|c|c|}
\hline$k$ & $\Lambda_{\mathrm{S}}$ (Dulla) & $\Lambda_{\mathrm{S}}$ (Gandini) & $\beta_{\mathrm{S}}$ (Dulla) & $\beta_{\mathrm{S}}$ (Gandini) \\
\hline 0,952024 & $5,45182 \mathrm{E}-6$ & $5,70025 \mathrm{E}-6$ & $4,363331 \mathrm{E}-3$ & $4,38633 \mathrm{E}-3$ \\
\hline 0,999727 & $7,23643 \mathrm{E}-6$ & $7,37611 \mathrm{E}-6$ & $4,452002 \mathrm{E}-3$ & $4,461010-3$ \\
\hline 1,0 & $9,417002 \mathrm{E}-6$ & $9,42175 \mathrm{E}-6$ & $4,5 \mathrm{E}-3$ & $4,50 \mathrm{E}-3$ \\
\hline
\end{tabular}

Percebe-se que houve uma variação nos parâmetros quando se muda da aproximação $S_{2}$ para $S_{12}$. Verifica-se, portanto que estes parâmetros também variam com o modelo adotado. Esta observação é importante, pois tais parâmetros não variam apenas o nível de subcriticalidade, mas também com o modelo de cálculo adotado.

O parâmetro $\rho_{\mathrm{S}}$ foi calculado através das duas metodologias e comparado ao resultado encontrado pelo método clássico para criticalidade definido por Bell e Glasstone [57]: $\rho=\frac{k-1}{k}$.

TABELA 12 - 1 Região e 1 grupo de energia, $\mathrm{S}_{2}$

\begin{tabular}{|c|c|c|c|c|c|}
\hline$K$ & 0,90 & 0,95 & 0,98 & 0,99 & 0,999 \\
\hline$\rho$ (Dulla) & $-0,0187024$ & $-0,046860$ & $-0,012302$ & $-0,008395$ & $-0,0007623$ \\
\hline$\rho$ (Gandini) & $-0,1900259$ & $-0,047369$ & $-0,012689$ & $-0,008411$ & $-0,0007676$ \\
\hline$\rho=\frac{k-1}{k}$ & $-0,11111$ & $-0,052631578$ & $-0,02040816$ & $-0,010101$ & $-0,001001$ \\
\hline
\end{tabular}


TABELA 13 - 1 Região e 3 grupos de energia, $\mathrm{S}_{2}$

\begin{tabular}{|c|c|c|c|c|c|}
\hline $\mathrm{K}$ & 0,90 & 0,95 & 0,98 & 0,99 & 0,999 \\
\hline$\rho$ (Dulla) & $-0,018624$ & $-0,046726$ & $-0,012178$ & $-0,008354$ & $-0,0007602$ \\
\hline$\rho$ (Gandini) & $-0,1900136$ & $-0,047522$ & $-0,012398$ & $-0,008401$ & $-0,0007619$ \\
\hline$\rho=\frac{k-1}{k}$ & $-0,11111$ & $-0,052631578$ & $-0,02040816$ & $-0,010101$ & $-0,001001$ \\
\hline
\end{tabular}

TABELA 14 - 3 Regiões e 3 grupos de energia, $\mathrm{S}_{2}$

\begin{tabular}{|c|c|c|c|c|c|}
\hline$k$ & 0,90 & 0,95 & 0,98 & 0,99 & 0,999 \\
\hline$\rho$ (Dulla) & $-0,0180025$ & $-0,046722$ & $-0,012224$ & $-0,008327$ & $-0,0007611$ \\
\hline$\rho$ (Gandini) & $-0,1901373$ & $-0,048020$ & $-0,012566$ & $-0,008529$ & $-0,0007637$ \\
\hline$\rho=\frac{k-1}{k}$ & $-0,11111$ & $-0,052631578$ & $-0,02040816$ & $-0,010101$ & $-0,001001$ \\
\hline
\end{tabular}

Nas TAB. 12, 13 e 14 foram comparados os parâmetros $\rho$ para as definições de Dulla, Gandini e Salvatores e Bell e Glasstone para a aproximação $\mathrm{S}_{2}$. Os valores encontrados para este parâmetro foram diferentes para as definições de Dulla e Gandini e Salvatores, o que já era esperado, pois o termo reatividade nas duas metodologias depende da integral de normalização, que é definida diferente nos dois casos. Através da definição de Bell e Glasstone também encontrou-se um valor diferente das outras duas, o que já era previsto pois Dulla [53] demonstrou que estes parâmetros variam com o grau de subcriticalidade e perturbação (fonte e seção de choque) e a equação clássica para cálculos de desvios de criticalidade $k-1 / k$ só pode ser usada quando o fator de multiplicação $\mathrm{k}$ tende à condição de criticalidade [53], como está sendo estudado por outras dissertações de mestrado e está inserido no Projeto Coordenado de Pesquisa (CRP) número 5380.170.3505..D20030231.ADS2007741293. 


\section{CÁlCULOS DE PARÂMETROS DA CONFIGURAÇÃO SUBCRÍTICA DO REATOR IPEN-MB-01 COM UMA FONTE EXTERNA DE NÊUTRONS, UTILIZANDO O CÓDIGO TORT}

Com o objetivo de verificar cálculos determinísticos bem como aprimorar os cálculos de constantes multigrupo para sistemas acionados por fontes externas, decidiu-se calcular uma configuração subcrítica do reator IPEN/MB-01 com a inserção de uma fonte externa de nêutrons. Como o reator IPEN/MB-01 é um reator de potência zero usado para "Benchmarks" de Física de Reatores e com o desenvolvimento de aceleradores compactos (e.g. laboratório de Berkeley) pensou-se em realizar cálculos que descrevem a Física envolvida em tais sistemas.

O Reator IPEN/MB-01 é um reator de potência zero (100 watts), refrigerado à água leve e consiste em um "array" retangular de 28x26 pinos combustíveis de $\mathrm{UO}_{2}, 4,3$ w/0, com "clad" de SS-304.

A instalação é controlada por dois bancos de controle, compostos por 12 varetas de Ag-In-Cd. Há também dois bancos de varetas de segurança, compostas por 12 varetas de $\mathrm{B} 4 \mathrm{C}$, que são mantidas fora do núcleo. O reator é usado para vários tipos de pesquisas em Física de Reatores, tais como determinação de índice espectral, coeficiente de reatividade, parâmetros cinéticos críticos, espectro, fluxo, etc. Bitelli [59] resumiu os principais experimentos realizados na instalação. Atualmente a instalação faz parte do "International Reactor Physics Evaluation Project" (IRPhE) [60].

Apesar de haver sido originalmente projetado com uma configuração crítica controlada por varetas de controle, o reator pode ser facilmente posto em uma configuração subcrítica, ou pela mudança da posição das varetas de controle, ou mudando o número de pinos combustíveis no núcleo.

No trabalho colaborativo em utilização de LEU (Urânio de baixo enriquecimento) em ADS, no Projeto Coordenado de Pesquisa (CRP), considera-se na primeira fase a análise da configuração subcrítica do reator IPEN/MB-01. Nesta 
configuração remove-se todas as varetas de controle e duas linhas e duas colunas de varetas da configuração crítica, como ilustrado na FIG. 20. Há também a inserção de uma fonte pontual de $14 \mathrm{MeV}$ (reação de fusão Deutério - Trítio, D-T) no centro do núcleo ativo, na posição M14, como mostra a FIG. 4. O tubo guia da fonte é considerado como um espaço vazio. As posições das varetas de controle e segurança são consideradas como tubos guias cheios de água. A matriz considerada para esta configuração é $24 \times 22$, como ilustrado na FIG. 20. A FIG. 21, também ilustra o modelo geométrico e o sistema de referência gerado pelo código MCNP.

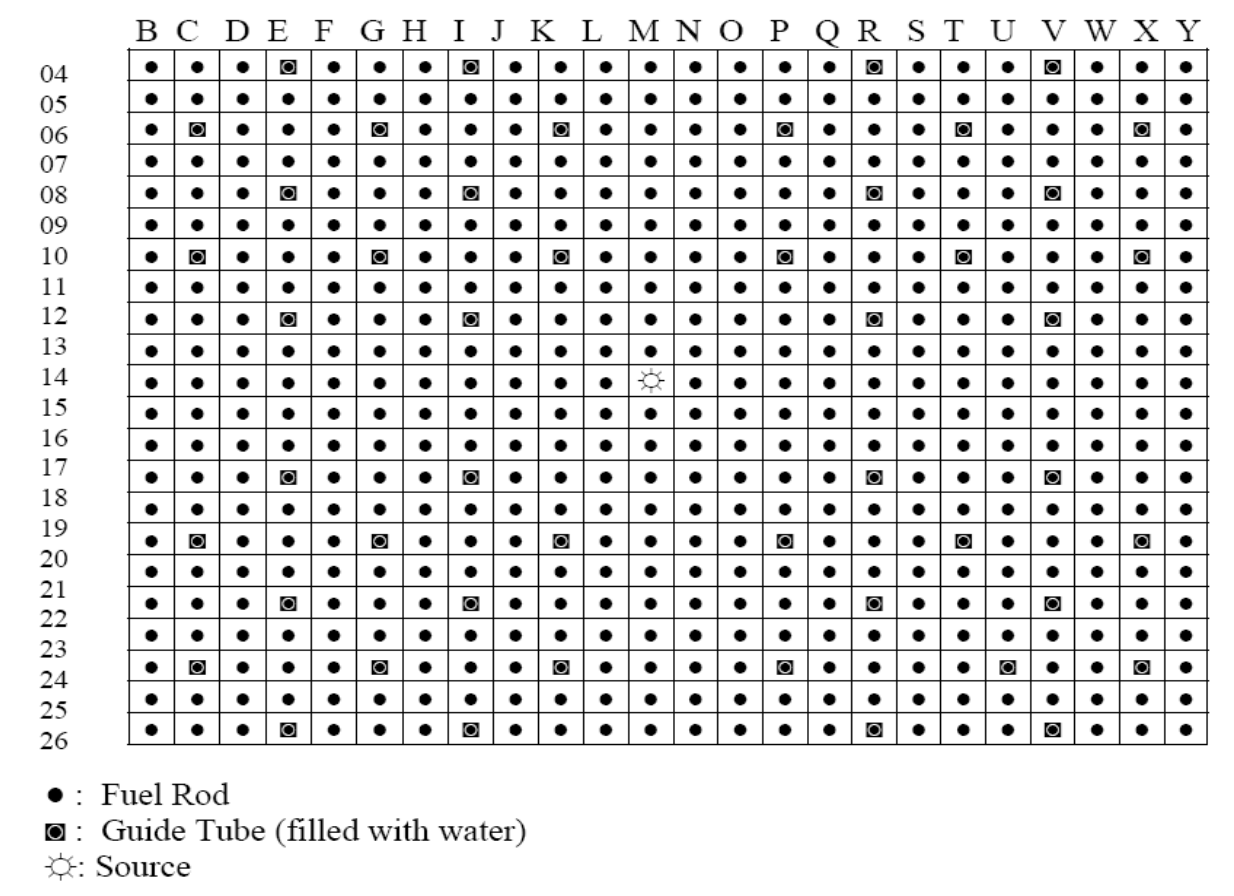

FIGURA 20 - Configuração subcrítica considerada 


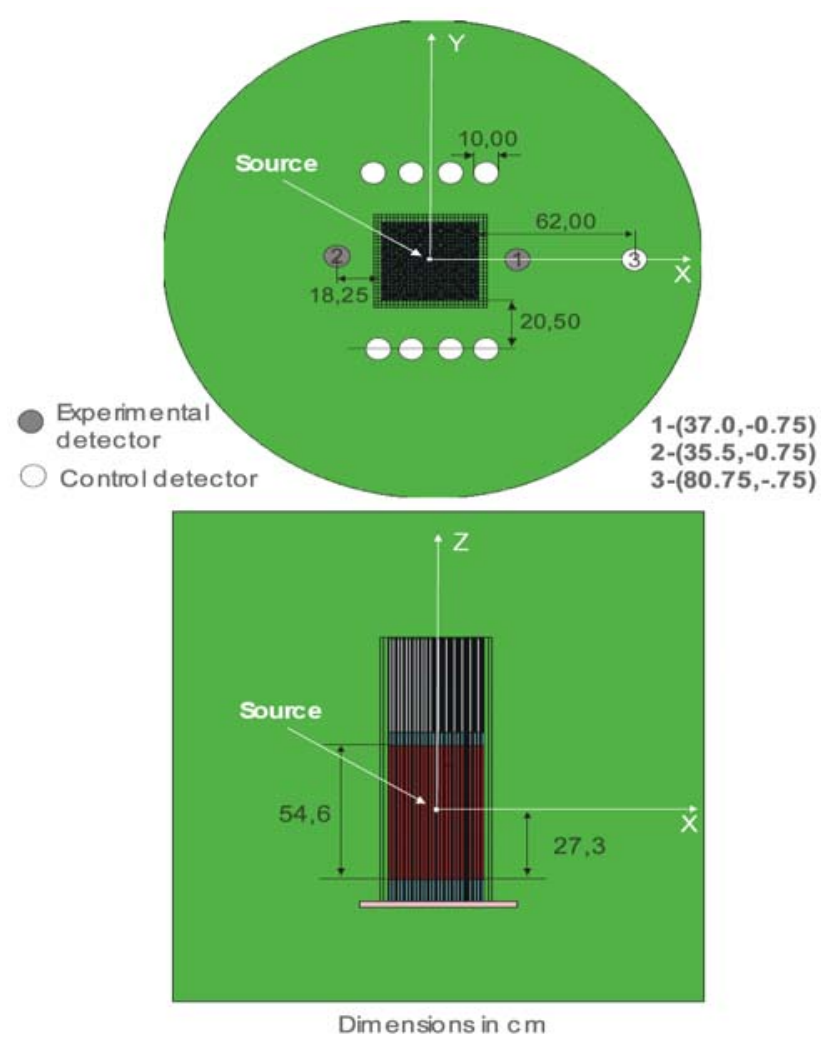

FIGURA 21 - Modelo do sistema e detectores onde os cálculos foram realizados.

Os dados nucleares (constantes de grupos) utilizados nos cálculos foram gerados utilizando-se da metodologia utilizada pelo grupo de pesquisa do IPEN que estuda dados nucleares. A metodologia empregada foi a mesma utilizada para reatores térmicos. A biblioteca de dados utilizada no cálculo dos parâmetros é a ENDF/B-VI. Esta metodologia está descrita no Anexo $\mathrm{C}$ desta dissertação. Inicialmente utilizou-se um espectro de ponderação de fissão, 1/E e térmico e posteriormente utilizou-se como espectro de ponderação da reação D-T, fissão, 1/E, térmico.

Os parâmetros foram calculados com o programa TORT (sistema geométrico em três dimensões) utilizando-se 16 e 34 grupos de energia; aproximação $\mathrm{P}_{3}$ e $\mathrm{S}_{16}$. A geometria do problema é mostrada na FIG. 22. Uma descrição do programa TORT é feita no Anexo B.2 deste trabalho. 


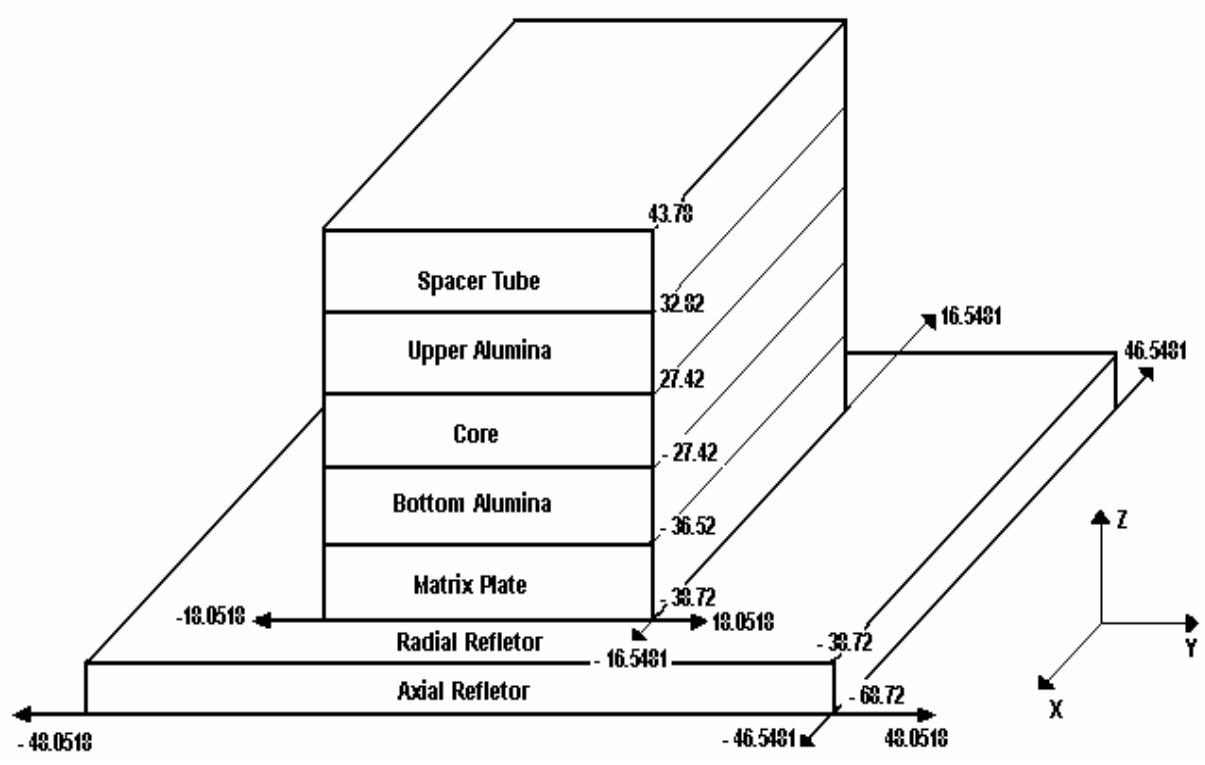

FIGURA 22 - Geometria do Reator IPEN/MB-01 usada no código TORT.

Para 16 grupos de energia a tabela 15 mostra alguns valores de parâmetros que foram calculados pelo programa TORT e comparados com o código Monte Carlo MCNP, que foi tomado como referência. Estes valores foram apresentados em um trabalho na "Internacional Nuclear Atlantic Conference" em Setembro de 2007. Para a obtenção do valor do fator de multiplicação de nêutrons de fonte $\left(k_{s}\right)$, o cálculo foi realizado manualmente utilizando a definição dada por Gandini, e com a função $u$ igual ao valor unitário.

TABELA 15 - Resultados de parâmetros utilizando o código TORT e comparado com o MCNP, 16 grupos de energia.

\begin{tabular}{|c|c|c|}
\hline & TORT & MCNP \\
\hline$k$ & 0,970004 & $0,9699 \pm 0,0001$ \\
\hline$k_{s}$ & 0,971786 & $0,9789 \pm 0,0002$ \\
\hline Fluxo no Detector $1\left[\mathrm{~cm}^{-2}\right]$ & $3,2934 \mathrm{E}-04$ & $3,55 \pm 0,03 \mathrm{E}-04$ \\
\hline Fluxo no Detector $2\left[\mathrm{~cm}^{-2}\right]$ & 6,1457 E-04 & $6,37 \pm 0,05 \mathrm{E}-04$ \\
\hline Fluxo no Detector 3 $\left[\mathrm{cm}^{-2}\right]$ & Fora do Modelo Geométrico & $8,6 \pm 0,8 \mathrm{E}-07$ \\
\hline
\end{tabular}

Verificou-se que o valor encontrado para o fator de multiplicação $(k)$ é muito próximo do valor encontrado pelo código MCNP, tomado como referência, assim como 
também com os valores encontrados por pesquisadores coreanos, argentinos e chineses [61], que calcularam o mesmo problema, pois estes também fazem parte do Projeto Coordenado de Pesquisa. Sabendo-se que o fator de multiplicação está relacionado à geometria e materiais do sistema, isto demonstra que a modelagem do problema está correta. Quando comparados os valores do fator de multiplicação de fonte, $k_{s}$, a diferença é muito maior que a do $k$, mesmo assim é um valor aceitável.

Calculou-se também o espectro de nêutrons em duas varetas combustível, (R14 e Y14). Estes espectros foram normalizados de tal forma que a soma em todos os grupos é um. Nas FIG. 23 e 24 percebe-se que quando comparado com o código MCNP, tomado como referência, nota-se uma pequena discrepância em alguns grupos de energia, e esta discrepância pode ser em parte creditada à estrutura de grupos, uma vez que possui apenas três grupos de energia acima de $1 \mathrm{MeV}$.

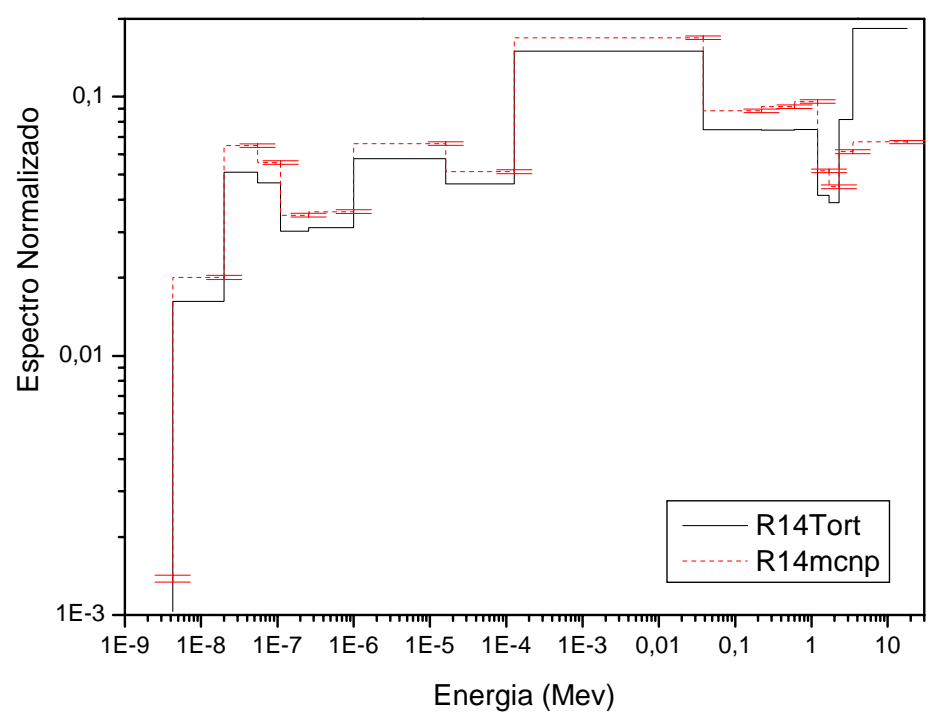

FIGURA 23 - Espectro da posição R14. 


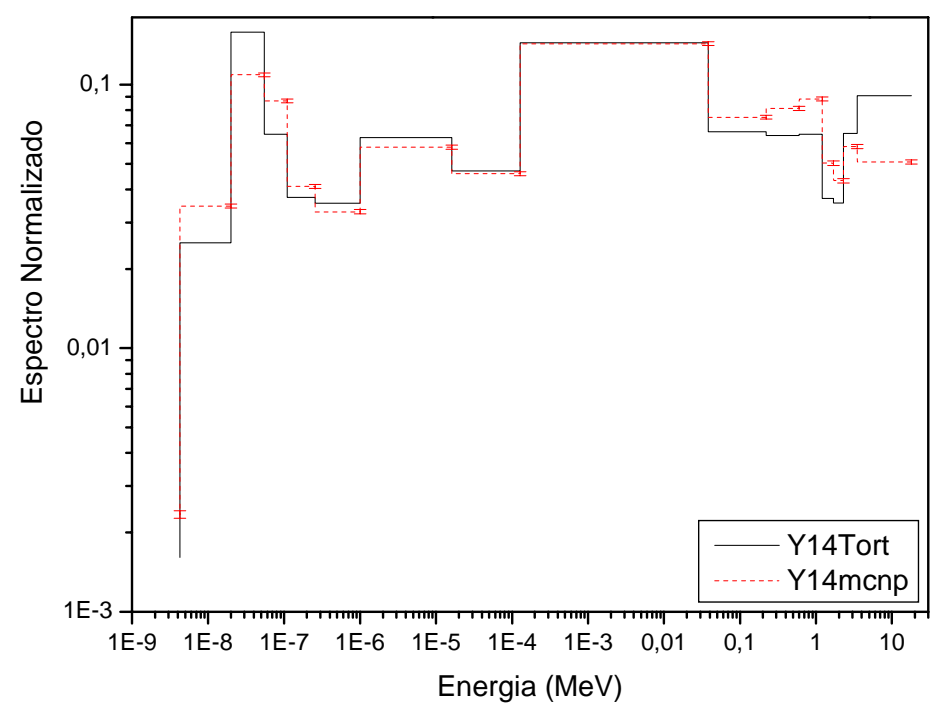

FIGURA 24 - Espectro da posição Y14.

O programa TORT também calculou em 16 grupos o fluxo de nêutrons em todos os intervalos geométricos. Nas FIG. 25 e 26 apresenta-se o fluxo para duas posições axiais no núcleo nas posições Y14 e R14. Estes dados estão comparados com a referência, MCNP. Os fluxos estão normalizados para o valor unitário.

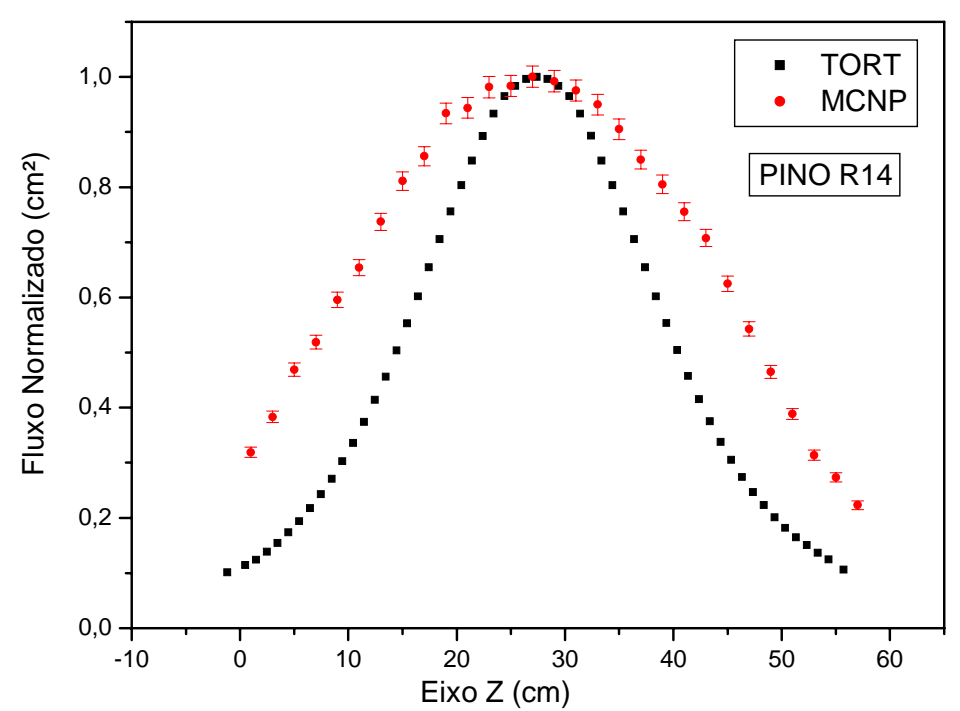

FIGURA 25 - Distribuição de fluxo na direção Z na posição R14. 


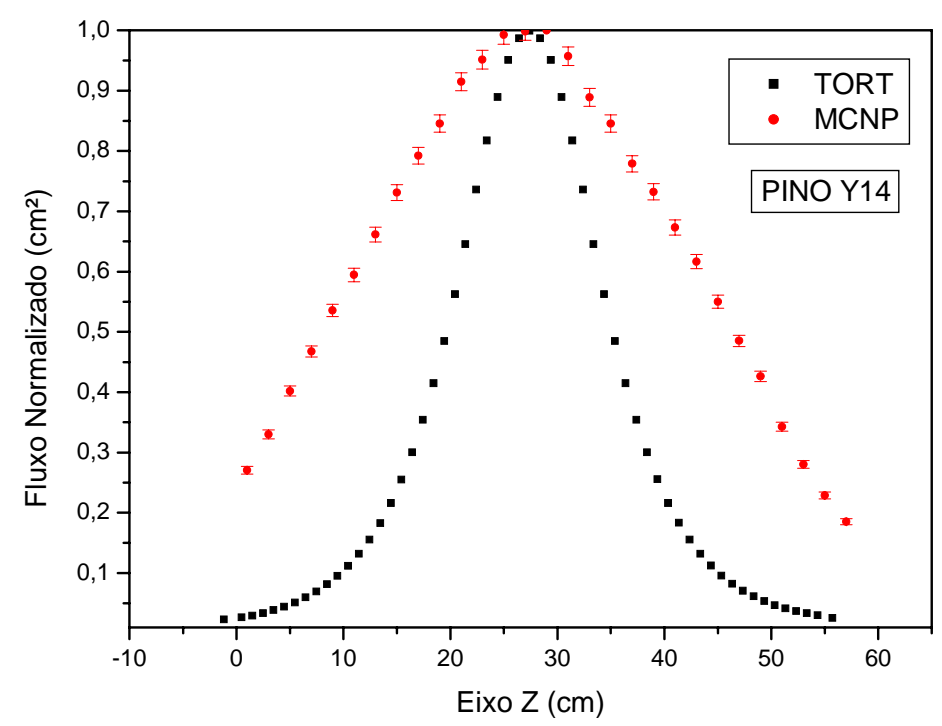

FIGURA 26 - Distribuição de fluxo na direção Z na posição Y14.

Quando comparados com o código MCNP, constata-se que há alguma discrepância na forma dos fluxos. Há várias razões pelas quais se pode tentar explicar estas discrepâncias, tais como: efeito raio, erro no código (pois o código não é mais o original e passou por várias alterações), erro na entrada de dados (a descrição do problema é muito difícil) ou então nas seções de choque que não levam em consideração, quando geradas, a fonte externa de nêutrons.

Pelos resultados acima se pode concluir que uma fonte de intensidade $10^{9}$ nêutrons $\mathrm{s}^{-1}$ irá produzir um fluxo de mesma ordem de magnitude que os experimentos conduzidos na instalação IPEN/MB-01.

Também foram realizados cálculos com uma estrutura com 34 grupos de energia com uma fonte de $14 \mathrm{MeV}$ (reação D-T) e com uma fonte de $2 \mathrm{MeV}$ (reação D-D) e espectro de ponderação da reação D-T, fissão, 1/E e térmico. Com a realização deste cálculo esperava-se que as discrepâncias encontradas nos cálculos realizados com 16 grupos de energia fossem minimizadas, pois se aumentou o número de grupos de energia. Os resultados, porém foram piores que os anteriores. Foram investigadas as causas de possíveis erros tais como na entrada de dados do código TORT, na geração das seções de choque, o efeito raio ou no próprio código. Não se chegou a nenhuma conclusão e as causas dos erros não puderam ser encontradas. 
Das FIG. 27 à 31 são mostrados os espectros de nêutrons para diferentes posições de varetas no núcleo combustível (N14, O11, P10, R8 e R14) com uma fonte de reação D-T, para a estrutura de 34 grupos de energia.

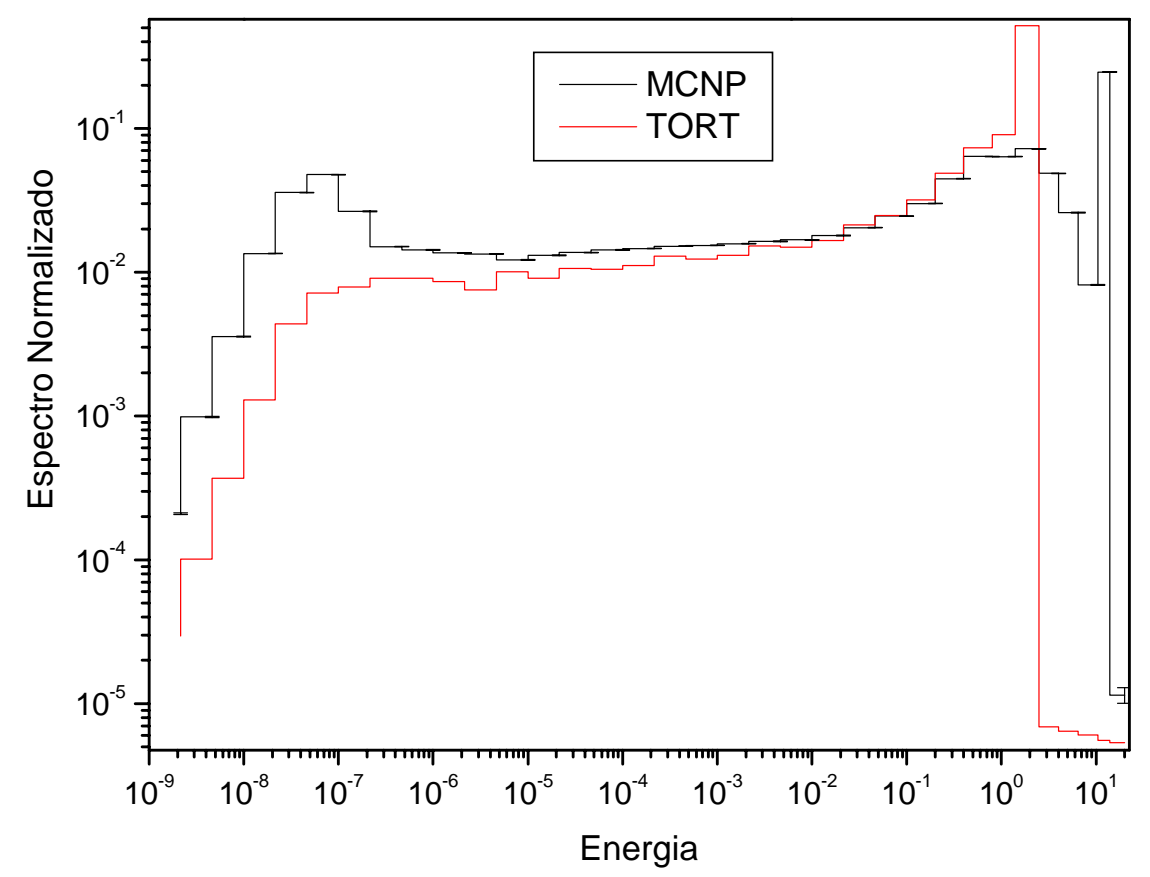

FIGURA 27 - Espectro normalizado da posição N14. 


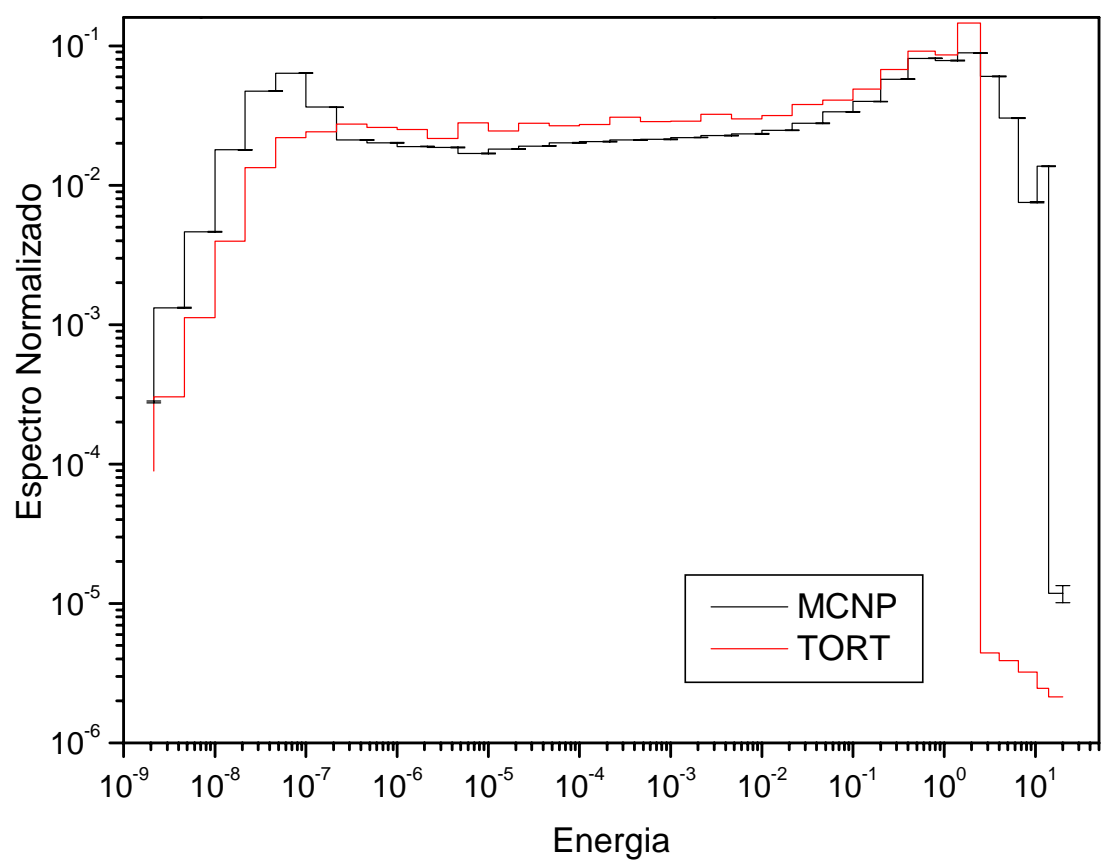

FIGURA 28 - Espectro normalizado da posição R14.

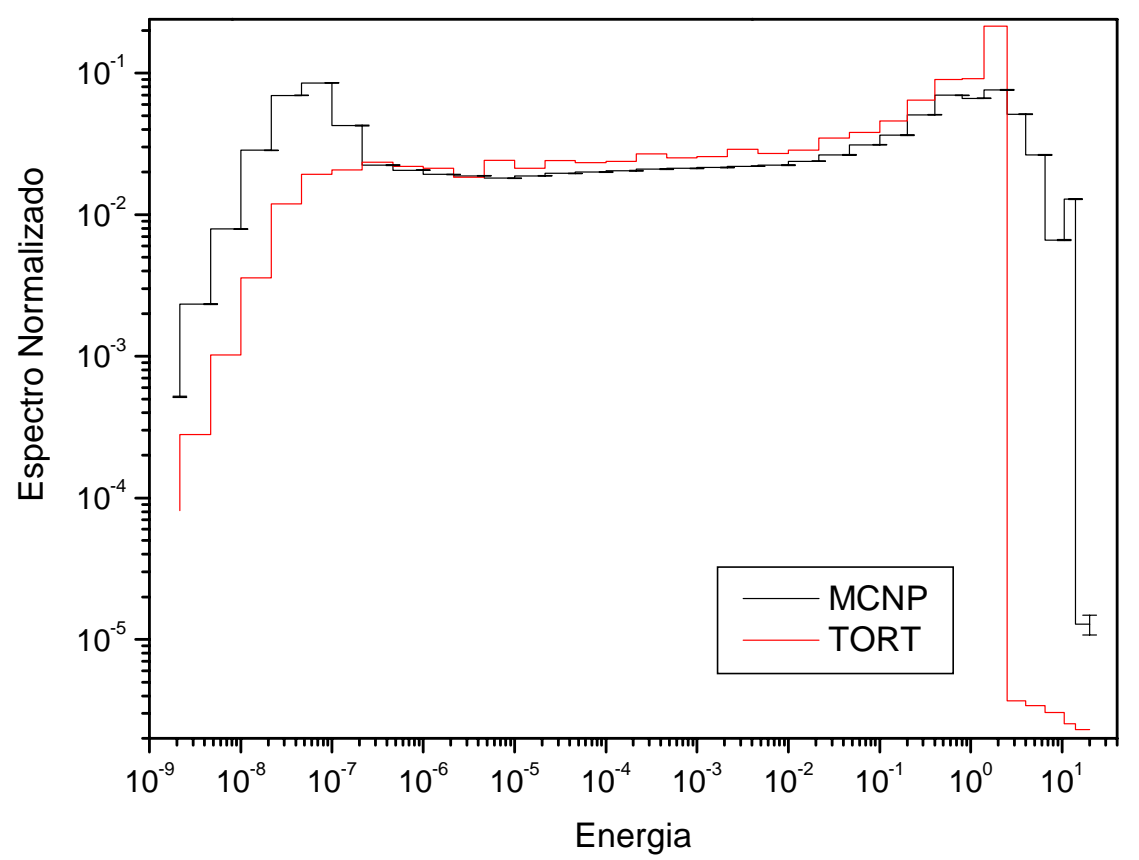

FIGURA 29 - Espectro normalizado da posição P10. 


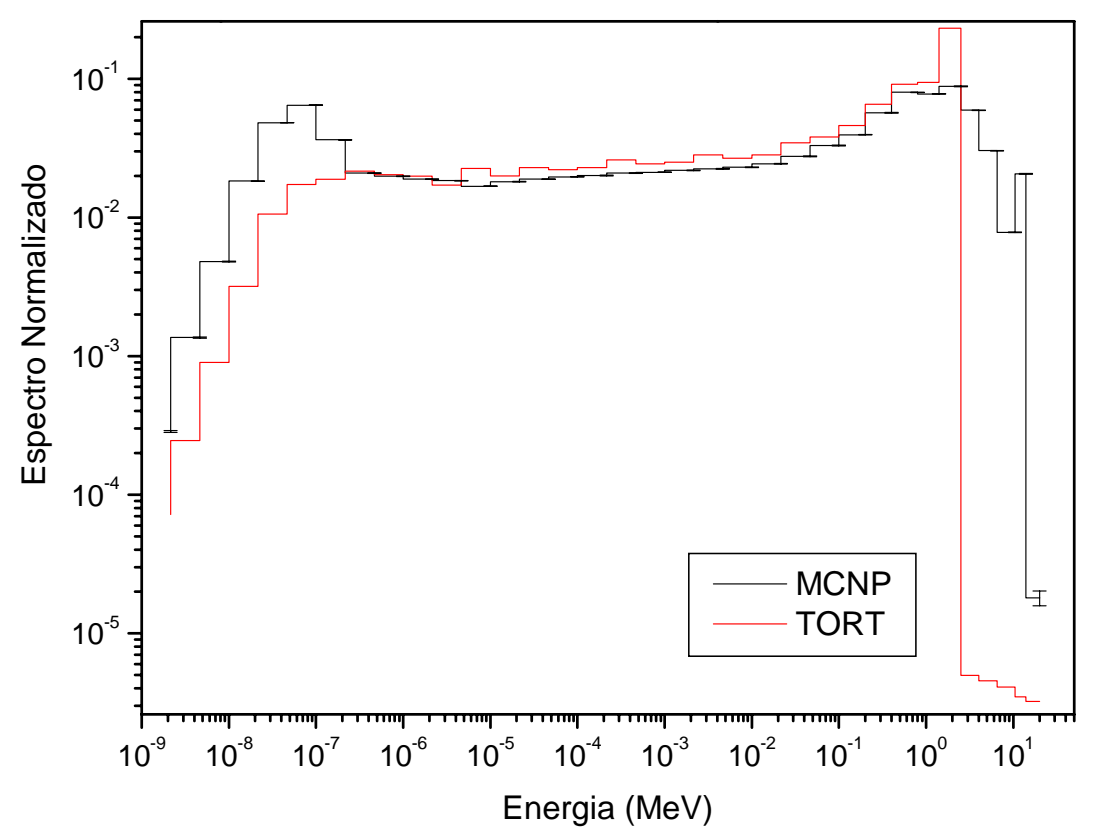

FIGURA 30 - Espectro normalizado da posição O11.

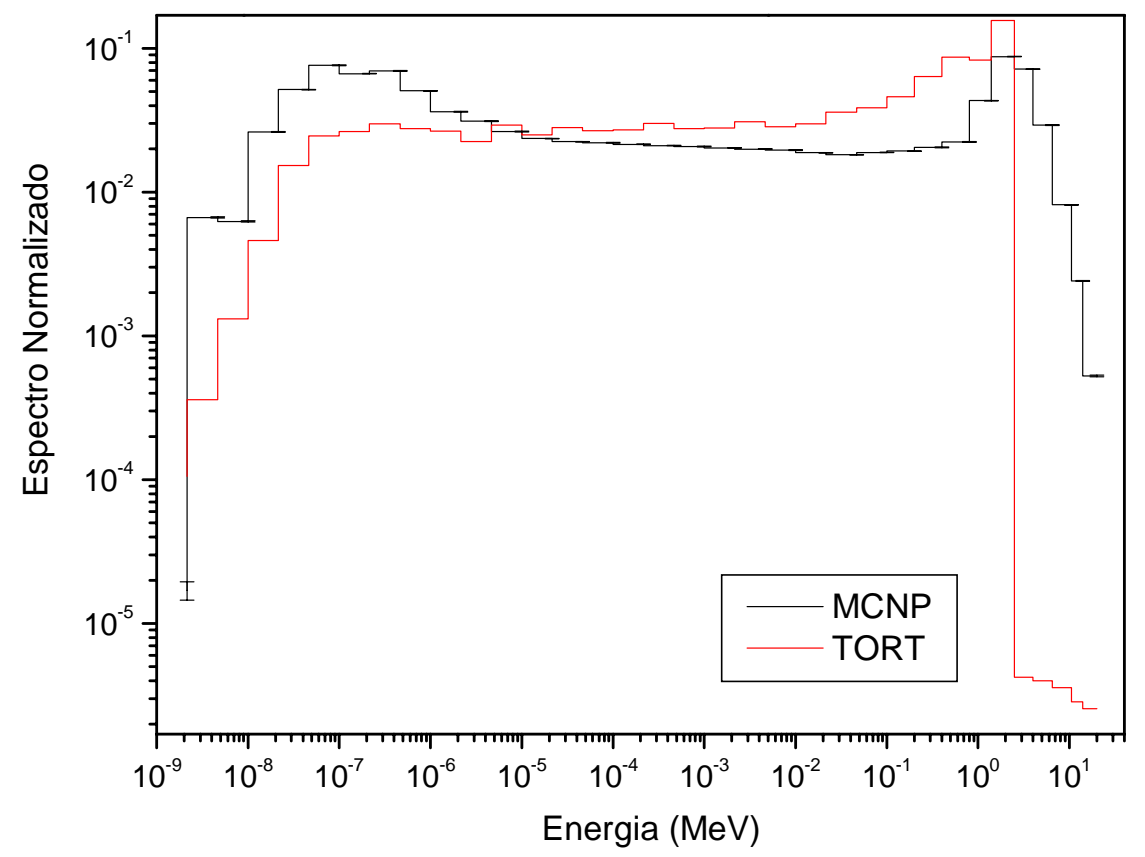

FIGURA 31 - Espectro normalizado da posição R8. 


\section{CONCLUSÕES}

No presente trabalho apresentou-se inicialmente um histórico dos sistemas acionados por fontes externas e verificou-se a importância de tais sistemas na atualidade, por poder ao mesmo tempo gerar energia e transmutar AM e PFLV, pois há um grande ganho de energia quando se tem o processo de "spallation". Verificou-se também que deve ser observada a relação ganho de energia "versus" transmutação nestes sistemas.

Atualmente em cálculos de sistemas acionados por fontes não há um consenso em relação à qual metodologia de cálculo usar. Por exemplo, nos cálculos realizados observou-se uma discrepância entre os valores encontrados utilizando-se as metodologias de Gandini e Salvatores e Dulla. Esta discrepância se deve ao fato principalmente da definição da integral de normalização ser definida diferente nas duas metodologias.

Pode-se verificar que é necessário escolher um modelo de cálculo adequado para calcular os parâmetros, pois o valor destes varia com o modelo adotado. Sabe-se que estes parâmetros variam com o grau de criticalidade.

Pode-se concluir também que uma nova metodologia de cálculo de constantes multigrupo deve ser utilizada nos cálculos de sistemas rápidos com fonte, pois a forma como as constantes multigrupo é gerada para sistemas com fontes é diferente do método clássico para sistemas críticos.

Também a consistência da chamada "point kinetics" para sistemas acionados por fontes e os chamados parâmetros cinéticos $(\rho, \beta, \Lambda)$ na região de subcriticalidade, discutidos por Dulla, Gandini e Salvatores, deixam claro que uma nova "point kinetics" deve ser usada na região de subcriticalidade e, principalmente o monitoramento da subcriticalidade deve ser revisto. A terminologia também deve ser revista. Não há consenso para usar na região de subcriticalidade termos como "reatividade", para a quantidade física (k-1)/k. Este termo deve ser chamado "desvio de criticalidade". A

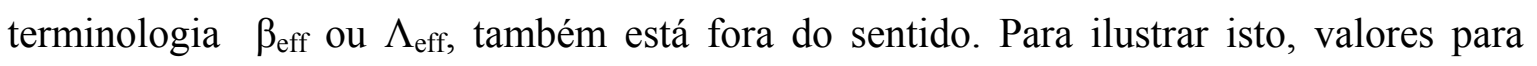
"reatividade" foram calculados pelo formalismo "source driven point kinetics" de Dulla e Gandini\&Salvatores e a forma clássica. 


\section{REFERÊNCIAS BIBLIOGRÁFICAS}

1. IAEA, Review of National Accelerator Driven System Programmes for Partitioning and Transmutation, IAEA TECDOC 1365, August 2003.

2. W. GUDOWSKI (Ed), Accelerator Driven Systems: Energy Generation and Transmutation of Nuclear Waste, Status Report, IAEA-TECDOC 985, IAEA Vienna, 1997.

3. S. TACZANOWSKI, Transmutation of Nuclear Waste in Accelerator-Driven Subcritical Systems, Applied Energy 75, pp 97-117, 2003.

4. W. GUDOWSKI, Accelerator-driven Transmutation Projects. The Importance of Nuclear Physics Research for Waste Transmutation, Nucl. Phys. A 654, 436-457, 1999.

5. J. R. MAIORINO, et al, Development of the CRISP Package for Spallation Studies and Accelerator-Driven Systems, Nuclear Science and Engineering, Volume 151, Number 1, September 2005, Pages 82-87, Technical Paper.

6. The European Technical Working Group on ADS, A European Roadmap for Developing Accelerator Driven System (ADS) for Nuclear Waste Incineration, April 2001.

7. C. D. BOWMAN, et al; Nuclear energy generation and waste transmutation using an accelerator - driven intense thermal neutron source, Nuclear Instruments and Methods in Physics Research A320 (1992) 336-367; North Holland.

8. S. ANDRIAMONJE et.al - Phys. Rev. Letters B348 (1995), 397-709.

9. P. D'HONDT, H. AÏT ABDERRAHIM, P. KUPSCHUS, E. MALAMBU, TH. AOUST, MYRRHA, a Multipurpose Accelerator Driven System for Research and Development. Pre-design phase completion, CAARI 2002: Seventeenth International Conference on the Application of Accelerators in Research and Industry, Denton, Texas, USA, November 12-16, 2002.

10. IAEA, Coordinated Research Project (CRP), on Analytical and Experimental Benchmark Analysis of Accelerator Driven Systems. (CRP) número 5380.170.3505..D20030231.ADS2007741293.

11. S. PILLON, J. WALLENIUS Oxide and nitride TRU-fuels: lessons drawn from the CONFIRM and FUTURE projects of the $5^{\text {th }}$ European framework programme, submitted to Nuclear Science and Engineering. ATALANTE 2004 conference, June 21-24 2004, Nimes, France.

12. C. FAZIO, R. STIEGLITZ, et al The MEGAPIE - TEST Project, Proceedings of the International Workshop on P\&T and ADS development, SCK $\cdot C E N C l u b-H o u s e$, Belgium, October 6-8, 2003.

13. O report final destes projetos pode ser encontrado na página $<\mathrm{http} / / /$ www.cordis.lu/fp5-euratom/src/lib_finalreports.htm>. Acesso em $01 \mathrm{de}$ dez. 2008. 
14. Preliminary Design Study of an Experimental Accelerator Driven System (PDSXADS). EC Contract Number FIKW - CT - 2001 - 00179. Framatome report PDSXADSDoc05/378,July2005.Disponível em $\quad<$ http://www.cordis.lu/fp5uratom/src/lib.fainalreports.htm>. Acesso em 25 nov. 2008.

15. Thematic Network on Advanced Options for Partitioning and Transmutation (ADOPT). EC Contract Number FIKW - CT - 2001 - 20179. Editor H. A. Abderrahim, October 13, 2005.

16. T. MUKAIYAMA, et al., Review of Research and Development of Accelerator-Driven System in Japan for Transmutation of Long-Lived Nuclides, Progress in Nuclear Energy, 38, 107 (2001).

17. J. R. MAIORINO et al, The utilization of a compact neutron generator to drive a subcritical core of the IPEN/MB-01 facility for reactor physics experiments, Meeting/Workshop on Low Enriched (LEU) Fuel Utilization in Accelerator Driven Subcritical Assembly System(ADS), IAEA, Vienna, 06-09 November, (2006).

18. ROSSI, P. C. R. ; MAIORINO, J. R. The utilization of MCNPX 2.5 for ADS target calculation; International Nuclear Atlantic Conference-INAC, 2007, Santos. 2007 INAC- International Nuclear Atlantic Conference. Rio de Janeiro: Associação Brasileira de Energia Nuclear, 2007. p. 1-6.

19. CARLUCCIO, T.; MAIORINO, J. R.; On The Solution of the Transmutation and Decay Chain Equations for Incineration of TRU Using an ADS (Th/U)-The case of Brazil. Revista Brasileira de Pesquisa e Desenvolvimento, 2006.

20. R.E. PRAEL AND H. LICHTENSTEIN. LA-Ur-89-3014, Los Alamos National Laboratory (1989).

21. A. FASSO et al., FLUKA: Status and Prospective for Hadronic Applications, Proceedings of the Monte Carlo 2000 Conference, Lisbon, October 23-26 2000, A. Kling, F. Barao, M. Nakagawa, L. Tavora, P. Vaz - eds., Springer-Verlag Berlim, p955-960 (2001).

22. EA-MC Neutronic Calculations on IAEA ADS Benchmark 3.2. TSL/ISV Report Series, TSL/ISV-2006(2006): no. 296

23. G. RIMPAULT et al. The ERANOS Code ans Data System for Fast Reactor Neutronic Analyses, Proc. Int. Conf. PHYSOR 2002, Seoul, Korea, October 7-10, 2002.

24. MACFARLANE, R. E.; MUIR, D.; BUICORT, R. M.; The NJOY Nuclear Data Processing System, Report LA-9303-M, Vol. I, 1982.

25. J.-CH. SUBLET, P.RIBON, CALENDF-2001, Int. Conf. On Nuclear Data for Science and Technology, Tsukuba, Japan, Oct. 7-12, 2001 (2001)

26. G. PALMIOTTI, J. M. RIEUNIER, C. GHO, M. SALVATORES, BISTRO Optimized Two Dimensional Sn Transport Code, Nucl. Sci. Eng., 104, 26 (1990).

27. SCALE: A Modular Code System for Performing Standardized Computer Analyses for Licensing Evaluations, ORNL/TM-2005/39, Version 5.1, Vols. I-III, November 2006. Available from Radiation Safety Information Computational Center at Oak Ridge National Laboratory as CCC-732.

28. W.A. RHOADES, The TORT Three-dimensional Discrete Ordinates Neutron/Photon Transport Code, ORNL-6268 (1987). 
29. G. MARLEAU, R.ROY AND A. H'EBERT, The DRAGON Code, DRAGON workshop at PHYSOR-2006, disponível em $<$ http://www.polymtl.ca/nucleaire/DRAGON/en/index.php $>$. Acesso em: 30 nov. 2008 .

30. A.G. CROFF, J.O. BLOMEKE, and B.C. FINNEY, ORNL-5566 (1980).

31. KINJI KOYAMA, NAOKI YAMANO, SHUN-ICH MIYASAKA, TOKAIMURA, IBARAKI-KEN Atomic Energy Research Institute, Japan, 11-JUN-1982

32. M.J. BELL: ORIGEN - The ORNL Isotope Generation and Depletion Code ORNL4628 (1973).

33. J. CETNAR, W. GUDOWSKI AND J. WALLENIUS, MCB: A continuous energy Monte Carlo Burnup simulation code, In "Actinide and Fission Product Partitioning and Transmutation", EUR 18898 EN, OECD/NEA (1999) 523.

34. MCNP - A General Monte Carlo N-Particle Transport Code - Version 5.1.40 (RSICCC00730MNYCP00).

35. E. FORT, W. ASSAL, G. RIMPAULT, J. ROWLANDS, P. SMITH, R. SOULE Realization and Performance of the Adjusted Nuclear Data Library ERALIB1 for Calculating Fast Reactors Neutronics, PHYSOR'96, Sept 16-20 1999, MITO, Japan.

36. J.Y. DORIATH, C.W. McCALLIAN, E. KIEFHABER, U. WEHMAN, "ERANOS1: The Advances European System of Codes for Reactor Physics Calculations", International Conference on Mathematical Methods, Karlsruhe, GERMANY, 1993.

37. M. SALVATORES et al., Experimental Investigation Multiplying subcritical media in presence of an external source operating in pulsed or continuous mode: the MUSE-3 Experiment.

38. OECD/NEA Report 17, The JEF-2.2 Nuclear Data Library, April 2000.

39. H. HENRYSON, II, B.J. TOPPEL, C.G. STENBERG, MC2-2: A Code to Calculate Fast Neutron Spectra and Multigroup Cross-Sections, ANL-8144, June 1976.

40. G. PALMIOTTI, C.B. CARRICO and E.E. LEWIS, Variatonal Nodal Transport Methods with Anisotropic Scattering, Nucl. Sc. Eng., 115, p.233 (1993).

41. A. RINEISKI, W. MASCHEK, G. RIMPAULT, Performance of Neutron Kinetics Models for ADS Transient Analyses, AccAPP/ADTTA'01, ANS 2001 Winter Meeting November 11-15, 2001, Reno, Nevada,U.S.A.

42. C. RUBBIA et al, The TRADE Experiment: Status of the Projetct and Physics of the Spallation Target, PHYSOR-2004, The Physics of Fuel Cycles and Advanced Nuclear Systems: Global Developments, Chicago, Illinois, April 25-29, 2004, on CDROM, American Nuclear Society, Lagrange Park, IL (2004).

43. Nuclear Energy Agency, Calculations of Diferente Transmutation Concepts - An International Benchmark Exercise, NEA Nuclear Science Committee, February 2000.

44. J. R. MAIORINO et al, The Participation of IPEN in the IAEA Coordinated Research Projects on Accelerator Driven Systems (ADS), International Nuclear Atlantic Conference - INAC, Santos, SP, Brazil, (September 2007). 
45. J.R. MAIORINO, Computer Code ANISN Multiplying Media and Shielding Calculation, in Reactor Physics Calculation for Application in Nuclear Technology, Word Scientific Publishing Co. Pte. Ltd., 442-561, 1991.

46. CLARK, M. JR; HANSEN, KENT F. Numerical Methods of Reactor Analysis, Academic Press, Inc. (London), 1964.

47. DUDERSTADT, J.J., MARTIN, W.R. (1975), Transport Theory, Wiley, New York, NY.

48. E. E. LEWIS \& W. F. MILLER Jr., Computational Methods of Neutron Transport, John Wiley \& Son New York, 1984, 401 pp. (Republished by Am. Nucl. Soc. 1993).

49. K. D. LATHROP, Spatial Differencing of the Transport Equation: Positivity vs. Accuracy, J. Comput. Phys, 4, 475 (1969).

50. G.C. WICK, Ubeer Ebene Difusion Problem, Physic 121, 702 (1943).

51. S. CHANDRASEKKAR, Radiative Transfer, Oxford University Press, London, England, (1950), Reprinted by Dover Publications, N.Y. (1960).

52. A. GANDINI, M. SALVATORES, The Physics of Subcritical Multiplying Systems", Journal of Nuclear Science and Technology, 39, No. 6, pp-673-686 (2002).

53. S. DULLA et al, Kinetic Parameters for Source Driven Systems, PHYSOR-2006, NS Topical Meeting on Reactor Physics Organized and hosted by the Canadian Nuclear Society. Vancouver, BC, Canada, September 10-14, 2006.

54. A. GANDINI, Ann. Nucl. Energy, 24, 1241 (1997), also: IAEA-TC-903.3, p. 377 [Proc. Madrid Conf. on ADS, 1997].

55. Specification of the Yalina Booster Benchmark within the IAEA CRP, Analytical and Experimental Benchmark Analisys on Accelerator Driven Systems, , Phase I, Joint Institute for Power and Nuclear Reserch - Belarus; Departament of Nuclear and Reactor Pahysics, Royal Insitute of Technology, Sweden; Argonne National Laboratory, USA.

56. S. DULLA, et al, Joint International Topical Meeting on Mathematics \& Computation and Supercomputing in Nuclear Applications (M\&C + SNA 2007) Monterey, California, April 15-19, 2007, on CD-ROM, American Nuclear Society, LaGrange Park, IL (2007).

57. BELL, G. I; GLASSTONE, S, Nuclear Reactor Theory, New York, Van Nostrand Reinhold, 1970.

58. SEUNG MIN LEE, “Um Estudo sobre Métodos de Cálculo e Medidas Experimentais de Parâmetros cinéticos em sistemas subcríticos acionados por fontes", seminário de área, apresentado em 31/10/2008.

59. U.BITELLI et al, Experimental Utilization of the IPEN/MB-01, Proceedings of 9th Meeting of the International Group on Research Reactor, 24-28 March, Sydney, Australia, (2003).

60. A. SANTOS et al, LEU-COMP-THERM-090, NEA/NSC/DOC (95)03/IV, V. IV, (2006).

61. J.R. MAIORINO, IAEA Collaborative Work on utilization of LEU in ADS, Report on the sub critical core of the IPEN/MB-01 driven by a neutron generator within the IAEA sub CRP on Low Enrichment Uranium(LEU) Fuel Utilization in Accelerator 
Driven Sub Critical Assembly System(ADS). (CRP) número 5380.170.3505..D20030231.ADS2007741293.

62. A. DOS SANTOS, A. ABE, A. G. MENDONÇA, G. S. ALMEIDA, L. C. C. B. FANNARO, Criticality Analyses Based on the Coupled NJOY/AMPX-II/TORT, ANS International Topical Meeting on Advances in Reactor Physics and Mathematics and Computation into the Next Millennium, Pittsburgh, USA, (2000).

63. GREENE, N. M.; et al; AMPX-II A Modular Code System for Generation Coupled Multigroup Neutron-Gamma Libraries from ENDF/B, ORNL-TM-3706, 1976.

64. SANTOS, A.; AMPX e BRDROL Interfaces NJOY para AMPX-II, Relatório Interno IPEN/COPESP, 1988.

65. RHOADES, W. A.; The GIP Program for Preparation of Group Organized Cross Section Libraries, ORNL, 1975. 
ANEXO A - CONSTANTES MULTIGRUPO UTILIZADAS NOS CÁLCULOS DE PARÂMETROS FÍSICOS E ESTRUTURAS DE GRUPOS DE ENERGIA

\section{A.1 - Uma região e um Grupo de Energia}

\begin{tabular}{|l|l|}
\hline $1 / V_{g}$ & \\
\hline$\Sigma_{t, g}$ & $3,45987 \mathrm{E}-01$ \\
\hline$\Sigma_{a, g}$ & $1,58430 \mathrm{E}-02$ \\
\hline$v \Sigma_{f, g}$ & $3,33029 \mathrm{E}-02$ \\
\hline$\Sigma_{g \rightarrow g}$ & $3,30178 \mathrm{E}-01$ \\
\hline
\end{tabular}

\section{A.2 - Uma região e três grupos de energia}

\begin{tabular}{|c|c|c|c|c|}
\hline & & $g=1$ & $g=2$ & $g=3$ \\
\hline $1 / V_{g}$ & {$\left[\mathrm{~s} \mathrm{~cm}^{-1}\right]$} & $5,35994 \mathrm{E}-8$ & $1,47756 \mathrm{E}-4$ & $1,33310 \mathrm{E}-6$ \\
\hline$\Sigma_{t, g}$ & {$\left[\mathrm{~cm}^{-1}\right]$} & $2,83110 \mathrm{E}-1$ & $3,65360 \mathrm{E}-1$ & $6,65500 \mathrm{E}-1$ \\
\hline$\Sigma_{a, g}$ & {$\left[\mathrm{~cm}^{-1}\right]$} & $1,40280 \mathrm{E}-2$ & $1,63760 \mathrm{E}-2$ & $6,98540 \mathrm{E}-2$ \\
\hline$\Sigma_{f, g}$ & {$\left[\mathrm{~cm}^{-1}\right]$} & $3,45310 \mathrm{E}-2$ & $3,2869 \mathrm{E}-2$ & $1,2002 \mathrm{E}-1$ \\
\hline$\chi_{g}$ & - & 0,7112 & 0,2886 & 0,0002 \\
\hline$\Sigma_{g \rightarrow g}$ & {$\left[\mathrm{~cm}^{-1}\right]$} & $2,36040 \mathrm{E}-1$ & $3,48954 \mathrm{E}-1$ & $5,95640 \mathrm{E}-1$ \\
\hline$\Sigma_{g \rightarrow g+1}$ & {$\left[\mathrm{~cm}^{-1}\right]$} & $3,31803 \mathrm{E}-2$ & $3,45000 \mathrm{E}-5$ & - \\
\hline$\Sigma_{g \rightarrow g+2}$ & {$\left[\mathrm{~cm}^{-1}\right]$} & $1,16620 \mathrm{E}-5$ & - & - \\
\hline
\end{tabular}




\section{A.3- Três regiões e três grupos de energia}

\begin{tabular}{|c|c|c|c|c|}
\hline \multicolumn{5}{|c|}{ Região 1-Alvo de Chumbo } \\
\hline & & $g=1$ & $g=2$ & $g=3$ \\
\hline $1 / V_{g}$ & {$\left[\mathrm{~s} \mathrm{~cm}^{-1}\right]$} & $5,38483 \mathrm{E}-8$ & $1,481090 \mathrm{E}-4$ & $1,33362 \mathrm{E}-6$ \\
\hline$\Sigma_{t, g}$ & {$\left[\mathrm{~cm}^{-1}\right]$} & $3,13317 \mathrm{E}-1$ & $3,76114 \mathrm{E}-1$ & $5,674691 \mathrm{E}-1$ \\
\hline$\Sigma_{a, g}$ & {$\left[\mathrm{~cm}^{-1}\right]$} & $1,79248 \mathrm{E}-4$ & $2,07856 \mathrm{E}-4$ & $9,5700 \mathrm{E}-4$ \\
\hline$v \sum_{f, g}$ & {$\left[\mathrm{~cm}^{-1}\right]$} & 0 & 0 & 0 \\
\hline$\chi_{g}$ & - & 0 & 0 & 0 \\
\hline$\Sigma_{g \rightarrow g}$ & {$\left[\mathrm{~cm}^{-1}\right]$} & $2,91848 \mathrm{E}-1$ & $3,75885 \mathrm{E}-1$ & $5,66512 \mathrm{E}-1$ \\
\hline$\Sigma_{g \rightarrow g+1}$ & {$\left[\mathrm{~cm}^{-1}\right]$} & $2,14326 \mathrm{E}-2$ & $2,05055 \mathrm{E}-5$ & - \\
\hline$\Sigma_{g \rightarrow g+2}$ & {$\left[\mathrm{~cm}^{-1}\right]$} & $3,41905 \mathrm{E}-6$ & - & - \\
\hline
\end{tabular}

\begin{tabular}{|c|c|c|c|c|}
\hline \multicolumn{5}{|c|}{ Região 2-U90\% } \\
\hline $1 / V_{g}$ & {$\left[\mathrm{~s} \mathrm{~cm}^{-1}\right]$} & $g=1$ & $g=2$ & $g=3$ \\
\hline$\Sigma_{t, g}$ & {$\left[\mathrm{~cm}^{-1}\right]$} & $2,85146 \mathrm{E}-1$ & $3,5648055 \mathrm{E}-1$ & $6,61038327 \mathrm{E}-1$ \\
\hline$\Sigma_{a, g}$ & {$\left[\mathrm{~cm}^{-1}\right]$} & $1,40696 \mathrm{E}-2$ & $1,61000 \mathrm{E}-2$ & $7,26000 \mathrm{E}-2$ \\
\hline$v \sum_{f, g}$ & {$\left[\mathrm{~cm}^{-1}\right]$} & $3,49481 \mathrm{E}-2$ & $3,26000 \mathrm{E}-2$ & $1,235751 \mathrm{E}-1$ \\
\hline$\chi_{g}$ & - & $7,11187 \mathrm{E}-1$ & $2,89000 \mathrm{E}-1$ & $1,38000 \mathrm{E}-4$ \\
\hline$\Sigma_{g \rightarrow g}$ & {$\left[\mathrm{~cm}^{-1}\right]$} & $2,39006 \mathrm{E}-1$ & $3,40318 \mathrm{E}-1$ & $5,88446 \mathrm{E}-1$ \\
\hline$\Sigma_{g \rightarrow g+1}$ & {$\left[\mathrm{~cm}^{-1}\right]$} & $3,22140 \mathrm{E}-2$ & $5,27662 \mathrm{E}-5$ & - \\
\hline$\Sigma_{g \rightarrow g+2}$ & {$\left[\mathrm{~cm}^{-1}\right]$} & $1,16000 \mathrm{E}-5$ & & \\
\hline
\end{tabular}




\begin{tabular}{|c|c|c|c|c|}
\hline \multicolumn{5}{|c|}{ Região 3 - U36\% } \\
\hline $1 / V_{g}$ & {$\left[\mathrm{~s} \mathrm{~cm}^{-1}\right]$} & $g=1$ & $g=2$ & $g=3$ \\
\hline$\Sigma_{t, g}$ & {$\left[\mathrm{~cm}^{-1}\right]$} & $2,84622 \mathrm{E}-1$ & $3,55728 \mathrm{E}-1$ & $5,378363 \mathrm{E}-1$ \\
\hline$\Sigma_{a, g}$ & {$\left[\mathrm{~cm}^{-1}\right]$} & $2,32334 \mathrm{E}-3$ & $1,98275 \mathrm{E}-3$ & $9,87283 \mathrm{E}-3$ \\
\hline$v \Sigma_{f, g}$ & {$\left[\mathrm{~cm}^{-1}\right]$} & $5,06234 \mathrm{E}-3$ & $3,14277 \mathrm{E}-3$ & $1,20282 \mathrm{E}-2$ \\
\hline$\chi_{g}$ & - & $7,10308 \mathrm{E}-1$ & $2,89552 \mathrm{E}-1$ & $1,40109 \mathrm{E}-4$ \\
\hline$\Sigma_{g \rightarrow g}$ & {$\left[\mathrm{~cm}^{-1}\right]$} & $2,56922 \mathrm{E}-1$ & $3,53704 \mathrm{E}-1$ & $5,68490 \mathrm{E}-1$ \\
\hline$\Sigma_{g \rightarrow g+1}$ & {$\left[\mathrm{~cm}^{-1}\right]$} & $2,54281 \mathrm{E}-2$ & $4,09735 \mathrm{E}-5$ & - \\
\hline$\Sigma_{g \rightarrow g+2}$ & {$\left[\mathrm{~cm}^{-1}\right]$} & $3,73570 \mathrm{E}-67$ & - & - \\
\hline
\end{tabular}

\section{A.4 - Estrutura de Grupos de Energia : 16 grupos}

\begin{tabular}{|c|c|}
\hline Grupo & Energia \\
\hline 1 & $1,80 \mathrm{E}+07$ \\
\hline 2 & $3,50 \mathrm{E}+06$ \\
\hline 3 & $2,30 \mathrm{E}+06$ \\
\hline 4 & $1,70 \mathrm{E}+05$ \\
\hline 5 & $1,20 \mathrm{E}+05$ \\
\hline 6 & $6,00 \mathrm{E}+05$ \\
\hline 7 & $2,20 \mathrm{E}+05$ \\
\hline 8 & $3,80 \mathrm{E}+04$ \\
\hline 9 & $3,80 \mathrm{E}+04$ \\
\hline 10 & $1,28 \mathrm{E}+02$ \\
\hline 11 & $1,60 \mathrm{E}+01$ \\
\hline 12 & $1,00 \mathrm{E}+00$ \\
\hline 13 & $2,55 \mathrm{E}-01$ \\
\hline 14 & $5,50 \mathrm{E}-02$ \\
\hline 15 & $2,00 \mathrm{E}-02$ \\
\hline 16 & $4,25 \mathrm{E}-03$ \\
\hline
\end{tabular}


A.5 - Estrutura de Grupos de Energia: 34 grupos

\begin{tabular}{|c|c|c|c|}
\hline Grupo & Energia & Grupo & Energia \\
\hline 1 & $1,80 \mathrm{E}+07$ & 18 & $4,75 \mathrm{E}+02$ \\
\hline 2 & $1,40 \mathrm{E}+07$ & 19 & $2,10 \mathrm{E}+02$ \\
\hline 3 & $1,05 \mathrm{E}+07$ & 20 & $1,00 \mathrm{E}+02$ \\
\hline 4 & $6,50 \mathrm{E}+06$ & 21 & $4,75 \mathrm{E}+01$ \\
\hline 5 & $4,00 \mathrm{E}+06$ & 22 & $2,10 \mathrm{E}+01$ \\
\hline 6 & $2,50 \mathrm{E}+06$ & 23 & $1,00 \mathrm{E}+01$ \\
\hline 7 & $1,40 \mathrm{E}+06$ & 24 & $2,10 \mathrm{E}+00$ \\
\hline 8 & $8,00 \mathrm{E}+05$ & 25 & $1,00 \mathrm{E}+00$ \\
\hline 9 & $4,00 \mathrm{E}+05$ & 26 & $4,75 \mathrm{E}-01$ \\
\hline 10 & $2,00 \mathrm{E}+05$ & 27 & $2,10 \mathrm{E}-01$ \\
\hline 11 & $1,00 \mathrm{E}+05$ & 28 & $1,00 \mathrm{E}-01$ \\
\hline 12 & $4,75 \mathrm{E}+04$ & 29 & $4,75 \mathrm{E}-02$ \\
\hline 13 & $2,10 \mathrm{E}+04$ & 30 & $2,10 \mathrm{E}-02$ \\
\hline 14 & $1,00 \mathrm{E}+04$ & 31 & $1,00 \mathrm{E}-02$ \\
\hline 15 & $4,75 \mathrm{E}+03$ & 32 & $2,10 \mathrm{E}-03$ \\
\hline 16 & $2,10 \mathrm{E}+03$ & 33 & \\
\hline 17 & $1,00 \mathrm{E}+03$ & 34 & \\
\hline
\end{tabular}




\section{ANEXO B - CÓDIGOS NUCLEARES S ${ }_{\mathrm{N}}$ ANISN e TORT}

\section{B.1 Código ANISN}

O código ANISN é um programa computacional escrito em linguagem FORTRAN-IV que resolve a equação de transporte de Boltzmann com espalhamento anisotrópico em uma dimensão, para nêutrons ou raios gamas em geometria plana, esférica ou cilíndrica. As fontes de partículas podem ser fixas, de fissão ou uma combinação das duas. Pesquisas de criticalidade podem ser realizadas em qualquer um dos diversos parâmetros. Podem-se ponderar as seções de choque utilizando-se os fluxos de partículas dependentes do espaço e da energia, gerados na solução da equação de transporte. A técnica de solução do código é o método de Ordenadas Discretas para a variável angular, de Multigrupo para a variável energia e de Diferenças Finitas para a variável espacial.

A forma conservativa da equação de transporte linear monoenergética em geometria unidimensional para geometrias planas, cilíndricas e esféricas, que são utilizadas no código ANISN, são apresentadas a seguir.

(a) Geometria plana: $(\mathrm{x}, \mu)$

$\mu \frac{\partial}{\partial x} \Phi(x, \mu)+\Sigma(x) \Phi(x, \mu)=\sum_{l=0}^{L} \frac{2 l+1}{2} \Sigma_{s}^{(l)}(x) P_{l}(\mu) \int_{-1}^{1} \Phi\left(x, \mu^{\prime}\right) P_{l}\left(\mu^{\prime}\right) d \mu^{\prime}+S(x, \mu)$,

onde $S(x, \mu)$ é a fonte externa fixa mais fissão e $L$ representa a ordem de espalhamento.

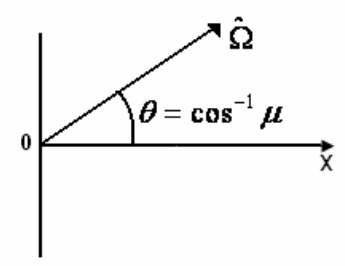

FIGURA 32: Geometria Plana. 
(b) Geometria Cilíndrica: $(r, \mu, \chi)$

$$
\begin{aligned}
& \sqrt{1-\mu^{2}} \cos \chi \frac{\partial}{\partial r} \Phi-\frac{\sqrt{1-\mu^{2}}}{r} \sin \chi \frac{\partial}{\partial x} \Phi+\Sigma \Phi= \\
& \sum_{l=0}^{L} \frac{2 l+1}{2} \Sigma_{s}^{(l)}(r) P_{l}(\mu) \int_{-1}^{1} d \mu \int_{0}^{2 \pi} d \chi \Phi\left(r, \mu^{\prime}, \chi^{\prime}\right) P_{l}\left(\mu^{\prime}\right) d \mu^{\prime}+S(r, \mu, \chi)
\end{aligned}
$$

(c) Geometria Esférica: $(r, \mu)$

$$
\begin{aligned}
& \frac{\mu}{r^{2}} \frac{\partial}{\partial r}\left[r^{2} \Phi(r, \mu)\right]+\frac{1}{r} \frac{\partial}{\partial \mu}\left[\left(1-\mu^{2}\right) \Phi(r, \mu)\right]+\Sigma \Phi= \\
& \sum_{l=0}^{L} \frac{2 l+1}{2} \Sigma_{s}^{(l)}(r) P_{l}(\mu) \int_{-1}^{1} \Phi\left(r, \mu^{\prime}\right) P_{l}\left(\mu^{\prime}\right) d \mu^{\prime}+S(r, \mu)
\end{aligned}
$$

Para exemplificar o Método de Ordenadas Discretas aplicado no código ANISN pode-se considerar a equação de transporte em geometria plana, com espalhamento isotrópico, $\mathrm{L}=0$, com discretização no espaço de fases. Pode-se escrever a equação de transporte para cada direção discreta, $\left(\mu_{m}\right)$; usa-se também uma discretização de diferenças centrais de segunda ordem para a variável espacial, além de aproximar o termo integral de espalhamento por uma fórmula de quadratura. Portanto, a forma conservativa da equação de transporte em ordenadas discretas, em geometria unidimensional plana pode ser escrita na forma:

$$
\mu_{m}\left(\frac{\Phi_{m, i+1 / 2}-\Phi_{m, i-1 / 2}}{\Delta x_{i}}\right)+\Sigma_{t}^{i} \Phi_{m, i}=Q_{m, i}
$$

onde

$$
Q_{m, i}=\frac{1}{2} \sum_{s}^{i} \sum_{m=1}^{M} w_{m} \Phi_{m, i}+S_{m, i}
$$

para $i=1,2, \ldots, I$, e $m=1,2, \ldots, M$. 
Nas Equações (94) e (95) o subscrito $i$ representa os intervalos na dimensão espacial; o subscrito $m$ refere-se a direção no conjunto ordenado de direções ao longo do fluxo que será avaliado; os subscritos tais como $i+1 / 2$ se referem às fronteiras do intervalo; o subscrito $g$ se refere ao grupo de energia.

A FIG. 33 mostra um outline dos cálculos de Multigrupo de nêutrons geralmente realizados pela maioria dos códigos nucleares, inclusive o código ANISN.

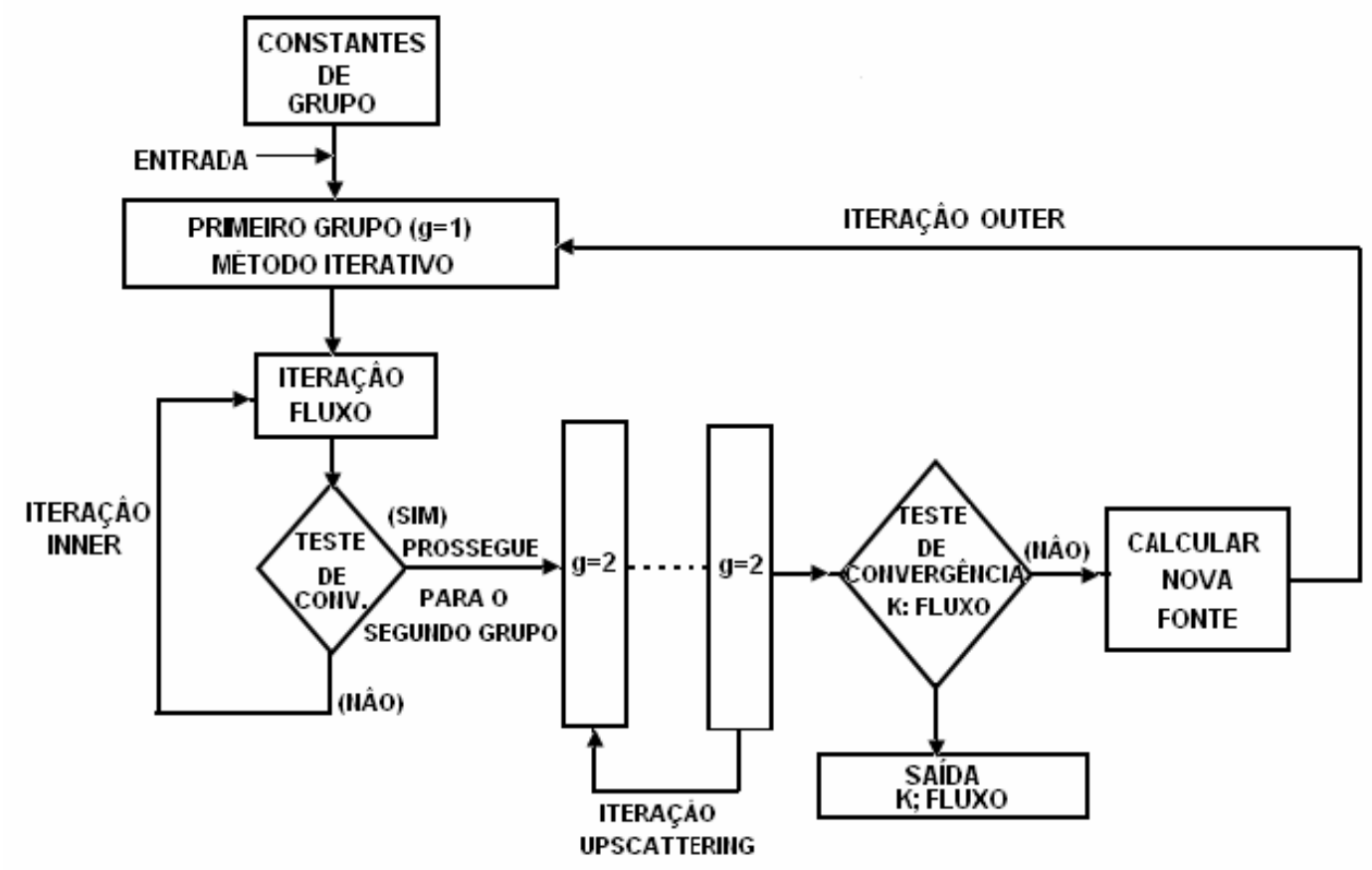

FIGURA 33: Diagrama de bloco de um cálculo Multigrupo.

\section{B.2 Código TORT}

O código TORT é um código determinístico de transporte de radiação que calcula fluxos ou fluências através de geometrias tridimensionais devido às partículas incidentes de fontes externas ou geradas internamente como resultado de interações das partículas com os materiais do sistema.

A equação de transporte de Boltzmann é solucionada usando o Método de Ordenadas Discretas para tratar a variável angular e o Método de Diferenças Pesadas, 
Nodal ou das Características para tratar as variáveis espaciais. A dependência da energia é tratada usando a Formulação de Multigrupo. A dependência no tempo não é tratada.

Nas três dimensões, em geometria R $\theta Z$ ou XYZ, a forma conservativa da equação de transporte usada é

$$
\begin{aligned}
& w_{m} \mu_{m}\left(A_{i+1 / 2, j, k} N_{i+1 / 2, j, k, m, g}-A_{i-1 / 2, j, k} N_{i-1 / 2, j, k, m, g}\right) \\
& +w_{m} \xi_{m}\left(B_{i, j+1 / 2, k} N_{i, j+1 / 2, k, m, g}-B_{i, j-1 / 2, k} N_{i, j-1 / 2, k, m, g}\right) \\
& +w_{m} \eta_{m}\left(C_{i, j, k+1 / 2} N_{i, j, k+1 / 2, m, g}-B_{i, j, k-1 / 2} N_{i, j, k-1 / 2, m, g}\right) \\
& +\left(A_{i+1 / 2, j, k}-A_{i-1 / 2, j, k}\right)\left(\alpha_{m+1 / 2} N_{i, j, k, m+1 / 2, g}-\alpha_{m-1 / 2} N_{i, j, k, m-1 / 2, g}\right) \\
& +\Sigma^{t}{ }_{i, j, k, g} w_{m} V_{i, j, k} N_{i, j, k, m, g}=w_{m} V_{i, j, k} S_{i, j, k, m, g}
\end{aligned}
$$

Nesta notação os subscritos, $i, j$ e $k$, representam os intervalos nas três dimensões espaciais. $\mathrm{O}$ subscrito $m$ refere-se a uma direção de um conjunto ordenado de direções ao longo do qual o fluxo que será calculado. Subscritos tais como $i+1 / 2$ se referem às fronteiras do intervalo; e.g., a fronteira $i+1 / 2$ é a fronteira que separa $o$ intervalo $i$ do intervalo $i+1$. No caso de $m$, isto é um tanto artificial, uma vez que $m$ representa uma direção discreta com nenhum setor definido do ângulo sólido associado. $\mathrm{Na}$ realidade, direções representadas por $m$ 's sucessivos podem não ser "adjacentes" no espaço de direção. Mesmo assim, a equação requer acoplamento entre certos fluxos tendo valores de $m$ consecutivos, e os termos com subscritos tais como $m+1 / 2$ meramente denotam valores intermediários artificiais. O subscrito $g$ se refere ao grupo de energia.

O conjunto ordenado de direções de movimento das partículas é caracterizado pelos cossenos direção delas, $\left(\mu_{m}, \xi_{m}, \eta_{m}\right)$. Em todas as geometrias, $\mu$, é o cosseno do ângulo que a direção de movimento faz com o eixo da primeira dimensão i.e., $\mathrm{X}$ ou R, enquanto $\eta$ é o cosseno do ângulo com o eixo $\mathrm{Z}$ e, $\xi$ é o cosseno com o vetor direção remanescente, no eixo Y ou no eixo Azimutal no caso de geometria R $\theta Z$.

Devido à simetria, nenhum fluxo é associado com algum dos cossenos direção, $\eta$ ou $\xi$. Conseqüentemente, $\tau$ é usado para representar $\eta$ e $\xi$. Também para $w$ é 
permitido representar o cosseno remanescente. Os parâmetros $A, B$ e $C$ são áreas das faces das células perpendiculares aos eixos dos quais $\mu, \xi$ e $\eta$ são medidos.

Cada direção tem um peso associado, $w_{m} . N$ representa o fluxo direcional, $\Phi$, na direção, $m . V$ e $S$ representam o volume e a fonte em uma dada célula, e $\Sigma^{t}$ é a seção de choque macroscópica total. Assume-se que $S$ inclui fontes externas, espalhamento de outros grupos de energia, espalhamento em uma dada energia de outras direções, fissão, e algumas outras fontes de partículas, e.g., $(n, 2 n)$. 


\section{ANEXO C - GERAÇÃO DE SEÇÕES DE CHOQUE - CONSTANTES DE MULTIGRUPO}

Para a realização de qualquer cálculo determinístico e MCNP é necessária a geração de constantes macroscópicas de grupo. A determinação das constantes de grupo envolve dois estágios: (i) variação das seções de choque com a energia tem que ser avaliada, e (ii) uma aproximação para o fluxo deve ser feita (espectro de energia). Isto é acompanhado pela realização de um conjunto de cálculos auxiliares. Há diversos sistemas de códigos que podem ser usados para gerar as constantes de grupo das bibliotecas de dados nucleares avaliados (ENDF, JENDL, JEFF, etc.).

Para cálculos de criticalidade há uma metodologia bem implementada, mas para cálculos de sistemas subcríticos com fontes externas esta é uma questão ainda em aberto, pois é necessário inserir no espectro de ponderação o espectro da fonte.

Nos cálculos realizados neste trabalho utiliza-se a metodologia de cálculo de constantes de grupo implementada no IPEN [62] para cálculos de criticalidade de reatores térmicos, apesar de se saber que ela não é adequada para cálculos de subcriticalidade com fontes externas, pois o espectro da fonte externa não é considerado quando as seções de choque são geradas. Na metodologia implementada no IPEN para geração de constantes de grupo, são utilizados dois sistemas: o sistema NJOY e o sistema AMPX-II [63].

O sistema NJOY é composto de módulos específicos com a finalidade de acessar a biblioteca básica, efetuar interpolações, alargamento de ressonâncias e ponderação pelo espectro típico do problema a ser calculado. No final do processo obtémse um conjunto de seções de choque no formato Multigrupo. A definição de seção de choque relativa ao grupo $g$ tem a forma

$$
<\sigma_{X}>_{g}=\frac{\int_{E_{g+1}}^{E_{g}} \sigma(E) w(E) d E}{\int_{E_{g+1}}^{E_{g}} w(E) d E}
$$

onde: $\sigma_{x}$ é a seção microscópica de choque; $w$ é a função ponderação; $E$ é o intervalo de energia; $g$ é o índice do grupo de energia; $x$ é o tipo de reação (captura, fissão, etc.). 
Os módulos que compõem o sistema NJOY são, dentre outros, o MODER, RECONR, BROADR, UNRESR, THERMR e GROUPR. O módulo MODER transforma um arquivo formatado (ASCII) em um arquivo binário, ou vice-versa, e fornece uma economia no meio físico de armazenamento. O módulo RECONR reconstrói explicitamente a dependência energética das seções de choque numa forma pontual e num "grid" único de energia a partir dos parâmetros de ressonância e das leis de interpolação da ENDF/B. As seções de choque resultantes são escritas em um arquivo denominado PEND ("Pointwise Evaluated Nuclear Data File") que possui a mesma padronização do formato ENDF. O módulo BROADR realiza o alargamento Doppler de todas as reações utilizando o arquivo PENDF, o alargamento é efetuado para uma dada temperatura de aplicação e o resultado final também é escrito num novo arquivo PENDF. O módulo UNRESR produz seções de choque efetivas na região de ressonâncias não resolvidas utilizando o método do código ETOXS. Os dados são escritos numa forma tabular: seções de choque em função da temperatura e "background cross sections" na região de ressonância não resolvida. O módulo THERMR produz seções de choque e matrizes de espalhamento na forma pontual para região de energia térmica dos nêutrons. Neste módulo é realizado o tratamento do modelo de espalhamento para as matrizes de espalhamento utilizando o modelo de gás livre ou as funções $S(\alpha, \beta)$. Até o módulo THERM os dados nucleares são produzidos independentes da aplicação e as seções de choque estão numa forma pontual e linearizada. O único parâmetro que restringe o uso destes dados é a temperatura utilizada na matriz de espalhamento térmica. O módulo GROUPR processa as seções de choque pontuais em parâmetros de multigrupo utilizando o método de Bondarenko. Neste ponto o elo entre os dados nucleares independentes da aplicação e os dados nucleares para uma aplicação específica é introduzido através da estrutura de multigrupo e do espectro de ponderação adequado ao problema. Os resultados são gravados num arquivo denominado GENDF (Groupwise ENDF).

Geralmente somente dois arquivos são de interesse: o arquivo PENDF e o arquivo GENDF; estes arquivos contêm seções de choque na forma pointwise e na forma multigrupo, respectivamente. A estrutura de grupos de energia utilizada no módulo GROUPR é uma estrutura pré definida para o código SAND-II com 620 grupos. 
A biblioteca de dados nucleares que o sistema NJOY acessou nos cálculos realizados neste trabalho para processar os arquivos de dados nucleares é a "Evaluated Nuclear Data File" (ENDF/B-VI).

Os arquivos PENDF e GENDF são reformatados do sistema NJOY para o sistema AMPEX-II através de dois programas de interface: AMPXR [64] e BRDROL [64].

O programa AMPXR transforma os dados nucleares multigrupo (GENDF) calculados com o módulo GROUPR em um formato compatível com o sistema AMPX-II, cujo arquivo de saída do programa é denominado de arquivo MASTER. O programa BRDROL transforma os dados nucleares no formato PENDF gerado pelo módulo BROADR num formato compatível com o sistema AMPXR-II. Os dados pontuais são utilizados pelo módulo ROLAIDS do sistema AMPX-II para o tratamento da autoblindagem na forma pontual.

O programa AMPX-II é um sistema modular com vários programas, porém, na elaboração das bibliotecas de seções de choque são utilizados somente alguns destes módulos. Geralmente os módulos são utilizados na forma seqüencial, i.e., o arquivo de saída gerado por um módulo constitui-se no arquivo de entrada do módulo seguinte.

Os módulos que compõem o sistema AMPX-II são: RADE, AJAX, ROLAIDS, CLAROL e XSDRNPM. O modulo RADE verifica a consistência do arquivo MASTER (formato padrão do sistema AMPX-II) onde se encontram os dados nucleares na forma multigrupo. A verificação da consistência é realizada em termos de comparação entre a soma das grandezas parciais em relação a grandeza total. O módulo AJAX adiciona ou exclui conjuntos de seções de choque de um dado nuclídeo da biblioteca MASTER. O módulo ROLAIDS resolve a equação integral de transporte de nêutrons assumindo correção de transporte na região de ressonâncias resolvidas. O módulo CLAROL substitui ou adiciona as seções de choque auto-blindadas geradas pelo módulo ROLAIDS na biblioteca MASTER proveniente do programa AMPXR. O arquivo de saída deste módulo é uma biblioteca de seções de choque multigrupo autoblindadas. No módulo XSDRNPM a equação de transporte é solucionada pelo Método de Ordenadas Discretas e a estrutura de grupo original é colapsada por zona num formato de poucos grupos. A FIG. 
34 mostra a metodologia de cálculo descrita anteriormente aplicada na geração de constantes de grupo.

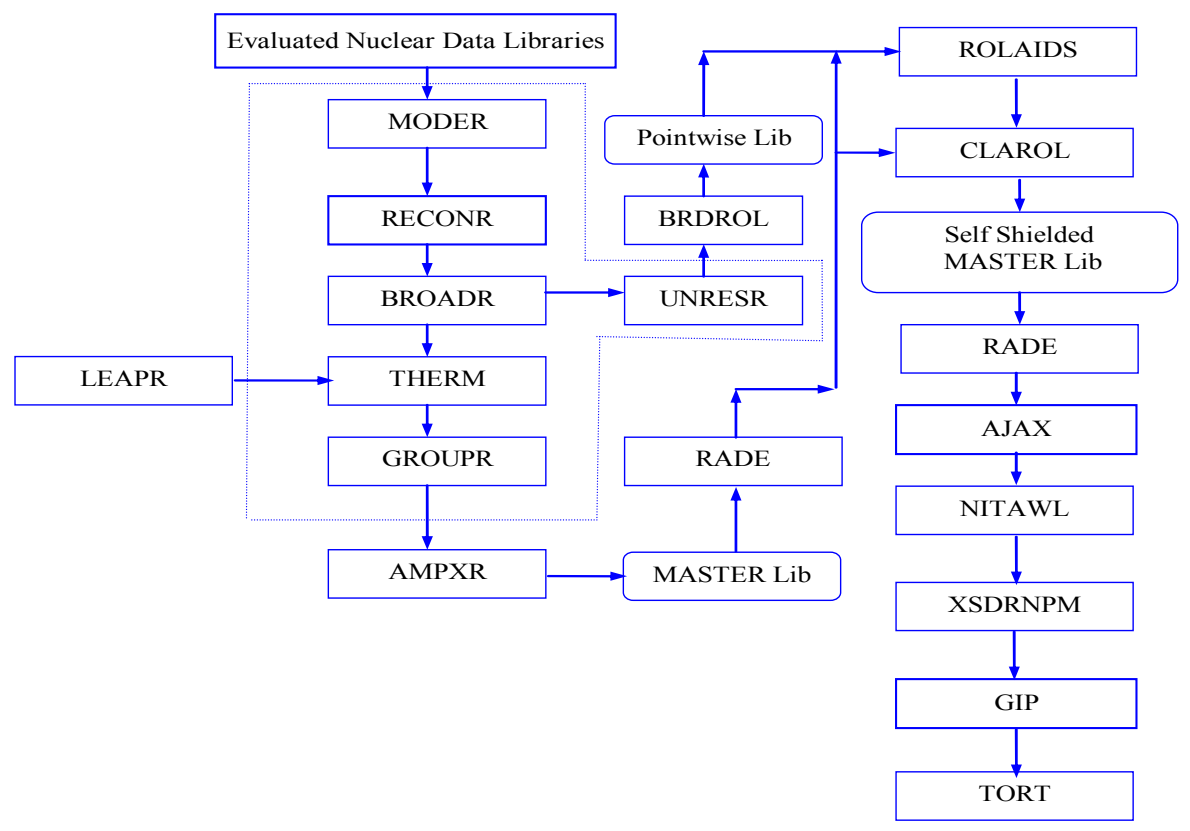

FIGURA 34: Processamento de Dados Nucleares para Cálculos Determinísticos.

Na FIG. 34 observa-se que após o módulo XSDRNPM aparece o módulo GIP (“Group Organized Cross Section Input Program”) [65]. Este módulo lê bibliotecas de seções de choque organizadas em nuclídeos preparadas para o programa ANISN e produz uma biblioteca organizada em regiões para o programa TORT. Através do processamento do módulo GIP é criada uma biblioteca de seções de choque macroscópicas. Esta biblioteca torna as exigências de memória do código TORT quase que independente do número de grupos de energia.

Para energias menores que $20 \mathrm{MeV}$ a forma de geração dos dados nucleares está bem estabelecida. Porém, para energias maiores de $20 \mathrm{MeV}$, ainda não existem dados precisos e esta ainda é uma questão em aberto.

Em Dezembro de 2004 durante um encontro da Agencia Internacional de Energia Atômica intitulado “Application Libraries for ADS and Transmutation”, realizado em Viena, os participantes recomendaram a geração de um biblioteca teste para códigos Monte Carlo e determinísticos que pudessem ser usados na analise de ADS. Foi criada então a biblioteca teste ADS-Lib/V1.0. A fonte de dados nucleares foi a JEFF-3.1, e o 
processamento utilizado foi realizado com o NJOY-99.90. Os arquivos processados foram disponibilizados no formato ACE para cálculos de transporte com Monte Carlo e formato MATXS para cálculos determinísticos de transporte. Quando esta biblioteca foi gerada foi utilizado um espectro típico de reator térmico. Atualmente já existe a segunda versão desta biblioteca (IAEA - ADS-2.0) que contém os materiais físseis que não havia na outra biblioteca. Esta biblioteca ainda precisa ser validada.

É necessário investigar com mais profundidade uma metodologia para gerar seções de choque para sistemas acionados por fontes, pois quando as seções de choque são geradas para tais sistemas deve-se levar em consideração não apenas a componente colidida, mas também a contribuição da componente não colidida originada dos nêutrons da fonte. 